\title{
Photocaged 5-(hydroxymethyl)pyrimidine nucleoside phosphoramidites for specific photoactivatable epigenetic labelling of DNA
}

Aswathi Chakrapani, ${ }^{\text {a,b }}$ Viola Vaňková Hausnerová, ${ }^{\mathrm{c}}$ Olatz Ruiz-Larrabeiti, ${ }^{\mathrm{c}}$ Radek Pohl, ${ }^{\mathrm{a}}$ Libor Krásný, ${ }^{\mathrm{c} *}$ Michal Hocek ${ }^{\mathrm{a}, \mathrm{b} *}$

Institute of Organic Chemistry and Biochemistry, Czech Academy of Sciences, Flemingovo nam. 2, 16610 Prague 6, Czech Republic; b) Department of Organic Chemistry, Faculty of Science, Charles University in Prague, Hlavova 8, CZ-12843 Prague 2, Czech Republic; c) Lab. of Microbial Genetics and Gene Expression, Institute of Microbiology, Czech Academy of Sciences, Videňská 1083, CZ-14220 Prague 4, Czech Republic

\section{Contents:}

1. Chemical synthesis $\quad$ S2

2. Solid phase synthesis of modified oligonucleotides $\quad$ S11

3. Enzymatic synthesis of modified DNA $\quad$ S13

4. Transcription studies $\quad$ S16

5. Copies of MALDI-TOF and ESI Spectra $\quad$ S20

6. Sequencing analysis of PCR products $\quad$ S24

7. Copies of NMR spectra $\quad$ S33

8. References $\quad$ S45 


\section{Chemical synthesis}

\subsection{Materials and methods}

All reagents and solvents were purchased from the commercial suppliers and used as received. $\mathrm{N}, \mathrm{N}$-diisopropylethylamine (DIPEA) was dried by distillation at reduced pressure over $\mathrm{CaH}_{2}$. The water used in the synthetic part was of HPLC quality and in the biochemical part of ultrapure quality $(18 \mathrm{M} \Omega \cdot \mathrm{cm})$. Unless otherwise stated, all the reactions were performed under a positive atmosphere of argon by standard syringe, cannula and septa techniques. The reactions were monitored by thin-layer chromatography (TLC) on Merck silica gel $60 \mathrm{~F}_{254}$ plates and visualized by UV $(254 \mathrm{~nm})$ and by solution of 4 -anisaldehyde in ethanol with $10 \%$ of sulphuric acid. Reactions were also monitored by Advion Expression Compact Mass Spectrometer connected with Plate Express $^{\circledR}$ TLC Plate Reader using electrospray ionization (ESI). Purification of nucleosides were done with ISCO Combiflash Rf system on RediSep Rf Gold Silica Gel Disposable columns. Purification of phosphoramidites were performed using manual column chromatography using silica gel $(40-63 \mu \mathrm{m})$. NMR spectra were recorded on a Bruker Avance III $500 \mathrm{MHz}\left({ }^{1} \mathrm{H}\right.$ at 500.0 $\mathrm{MHz},{ }^{13} \mathrm{C}$ at $125.7 \mathrm{MHz}$ and ${ }^{31} \mathrm{P}$ at $\left.202.4 \mathrm{MHz}\right)$ and JEOL ECZR $500 \mathrm{MHz}\left({ }^{1} \mathrm{H}\right.$ at $500.2 \mathrm{MHz},{ }^{13} \mathrm{C}$ at 125.8 $\mathrm{MHz}$ and ${ }^{31} \mathrm{P}$ at $202.5 \mathrm{MHz}$ ) in $\mathrm{CDCl}_{3}$ or $\mathrm{CD}_{3} \mathrm{CN}$ (referenced to the residual solvent signal) at $25^{\circ} \mathrm{C}$. Chemical shifts are given in ppm $(\delta$-scale), coupling constants $(J)$ in $\mathrm{Hz}$. Complete assignment of all NMR signals was performed using a combination of $\mathrm{H}, \mathrm{H}-\mathrm{COSY}, \mathrm{H}, \mathrm{C}-\mathrm{HSQC}$ and H,C-HMBC experiments. Mass spectra and high resolution mass spectra were measured on a LTQ Orbitrap XL spectrometer (Thermo Fisher Scientific) by ESI ionization technique. The MALDI-TOF spectra were measured on a UltrafleXtreme MALDI-TOF/TOF (Bruker) mass spectrometer. All mass spectra were acquired by the MS service at IOCB. Melting points were determined on a Stuart SMP40 melting point apparatus and are uncorrected. Purity of all final compounds was determined by NMR spectra. Known starting compounds were prepared by reported procedures. ${ }^{1-8}$ FAIR Data is available as Supporting Information for Publication and includes the primary NMR FID files for compounds $\mathbf{3 a}, \mathbf{3 b}, \mathbf{4 a}, \mathbf{4 b}, \mathbf{5 a}$ and $\mathbf{5 b}$. 


\subsection{General scheme of the synthesis of the modified nucleoside phosphoramidites 5a-5b.}

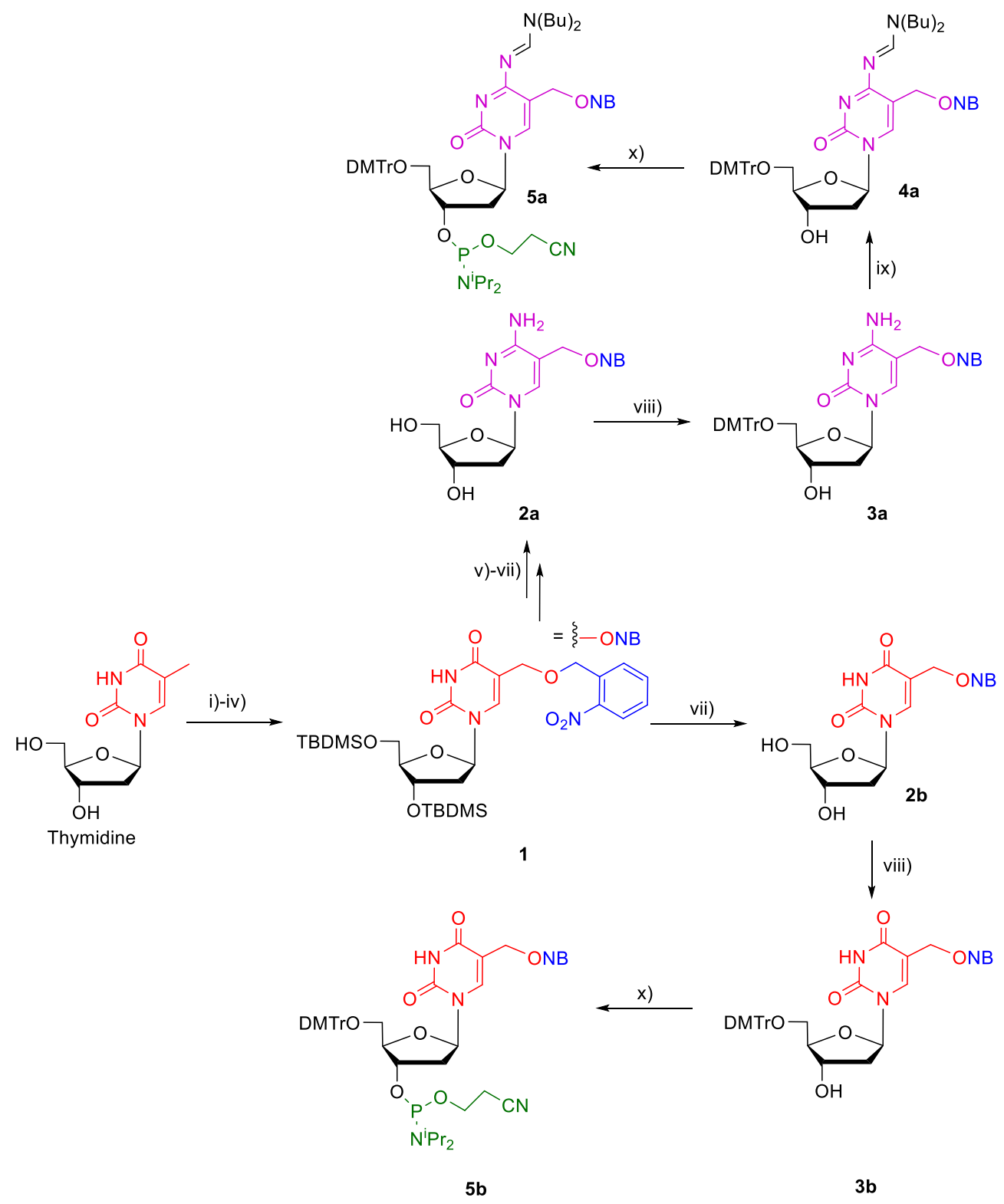

Figure S1: Synthetic scheme of the photocaged phosphoramidites $\mathbf{5 a}$ and $\mathbf{5 b}$. Reaction conditions: (i) TBDMSCl, imidazole, DMF, r.t., 12 h; 95\% (ii) NBS, AIBN, Benzene, $85^{\circ} \mathrm{C}, 30 \mathrm{~min}$ (iii) DIPEA, $\mathrm{H}_{2} \mathrm{O}$, DMF, r.t., 5 h; 27\% (after two steps) (iv) 2-nitrobenzyl bromide, AgOTf, 2,6-di-tertbutylpyridine, $\mathrm{DCM}, 0^{\circ} \mathrm{C}$ to r.t., $3 \mathrm{~h} ; 40 \%$ (v) 1. 2,4,6-triisopropylbenzenesulfonyl chloride, DMAP, $\mathrm{Et}_{3} \mathrm{~N}, \mathrm{DCM}$; r.t., $12 \mathrm{~h}$ (vi) $\mathrm{NH}_{3}$ (g); dioxane; r.t., 3 h; 80\% (after two steps) (vii) $\mathrm{Et}_{3} \mathrm{~N}$.3HF, THF, r.t., 12 h; 40-50\% (viii) DMTrCl, DMAP, Pyridine, r.t., 6 h; 50-70\%; (ix) DBF-DMA; DMF, r.t., 12 h; 76\% (x) CEOP(Cl)N'Pr2, DIPEA, DCM, 0C-r.t., 1.5 h; 70-85\%. 


\subsection{Synthesis of nucleosides $2 \mathrm{a}$ and $2 \mathrm{~b}$ :}

The synthesis of the known modified nucleosides $\mathbf{2} \mathbf{a}$ and $\mathbf{2} \mathbf{b}$ were carried out according to the reported procedures ${ }^{1-8}$ from thymidine.

\subsection{General procedure A: Synthesis of 5'-O-DMT-protected nucleosides 3a and 3b.}

Precursors $\mathbf{2 a}$ or $\mathbf{2} \mathbf{b}$ were dried by repeated co-evaporations with anhydrous pyridine $(3 \times 5 \mathrm{~mL})$ and finally dissolved in $10 \mathrm{~mL}$ of anhydrous pyridine along with DMAP (0.10 equiv.). 4,4'Dimethoxytrityl chloride (1.2 equiv.) in $5 \mathrm{ml}$ of anhydrous pyridine, was added in 4 portions over one hour and the reaction mixture was stirred at room temperature for 6 hours. Pyridine was removed under reduced pressure at a rotary evaporator and the crude reaction mixture was redissolved in $\mathrm{CH}_{2} \mathrm{Cl}_{2}(50 \mathrm{~mL})$, washed with $10 \%$ aqueous $\mathrm{NaHCO}_{3}(50 \mathrm{~mL}), \mathrm{H}_{2} \mathrm{O}(100 \mathrm{~mL})$ and brine $(50 \mathrm{~mL})$, and dried over $\mathrm{Na}_{2} \mathrm{SO}_{4}$. Purification by flash chromatography $\left(\mathrm{CH}_{2} \mathrm{Cl}_{2}: \mathrm{MeOH}\right.$, with $0.5 \%$ $\mathrm{Et}_{3} \mathrm{~N}$ ) afforded the desired compounds.

\section{5'-0-[Bis(4-methoxyphenyl)phenylmethyl]-5-(2"'-nitrobenzyloxymethyl)-2'-deoxycytidine}

(3a).

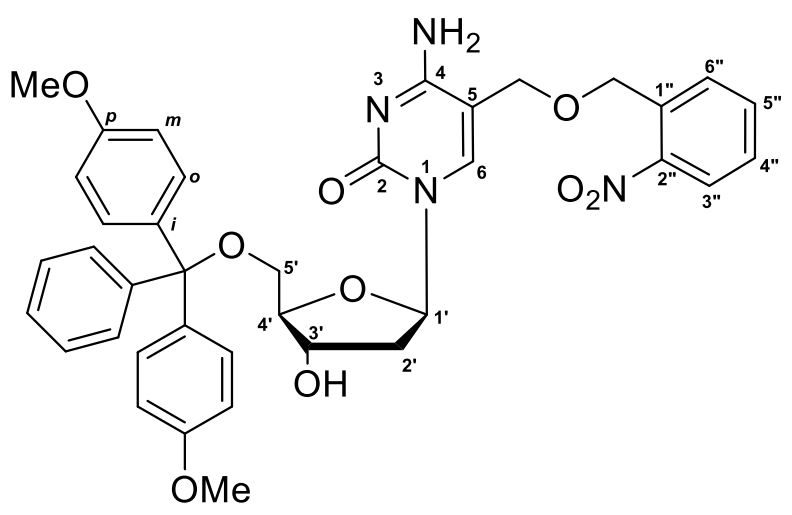

The title product $3 \mathrm{a}$ was obtained from the nucleoside $2 \mathrm{a}(1.1 \mathrm{~g}, 2.8 \mathrm{mmol})$, DMAP $(34 \mathrm{mg}, 0.3$ mmol, 0.10 equivalent) and 4,4'-dimethoxytrityl chloride (1.15 g, $3.4 \mathrm{mmol}, 1.2$ equiv.) following the general procedure $A$. The product was purified by flash chromatography $\left(\mathrm{CH}_{2} \mathrm{Cl}_{2}\right.$ : $\mathrm{MeOH} 99: 1$, $\mathrm{Et}_{3} \mathrm{~N} 0.5 \%$ ) and obtained as a yellowish foam (1.32 g, $68 \%$ ). m.p. $148-150{ }^{\circ} \mathrm{C}$.

${ }^{1} \mathrm{H} \mathrm{NMR}\left(\mathrm{CDCl}_{3}, 500.0 \mathrm{MHz}\right): \delta 8.04$ (dd, $\left.1 \mathrm{H}, J_{3^{\prime \prime}, 4^{\prime \prime}}=8.2 \mathrm{~Hz}, J_{3^{\prime \prime}, 5^{\prime \prime}}=1.3 \mathrm{~Hz}, \mathrm{H}-3^{\prime \prime}\right) ; 8.02$ (s, 1H, H-6); 7.55 (ddd, $\left.1 \mathrm{H}, J_{5^{\prime \prime}, 6^{\prime \prime}}=7.8 \mathrm{~Hz}, J_{5^{\prime \prime}, 4^{\prime \prime}}=7.3 \mathrm{~Hz}, J_{5^{\prime \prime}, 3^{\prime \prime}}=1.3 \mathrm{~Hz}, \mathrm{H}-5^{\prime \prime}\right) ; 7.50$ (dd, $1 \mathrm{H}, J_{6^{\prime \prime}, 5^{\prime \prime}}=7.8 \mathrm{~Hz}, J_{6^{\prime \prime}, 4^{\prime \prime}}=$ 
$\left.1.6 \mathrm{~Hz}, \mathrm{H}-6^{\prime \prime}\right) ; 7.43\left(\mathrm{ddd}, 1 \mathrm{H}, J_{4^{\prime \prime}, 3^{\prime \prime}}=8.2 \mathrm{~Hz}, J_{4^{\prime \prime}, 5^{\prime \prime}}=7.3 \mathrm{~Hz}, J_{4^{\prime \prime}, 6^{\prime \prime}}=1.6 \mathrm{~Hz}, \mathrm{H}-4^{\prime \prime}\right) ; 7.36-7.40(\mathrm{~m}, 2 \mathrm{H}$, $\left.\mathrm{H}-\mathrm{o}-\mathrm{C}_{6} \mathrm{H}_{5}-\mathrm{DMTr}\right) ; 7.24-7.29$ (m, 6H, H-o- $\mathrm{C}_{6} \mathrm{H}_{4}-\mathrm{DMTr}, \mathrm{H}-m-\mathrm{C}_{6} \mathrm{H}_{5}-\mathrm{DMTr}$ ); 7.18 (m, 1H, H-p- $\mathrm{C}_{6} \mathrm{H}_{5}-$ DMTr); $6.78-6.82\left(\mathrm{~m}, 4 \mathrm{H}, \mathrm{H}-m-\mathrm{C}_{6} \mathrm{H}_{4}-\mathrm{DMTr}\right.$ ); 6.44 (dd, $\left.1 \mathrm{H}, J_{1^{\prime}, 2^{\prime}}=6.7 \mathrm{~Hz}, 6.1 \mathrm{~Hz}, \mathrm{H}-1^{\prime}\right) ; 4.57$ (ddd, $\left.1 \mathrm{H}, J_{3^{\prime}, 2^{\prime}}=6.4 \mathrm{~Hz}, 3.8 \mathrm{~Hz}, J_{3^{\prime}, 4^{\prime}}=3.0 \mathrm{~Hz}, \mathrm{H}-3^{\prime}\right) ; 4.47\left(\mathrm{~s}, 2 \mathrm{H}, \mathrm{CH}_{2} \mathrm{O}-1^{\prime \prime}\right) ; 4.11\left(\mathrm{q}, 1 \mathrm{H}, J_{4^{\prime}, 3^{\prime}}=J_{4^{\prime}, 5^{\prime}}=3.0 \mathrm{~Hz}\right.$, $\left.\mathrm{H}-4^{\prime}\right) ; 3.83\left(\mathrm{~d}, J_{\text {gem }}=11.9 \mathrm{~Hz}, \mathrm{CH}_{\mathrm{a}} \mathrm{H}_{\mathrm{b}} \mathrm{O}-5\right) ; 3.72,3.73\left(2 \times \mathrm{s}, 2 \times 3 \mathrm{H}, \mathrm{CH}_{3} \mathrm{O}\right) ; 3.62\left(\mathrm{~d}, 1 \mathrm{H}, J_{\text {gem }}=11.9\right.$ $\left.\mathrm{Hz}, \mathrm{CH}_{\mathrm{a}} \mathrm{H}_{\mathrm{b}} \mathrm{O}-5\right)$; 3.32, $3.51\left(2 \times \mathrm{dd}, 2 \times 1 \mathrm{H}, J_{\text {gem }}=10.6 \mathrm{~Hz}, J_{5^{\prime}, 4^{\prime}}=3.0 \mathrm{~Hz}, \mathrm{H}-5^{\prime}\right) ; 2.66\left(\mathrm{ddd}, 1 \mathrm{H}, J_{\text {gem }}=\right.$ $\left.13.6 \mathrm{~Hz}, J_{2^{\prime} \mathrm{a}, 1^{\prime}}=6.1 \mathrm{~Hz}, J_{2^{\prime} \mathrm{a}, 3^{\prime}}=3.8 \mathrm{~Hz}, \mathrm{H}-2^{\prime} \mathrm{a}\right) ; 2.28\left(\mathrm{ddd}, 1 \mathrm{H}, J_{\text {gem }}=13.6 \mathrm{~Hz}, J_{2^{\prime} \mathrm{b}, 1^{\prime}}=6.7 \mathrm{~Hz}, J_{2^{\prime} \mathrm{b}, 3^{\prime}}=\right.$ $\left.6.2 \mathrm{~Hz}, \mathrm{H}-2^{\prime} \mathrm{b}\right)$.

${ }^{13} \mathrm{C}\{1 \mathrm{H}\} \operatorname{NMR}\left(\mathrm{CDCl}_{3}, 125.7 \mathrm{MHz}\right): \delta 165.1$ (C-4); 158.7 (C-p-C $\left.\mathrm{C}_{6} \mathrm{H}_{4}-\mathrm{DMTr}\right) ; 155.9$ (C-2); 147.3 (C-2"); 144.3 (C-i-C $6 \mathrm{H}_{5}-\mathrm{DMTr}$ ); 140.8 (CH-6); 135.38, 135.44 (C-i-C $\mathrm{H}_{4}-\mathrm{DMTr}$ ); 133.8 (CH-5"); 133.4 (C-1"); 130.1 (CH-o- $\left.\mathrm{C}_{6} \mathrm{H}_{4}-\mathrm{DMTr}\right) ; 129.2$ (CH-6"); 128.5 (CH-4"); 128.2 (CH-o- $\left.\mathrm{C}_{6} \mathrm{H}_{5}-\mathrm{DMTr}\right) ; 128.0$ (CH-m-

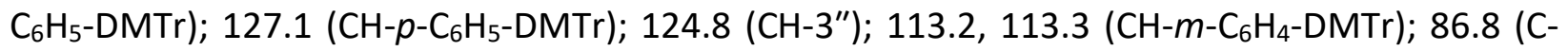
DMTr); 102.2 (C-5); $86.2\left(\mathrm{CH}-1^{\prime}\right) ; 86.1\left(\mathrm{CH}-4^{\prime}\right) ; 71.9\left(\mathrm{CH}-3^{\prime}\right) ; 68.9\left(\mathrm{CH}_{2} \mathrm{O}-1^{\prime \prime}\right) ; 67.8\left(\mathrm{CH}_{2} \mathrm{O}-5\right) ; 63.3$ $\left(\mathrm{CH}_{2}-5^{\prime}\right) ; 55.2\left(\mathrm{CH}_{3} \mathrm{O}\right) ; 42.2\left(\mathrm{CH}_{2}-2^{\prime}\right)$.

HR MS (ESI+) m/z : [M+Na] $]^{+}$Calcd for $\mathrm{C}_{38} \mathrm{H}_{38} \mathrm{O}_{9} \mathrm{~N}_{4} \mathrm{Na}$ 717.2531; found 717.2525.

\section{5'-O-[Bis(4-methoxyphenyl)phenylmethyl]-5-(2'"-nitrobenzyloxymethyl)-2'-deoxyuridine (3b).}

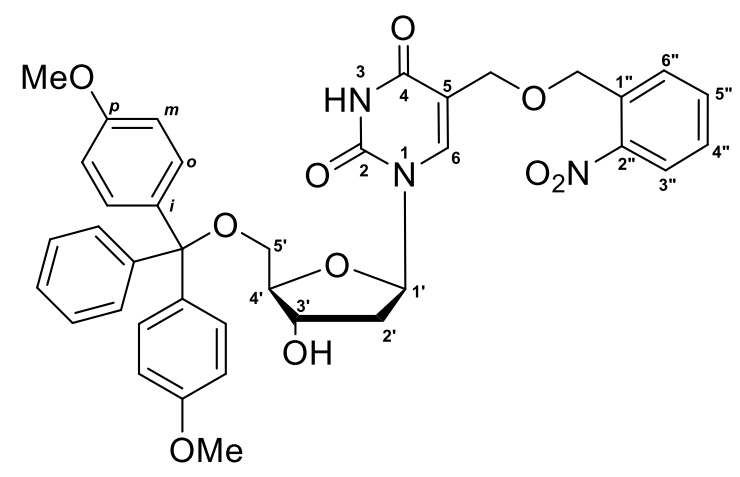

The title product $\mathbf{3 b}$ was obtained from the nucleoside $\mathbf{2 b}(1 \mathrm{~g}, 2.5 \mathrm{mmol})$, DMAP (31 $\mathrm{mg}, 0.2$ mmol, 0.10 equivalent) and 4,4'-dimethoxytrityl chloride ( $1 \mathrm{~g}, 3.0 \mathrm{mmol}, 1.2$ equiv.) following the general procedure $A$. The product was purified by flash chromatography $\left(\mathrm{CH}_{2} \mathrm{Cl}_{2}\right.$ : $\mathrm{MeOH} 99: 1$, $\mathrm{Et}_{3} \mathrm{~N} 0.5 \%$ ) and obtained as a yellowish foam (885 mg, 50\%). m.p. $58-65^{\circ} \mathrm{C}$. 
${ }^{1} \mathrm{H} \mathrm{NMR}\left(\mathrm{CDCl}_{3}, 500.0 \mathrm{MHz}\right): \delta 8.01\left(\mathrm{dd}, 1 \mathrm{H}, J_{3^{\prime \prime}, 4^{\prime \prime}}=8.2 \mathrm{~Hz}, J_{3^{\prime \prime}, 5^{\prime \prime}}=1.4 \mathrm{~Hz}, \mathrm{H}-3^{\prime \prime}\right) ; 7.91$ (s, 1H, H-6); $7.71\left(\mathrm{dq}, 1 \mathrm{H}, J_{6^{\prime \prime}, 5^{\prime \prime}}=7.7 \mathrm{~Hz}, J_{6^{\prime \prime}, 4^{\prime \prime}}=J_{6^{\prime \prime}, \mathrm{CH} 2}=1.2 \mathrm{~Hz}, \mathrm{H}-6^{\prime \prime}\right) ; 7.54\left(\mathrm{td}, 1 \mathrm{H}, J_{5^{\prime \prime}, 4^{\prime \prime}}=J_{5^{\prime \prime}, 6^{\prime \prime}}=7.7 \mathrm{~Hz}, J_{5^{\prime \prime}, 3^{\prime \prime}}=\right.$ $\left.1.4 \mathrm{~Hz}, \mathrm{H}-5^{\prime \prime}\right)$; 7.367 .40 (m, 3H, H-4", H-o-C $6 \mathrm{H}_{5}-\mathrm{DMTr}$ ); $7.23-7.31$ (m, 6H, H-o-C $6 \mathrm{H}_{4}-\mathrm{DMTr}, \mathrm{H}-m-$ $\mathrm{C}_{6} \mathrm{H}_{5}-\mathrm{DMTr}$ ); 7.17 (m, 1H, H-p-C $\left.\mathrm{H}_{5}-\mathrm{DMTr}\right) ; 6.76-6.80$ (m, 4H, H-m-C $\left.6 \mathrm{H}_{4}-\mathrm{DMTr}\right) ; 6.40$ (dd, $1 \mathrm{H}, J_{1^{\prime}, 2^{\prime}}$ = $\left.7.5 \mathrm{~Hz}, 6.0 \mathrm{~Hz}, \mathrm{H}-1^{\prime}\right)$; $4.60\left(\mathrm{ddd}, 1 \mathrm{H}, J_{3^{\prime}, 2^{\prime}}=6.2 \mathrm{~Hz}, 3.6 \mathrm{~Hz}, J_{3^{\prime}, 4^{\prime}}=2.9 \mathrm{~Hz}, \mathrm{H}-3^{\prime}\right)$; 4.55, $4.59(2 \times \mathrm{d}$, $\left.J_{\text {gem }}=15.3 \mathrm{~Hz}, \mathrm{CH}_{2} \mathrm{O}-1^{\prime \prime}\right) ; 4.06\left(\mathrm{ddd}, 1 \mathrm{H}, J_{4^{\prime}, 5^{\prime}}=3.4 \mathrm{~Hz}, 3.1 \mathrm{~Hz}, J_{4^{\prime}, 3^{\prime}}=2.9 \mathrm{~Hz}, \mathrm{H}-4^{\prime}\right) ; 3.89$ (d, Jgem $=$ 11.0 Hz, $\left.\mathrm{CH}_{\mathrm{a}} \mathrm{H}_{\mathrm{b}} \mathrm{O}-5\right)$; 3.71, $3.72\left(2 \times \mathrm{s}, 2 \times 3 \mathrm{H}, \mathrm{CH}_{3} \mathrm{O}\right) ; 3.57\left(\mathrm{~d}, 1 \mathrm{H}, \mathrm{J}_{\text {gem }}=11.0 \mathrm{~Hz}, \mathrm{CH}_{\mathrm{a}} \mathrm{H}_{\mathrm{b}} \mathrm{O}-5\right) ; 3.46$ (dd, $\left.1 \mathrm{H}, J_{\text {gem }}=10.6 \mathrm{~Hz}, J_{5^{\prime} \mathrm{a}, 4^{\prime}}=3.4 \mathrm{~Hz}, \mathrm{H}-5^{\prime} \mathrm{a}\right) ; 3.38$ (dd, $1 \mathrm{H}, J_{\text {gem }}=10.6 \mathrm{~Hz}, J_{5^{\prime} \mathrm{b}, 4^{\prime}}=3.1 \mathrm{~Hz}, \mathrm{H}-5^{\prime} \mathrm{b}$ ); 2.45 (ddd, $\left.1 \mathrm{H}, J_{\text {gem }}=13.6 \mathrm{~Hz}, J_{2^{\prime} \mathrm{a}, 1^{\prime}}=6.0 \mathrm{~Hz}, J_{2^{\prime} \mathrm{a}, 3^{\prime}}=3.6 \mathrm{~Hz}, \mathrm{H}-2^{\prime} \mathrm{a}\right) ; 2.35$ (ddd, $1 \mathrm{H}, J_{\text {gem }}=13.6 \mathrm{~Hz}$, $\left.J_{2^{\prime} b, 1^{\prime}}=7.5 \mathrm{~Hz}, J_{2^{\prime} b, 3^{\prime}}=6.2 \mathrm{~Hz}, \mathrm{H}-2^{\prime} b\right)$.

${ }^{13} \mathrm{C}\{1 \mathrm{H}\} \mathrm{NMR}\left(\mathrm{CDCl}_{3}, 125.7 \mathrm{MHz}\right): \delta 162.4$ (C-4); 158.6, 158.6 (C-p-C 6 H $\left.\mathrm{H}_{4}-\mathrm{DMTr}\right) ; 150.0$ (C-2); 147.0 (C-2"); 144.3 (C-i-C $\mathrm{H}_{5}-\mathrm{DMTr}$ ); 139.6 (CH-6); 135.2, 135.3 (C-i-C $6 \mathrm{H}_{4}-\mathrm{DMTr}$ ); 134.9 (C-1"); 133.7 $\left(\mathrm{CH}-5^{\prime \prime}\right) ; 130.07,130.08$ (CH-o- $\left.\mathrm{C}_{6} \mathrm{H}_{4}-\mathrm{DMTr}\right) ; 128.7$ (CH-6"); 128.1 (CH-o- $\left.\mathrm{C}_{6} \mathrm{H}_{5}-\mathrm{DMTr}\right) ; 128.0$ (CH-m$\left.\mathrm{C}_{6} \mathrm{H}_{5}-\mathrm{DMTr}\right) ; 127.8$ (CH-4"); 127.1 (CH-p- $\left.\mathrm{C}_{6} \mathrm{H}_{5}-\mathrm{DMTr}\right) ; 124.5\left(\mathrm{CH}-3^{\prime \prime}\right) ; 113.2,113.2\left(\mathrm{CH}-m-\mathrm{C}_{6} \mathrm{H}_{4}-\right.$ DMTr); 111.5 (C-5); 86.9 (C-DMTr); 86.1 (CH-4'); 84.8 (CH-1'); $72.1\left(\mathrm{CH}-3^{\prime}\right) ; 69.1\left(\mathrm{CH}_{2} \mathrm{O}-1^{\prime \prime}\right) ; 64.9$ $\left(\mathrm{CH}_{2} \mathrm{O}-5\right) ; 55.2\left(\mathrm{CH}_{3} \mathrm{O}\right) ; 63.4\left(\mathrm{CH}_{2}-5^{\prime}\right) ; 41.0\left(\mathrm{CH}_{2}-2^{\prime}\right)$.

HR MS (ESI+) m/z : [M+Na] ${ }^{+}$Calcd for $\mathrm{C}_{38} \mathrm{H}_{37} \mathrm{O}_{10} \mathrm{~N}_{3} \mathrm{Na}$ 718.2371; found 718.2363.

$\mathrm{N}^{4}$-Dibutylformimidamide-5'-0-[bis(4-methoxyphenyl)phenylmethyl]-5-(2"'-nitrobenzyl oxymethyl)-2'-deoxycytidine (4a).

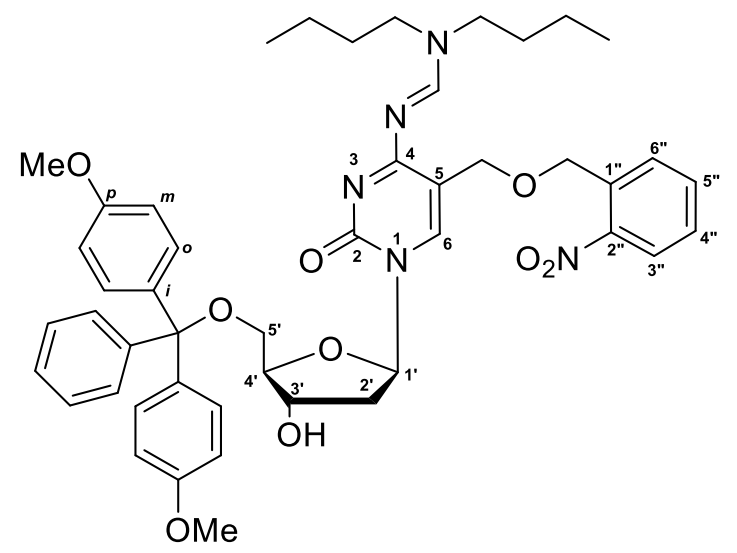


The title product $4 \mathrm{a}$ was obtained from the protected nucleoside $3 \mathrm{a}$ ( $1.36 \mathrm{~g}, 1.9 \mathrm{mmol})$. To the precursor 3a dissolved in anhydrous DMF $(10 \mathrm{~mL})$ under inert conditions, dibutylformamide dimethylacetal ( $2.2 \mathrm{~mL}, 9.8 \mathrm{mmol}, 5$ equiv.) was added and the reaction was stirred overnight at room temperature. The solvent was evaporated under vacuum and the crude reaction mixture was re-dissolved in $\mathrm{CH}_{2} \mathrm{Cl}_{2}(50 \mathrm{~mL})$, washed twice with saturated $\mathrm{NaHCO}_{3}(50 \mathrm{~mL})$ and dried over $\mathrm{Na}_{2} \mathrm{SO}_{4}$. The crude was then purified by flash chromatography $\left(\mathrm{CH}_{2} \mathrm{Cl}_{2}: \mathrm{MeOH} 98: 2, \mathrm{Et} 3 \mathrm{~N} \mathrm{0.5 \% )}\right.$ and obtained as a yellowish foam (1.24 g, 76 \%). m.p. $79-82{ }^{\circ} \mathrm{C}$.

${ }^{1} \mathrm{H} \mathrm{NMR}\left(\mathrm{CDCl}_{3}, 500.0 \mathrm{MHz}\right): \delta 8.79(\mathrm{~s}, 1 \mathrm{H}, \mathrm{CH}=\mathrm{N}) ; 8.09(\mathrm{~s}, 1 \mathrm{H}, \mathrm{H}-6) ; 8.00\left(\mathrm{dd}, 1 \mathrm{H}, J_{3^{\prime \prime}, 4^{\prime \prime}}=8.0 \mathrm{~Hz}\right.$, $\left.J_{3^{\prime \prime}, 5^{\prime \prime}}=1.5 \mathrm{~Hz}, \mathrm{H}-3^{\prime \prime}\right) ; 7.59$ (ddt, $\left.1 \mathrm{H}, J_{6^{\prime \prime}, 5^{\prime \prime}}=7.5 \mathrm{~Hz}, J_{6^{\prime \prime}, 4^{\prime \prime}}=1.6 \mathrm{~Hz}, J_{6^{\prime \prime}, 3^{\prime \prime}}=J_{6^{\prime \prime}, \mathrm{CH} 2 \mathrm{O}}=1.4 \mathrm{~Hz}, \mathrm{H}-6^{\prime \prime}\right) ; 7.40$ - $7.43\left(\mathrm{~m}, 2 \mathrm{H}, \mathrm{H}-\mathrm{o}-\mathrm{C}_{6} \mathrm{H}_{5}-\mathrm{DMTr}\right.$ ); 7.38 (td, $1 \mathrm{H}, J_{5^{\prime \prime}, 4^{\prime \prime}}=J_{5^{\prime \prime}, 6^{\prime \prime}}=7.5 \mathrm{~Hz}, J_{5^{\prime \prime}, 3^{\prime \prime}}=1.5 \mathrm{~Hz}, \mathrm{H}-5^{\prime \prime}$ ); 7.33 (ddd, $\left.1 \mathrm{H}, J_{4^{\prime \prime}, 3^{\prime \prime}}=8.0 \mathrm{~Hz}, J_{4^{\prime \prime}, 5^{\prime \prime}}=7.5 \mathrm{~Hz}, J_{4^{\prime \prime}, 6^{\prime \prime}}=1.6 \mathrm{~Hz}, \mathrm{H}-4^{\prime \prime}\right)$; $7.28-7.31$ (m, 6H, H-o-C $\mathrm{H}_{4}-\mathrm{DMTr}, \mathrm{H}-m-$ $\left.\mathrm{C}_{6} \mathrm{H}_{5}-\mathrm{DMTr}\right) ; 7.14\left(\mathrm{~m}, 1 \mathrm{H}, \mathrm{H}-\mathrm{p}-\mathrm{C}_{6} \mathrm{H}_{5}-\mathrm{DMTr}\right) ; 6.75-6.78$ (m, 4H, H-m- $\left.\mathrm{C}_{6} \mathrm{H}_{4}-\mathrm{DMTr}\right) ; 6.45$ (dd, 1H, $\left.J_{1^{\prime}, 2^{\prime}}=7.2 \mathrm{~Hz}, 5.9 \mathrm{~Hz}, \mathrm{H}-1^{\prime}\right)$; $4.69\left(\mathrm{~s}, 2 \mathrm{H}, \mathrm{CH}_{2} \mathrm{O}-1^{\prime \prime}\right.$ ); $4.55\left(\mathrm{dt}, 1 \mathrm{H}, J_{3^{\prime}, 2^{\prime}}=6.2 \mathrm{~Hz}, 3.5 \mathrm{~Hz}, J_{3^{\prime}, 4^{\prime}}=3.5 \mathrm{~Hz}\right.$, $\mathrm{H}-3^{\prime}$ ); $4.24\left(\mathrm{~d}, J_{\text {gem }}=11.1 \mathrm{~Hz}, \mathrm{CH}_{\mathrm{a}} \mathrm{H}_{\mathrm{b}} \mathrm{O}-5\right)$; 4.15 (q, $\left.1 \mathrm{H}, J_{4^{\prime}, 3^{\prime}}=J_{4^{\prime}, 5^{\prime}}=3.5 \mathrm{~Hz}, \mathrm{H}-4^{\prime}\right) ; 3.99\left(\mathrm{~d}, 1 \mathrm{H}, J_{\text {gem }}=\right.$ $\left.11.1 \mathrm{~Hz}, \mathrm{CH}_{\mathrm{a}} \mathrm{H}_{\mathrm{b}} \mathrm{O}-5\right)$; 3.70, $3.71\left(2 \times \mathrm{s}, 2 \times 3 \mathrm{H}, \mathrm{CH}_{3} \mathrm{O}\right) ; 3.45-3.49\left(\mathrm{~m}, 2 \mathrm{H}, \mathrm{CH}_{3} \mathrm{CH}_{2} \mathrm{CH}_{2} \mathrm{CH}_{2} \mathrm{~N}\right) ; 3.36$, $3.43\left(2 \times \mathrm{dd}, 2 \times 1 \mathrm{H}, J_{\text {gem }}=10.4 \mathrm{~Hz}, J_{5^{\prime}, 4^{\prime}}=3.5 \mathrm{~Hz}, \mathrm{H}-5^{\prime}\right) ; 3.29-3.33\left(\mathrm{~m}, 2 \mathrm{H}, \mathrm{CH}_{3} \mathrm{CH}_{2} \mathrm{CH}_{2} \mathrm{CH}_{2} \mathrm{~N}\right) ; 2.70$ (ddd, $\left.1 \mathrm{H}, J_{\text {gem }}=13.5 \mathrm{~Hz}, J_{2^{\prime} \mathrm{a}, 1^{\prime}}=5.9 \mathrm{~Hz}, J_{2^{\prime} \mathrm{a}, 3^{\prime}}=3.5 \mathrm{~Hz}, \mathrm{H}-2^{\prime} \mathrm{a}\right) ; 2.24$ (ddd, $1 \mathrm{H}, J_{\text {gem }}=13.5 \mathrm{~Hz}, J_{2^{\prime} b, 1^{\prime}}=$ $\left.7.2 \mathrm{~Hz}, J_{2^{\prime} b, 3^{\prime}}=6.2 \mathrm{~Hz}, \mathrm{H}-2^{\prime} \mathrm{b}\right) ; 1.49-1.62\left(\mathrm{~m}, 4 \mathrm{H}, \mathrm{CH}_{3} \mathrm{CH}_{2} \mathrm{CH}_{2} \mathrm{CH}_{2} \mathrm{~N}\right) ; 1.17-1.34(\mathrm{~m}, 4 \mathrm{H}$, $\left.\mathrm{CH}_{3} \mathrm{CH}_{2} \mathrm{CH}_{2} \mathrm{CH}_{2} \mathrm{~N}\right) ; 0.80,0.92\left(2 \times \mathrm{t}, 2 \times 3 \mathrm{H}, J_{\text {vic }}=7.4 \mathrm{~Hz}, \mathrm{CH}_{3} \mathrm{CH}_{2} \mathrm{CH}_{2} \mathrm{CH}_{2} \mathrm{~N}\right)$.

${ }^{13} \mathrm{C}\{1 \mathrm{H}\} \operatorname{NMR}\left(\mathrm{CDCl}_{3}, 125.7 \mathrm{MHz}\right): \delta 170.1$ (C-4); $158.4\left(\mathrm{C}-p-\mathrm{C}_{6} \mathrm{H}_{4}-\mathrm{DMTr}\right) ; 157.7(\mathrm{CH}=\mathrm{N}) ; 156.4$ (C2); 146.8 (C-2"); 144.6 (C-i- $\mathrm{C}_{6} \mathrm{H}_{5}-\mathrm{DMTr}$ ); 141.1 (CH-6); 135.57, 135.60, 135.68 (C-1", C-i-C $\mathrm{H}_{4-}$ DMTr); 133.5 (CH-5"); 130.0 (CH-o-C $6 \mathrm{H}_{4}-\mathrm{DMTr}$ ); 128.5 (CH-6"); 128.1 (CH-o-C6 $\left.\mathrm{H}_{5}-\mathrm{DMTr}\right) ; 127.8$

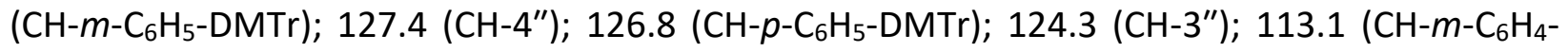
DMTr); 111.2 (C-5); 86.5 (C-DMTr); $86.4\left(\mathrm{CH}-1^{\prime}\right)$; $86.0\left(\mathrm{CH}-4^{\prime}\right) ; 72.1\left(\mathrm{CH}-3^{\prime}\right) ; 69.0\left(\mathrm{CH}_{2} \mathrm{O}-1^{\prime \prime}\right) ; 66.6$ $\left(\mathrm{CH}_{2} \mathrm{O}-5\right) ; 63.5\left(\mathrm{CH}_{2}-5^{\prime}\right) ; 55.1\left(\mathrm{CH}_{3} \mathrm{O}\right) ; 45.7,52.3\left(\mathrm{CH}_{3} \mathrm{CH}_{2} \mathrm{CH}_{2} \mathrm{CH}_{2} \mathrm{~N}\right) ; 42.1\left(\mathrm{CH}_{2}-2^{\prime}\right) ; 28.9,30.9$ $\left(\mathrm{CH}_{3} \mathrm{CH}_{2} \mathrm{CH}_{2} \mathrm{CH}_{2} \mathrm{~N}\right)$; 19.7, $20.0\left(\mathrm{CH}_{3} \mathrm{CH}_{2} \mathrm{CH}_{2} \mathrm{CH}_{2} \mathrm{~N}\right)$; 13.6, $13.6\left(\mathrm{CH}_{3} \mathrm{CH}_{2} \mathrm{CH}_{2} \mathrm{CH}_{2} \mathrm{~N}\right)$.

HR MS (ESI+) m/z : [M+H] $]^{+}$Calcd for $\mathrm{C}_{47} \mathrm{H}_{56} \mathrm{O}_{9} \mathrm{~N}_{5}$ 834.4072; found 834.4071, [M+Na] ${ }^{+}$Calcd for $\mathrm{C}_{47} \mathrm{H}_{55} \mathrm{O}_{9} \mathrm{~N}_{5} \mathrm{Na}$ 856.3892; found 856.3894. 


\subsection{General procedure B: Synthesis of 3'-O-phosphoramidites $5 a$ and $5 b$.}

5'-O-DMT-substituted nucleosides $\mathbf{4 a}$ or $\mathbf{3 b}$ were dried by repeated co-evaporations with anhydrous pyridine $\left(3 \times 5 \mathrm{~mL}\right.$ ) and subsequent co-evaporations with anhydrous $\mathrm{CH}_{2} \mathrm{Cl}_{2}(3 \times 5$ $\mathrm{mL}$ ), and finally dissolved in $10 \mathrm{~mL}$ of anhydrous $\mathrm{CH}_{2} \mathrm{Cl}_{2}$. Freshly distilled $\mathrm{N}, \mathrm{N}$ diisopropylethylamine (DIPEA, 2.5 equiv.) was added, followed by the addition of 2-cyanoethyl$\mathrm{N}, \mathrm{N}$-diisopropylchlorophosphoramidite $\left(1.2\right.$ equiv.) at $0^{\circ} \mathrm{C}$, and the reaction mixture was stirred at room temperature until a complete conversion was observed by TLC analysis (approx. $1.5 \mathrm{~h}$ ). The reaction mixture was diluted with anhydrous $\mathrm{CH}_{2} \mathrm{Cl}_{2}(50 \mathrm{~mL})$, quickly washed under an argon atmosphere with saturated aqueous $\mathrm{KCl}(20 \mathrm{~mL})$ and dried over $\mathrm{Na}_{2} \mathrm{SO}_{4}$. Purification by flash chromatography (Cyclohexane : EtOAc, with $0.5 \% \mathrm{Et}_{3} \mathrm{~N}$ ) under argon atmosphere provided each desired compounds as two pure diastereomers.

$N^{4}$-Dibutylformimidamide-5'-O-[bis(4-methoxyphenyl)phenylmethyl]-5-(2"-nitrobenzyl oxymethyl)-2'-deoxycytidine-3'-[2-cyanoethyl bis(1-methylethyl)phosphoramidite] (5a).

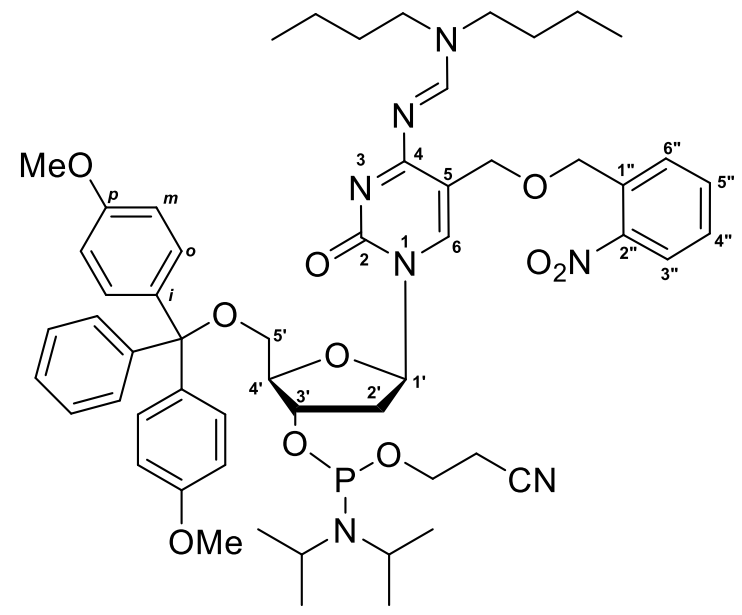

The title product $5 \mathbf{a}$ was obtained from the precursor $4 a(300 \mathrm{mg}, 0.36 \mathrm{mmol}), \mathrm{N}, \mathrm{N}$ diisopropylethylamine (157 $\mu \mathrm{L}, 0.9 \mathrm{mmol}, 2.5$ equiv.) and 2-cyanoethyl-N,Ndiisopropylchlorophosphoramidite (96 $\mu \mathrm{L}, 0.43 \mathrm{mmol}, 1.2$ equiv,.) following the general procedure B. The product was purified by flash chromatography (Cyclohexane: EtOAc 40:60, Et ${ }_{3} \mathrm{~N}$ $0.5 \%)$ and obtained as a yellowish foam (318 $\mathrm{mg}, 85 \%$ ). 
${ }^{1} \mathrm{H}$ NMR $\left(\mathrm{CD}_{3} \mathrm{CN}, 500.0 \mathrm{MHz}\right): \delta 8.67(\mathrm{~s}, 1 \mathrm{H}, \mathrm{CH}=\mathrm{N}) ; 7.97\left(\mathrm{dd}, 1 \mathrm{H}, J_{3^{\prime \prime}, 4^{\prime \prime}}=8.1 \mathrm{~Hz}, J_{3^{\prime \prime}, 5^{\prime \prime}}=1.4 \mathrm{~Hz}, \mathrm{H}-\right.$ 3"); $7.96(\mathrm{~s}, 1 \mathrm{H}, \mathrm{H}-6) ; 7.57\left(\mathrm{~m}, 1 \mathrm{H}, \mathrm{H}-6^{\prime \prime}\right) ; 7.52\left(\mathrm{~m}, 1 \mathrm{H}, \mathrm{H}-5^{\prime \prime}\right) ; 7.42-7.46\left(\mathrm{~m}, 3 \mathrm{H}, \mathrm{H}-4^{\prime \prime}, \mathrm{H}-\mathrm{o}-\mathrm{C}_{6} \mathrm{H}_{5}-\right.$ DMTr); 7.30 - 7.34 (m, 4H, H-o- $\left.\mathrm{C}_{6} \mathrm{H}_{4} \mathrm{OMe}-\mathrm{DMTr}\right)$; 7.24 - 7.29 (m, 2H, H-m- $\left.\mathrm{C}_{6} \mathrm{H}_{5}-\mathrm{DMTr}\right)$; 7.18 (m, $\left.1 \mathrm{H}, \mathrm{H}-p-\mathrm{C}_{6} \mathrm{H}_{5}-\mathrm{DMTr}\right) ; 6.79-6.83\left(\mathrm{~m}, 4 \mathrm{H}, \mathrm{H}-m-\mathrm{C}_{6} \mathrm{H}_{4} \mathrm{OMe}-\mathrm{DMTr}\right) ; 6.23\left(\mathrm{t}, 1 \mathrm{H}, J_{1^{\prime}, 2^{\prime}}=6.5 \mathrm{~Hz}, \mathrm{H}-1^{\prime}\right)$; 4.62, $4.66\left(2 \times d, 2 \times 1 \mathrm{H}, J_{\text {gem }}=14.8 \mathrm{~Hz}, \mathrm{CH}_{2} \mathrm{O}-5^{\prime \prime}\right) ; 4.61\left(\mathrm{~m}, 1 \mathrm{H}, \mathrm{H}-3^{\prime}\right) ; 4.27\left(\mathrm{~d}, 1 \mathrm{H}, J_{\text {gem }}=11.0 \mathrm{~Hz}\right.$, $\mathrm{CH}_{\mathrm{a}} \mathrm{H}_{\mathrm{b}} \mathrm{O}-5$ ); 4.14 (dddd, $1 \mathrm{H}, J_{4^{\prime}, 3^{\prime}}=4.3 \mathrm{~Hz}, J_{4^{\prime}, 5^{\prime}}=3.9 \mathrm{~Hz}, 3.1 \mathrm{~Hz}, J_{\mathrm{H}, \mathrm{P}}=1.0 \mathrm{~Hz}, \mathrm{H}-4^{\prime}$ ); 3.93 (d, $1 \mathrm{H}, J_{\text {gem }}$ $\left.=11.0 \mathrm{~Hz}, \mathrm{CH}_{\mathrm{a}} \mathrm{H}_{\mathrm{b}} \mathrm{O}-5\right) ; 3.697,3.699\left(2 \times \mathrm{s}, 2 \times 3 \mathrm{H}, \mathrm{CH}_{3} \mathrm{O}\right) ; 3.37-3.41,3.42-3.52(2 \times \mathrm{m}, 2 \times 2 \mathrm{H}$, $\left.\left(\mathrm{CH}_{3} \mathrm{CH}_{2} \mathrm{CH}_{2} \mathrm{CH}_{2}\right)_{2} \mathrm{~N}\right) ; 3.37$ (dd, $\left.1 \mathrm{H}, J_{\text {gem }}=10.7 \mathrm{~Hz}, J_{5^{\prime} \mathrm{a}, 4^{\prime}}=3.1 \mathrm{~Hz}, \mathrm{H}-5^{\prime} \mathrm{a}\right) ; 3.33\left(\mathrm{dd}, 1 \mathrm{H}, J_{\text {gem }}=10.7\right.$ $\left.\mathrm{Hz}, J_{5^{\prime} \mathrm{b}, 4^{\prime}}=3.9 \mathrm{~Hz}, \mathrm{H}-5^{\prime} \mathrm{b}\right) ; 2.50-2.54\left(\mathrm{~m}, 2 \mathrm{H}, \mathrm{OCH}_{2} \mathrm{CH}_{2} \mathrm{CN}\right.$ ); 2.49 (ddd, $1 \mathrm{H}, 1 \mathrm{H}, J_{\text {gem }}=13.6 \mathrm{~Hz}, J_{2^{\prime} \mathrm{a}, 1^{\prime}}$ $\left.=6.5 \mathrm{~Hz}, J_{2^{\prime} b, 3^{\prime}}=4.3 \mathrm{~Hz}, \mathrm{H}-2^{\prime} \mathrm{a}\right) ; 2.31\left(\mathrm{dt}, 1 \mathrm{H}, J_{\text {gem }}=13.6 \mathrm{~Hz}, J_{2^{\prime} b, 1^{\prime}}=J_{2^{\prime} b, 3^{\prime}}=6.5 \mathrm{~Hz}, \mathrm{H}-2^{\prime} \mathrm{b}\right) ; 1.50-1.62$ (m, 4H, $\left.\left(\mathrm{CH}_{3} \mathrm{CH}_{2} \mathrm{CH}_{2} \mathrm{CH}_{2}\right)_{2} \mathrm{~N}\right) ; 1.18-1.35\left(\mathrm{~m}, 4 \mathrm{H},\left(\mathrm{CH}_{3} \mathrm{CH}_{2} \mathrm{CH}_{2} \mathrm{CH}_{2}\right)_{2} \mathrm{~N}\right) ; 1.15,1.16\left(2 \times \mathrm{d}, 2 \times 6 \mathrm{H}, J_{\text {vic }}\right.$ $\left.=6.8 \mathrm{~Hz},\left(\mathrm{CH}_{3}\right)_{2} \mathrm{CH}\right) ; 0.80,0.93\left(2 \times \mathrm{t}, 2 \times 3 \mathrm{H}, J_{\text {vic }}=7.4 \mathrm{~Hz},\left(\mathrm{CH}_{3} \mathrm{CH}_{2} \mathrm{CH}_{2} \mathrm{CH}_{2}\right)_{2} \mathrm{~N}\right)$.

${ }^{13} \mathrm{C}\{1 \mathrm{H}\}$ NMR $\left(\mathrm{CD}_{3} \mathrm{CN}, 125.7 \mathrm{MHz}\right): \delta 171.2(\mathrm{C}-4) ; 159.7\left(\mathrm{C}-p-\mathrm{C}_{6} \mathrm{H}_{4} \mathrm{OMe}-\mathrm{DMTr}\right) ; 158.2(\mathrm{CH}=\mathrm{N})$;

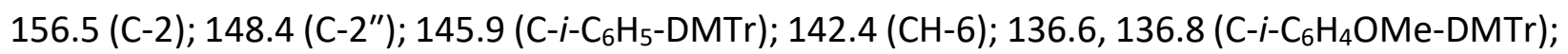
136.0 (C-1"); 134.5 (CH-5"); 131.1, 131.1 (CH-o-C $\left.\mathrm{H}_{4} \mathrm{OMe}-\mathrm{DMTr}\right) ; 129.7$ (CH-6"); 129.1 (CH-o$\left.\mathrm{C}_{6} \mathrm{H}_{5}-\mathrm{DMTr}\right) ; 129.0$ (CH-4");127.9 ( $\left.\mathrm{CH}-p-\mathrm{C}_{6} \mathrm{H}_{5}-\mathrm{DMTr}\right) ; 125.4$ (CH-3"); 119.4 (CN); 114.1 (CH-m$\mathrm{C}_{6} \mathrm{H}_{4} \mathrm{OMe}-\mathrm{DMTr}$ ); 111.3 (C-5); 87.4 (C-DMTr); 86.9 (CH-1'); 86.2 (d, JC,P $=4.3 \mathrm{~Hz}, \mathrm{CH}-4^{\prime}$ ); 73.6 (d, $\left.J_{C, P}=16.5 \mathrm{~Hz}, \mathrm{CH}-3^{\prime}\right) ; 69.5\left(\mathrm{CH}_{2} \mathrm{O}-5\right) ; 67.4\left(\mathrm{CH}_{2} \mathrm{O}-1^{\prime \prime}\right) ; 63.8\left(\mathrm{CH}_{2}-5^{\prime}\right) ; 59.5\left(\mathrm{~d}, J_{C, P}=19.1 \mathrm{~Hz}\right.$, $\left.\mathrm{OCH}_{2} \mathrm{CH}_{2} \mathrm{CN}\right) ; 55.9\left(\mathrm{CH}_{3} \mathrm{O}\right) ; 46.5,52.9\left(\left(\mathrm{CH}_{3} \mathrm{CH}_{2} \mathrm{CH}_{2} \mathrm{CH}_{2}\right)_{2} \mathrm{~N}\right) ; 44.0\left(\mathrm{~d}, \mathrm{~J}_{\mathrm{C}, \mathrm{P}}=2.4 \mathrm{~Hz},\left(\mathrm{CH}_{3}\right)_{2} \mathrm{CH}\right) ; 41.1$ (d, $\left.J_{C, P}=4.3 \mathrm{~Hz}, \mathrm{CH}_{2}-2^{\prime}\right) ; 29.8,31.6\left(\left(\mathrm{CH}_{3} \mathrm{CH}_{2} \mathrm{CH}_{2} \mathrm{CH}_{2}\right)_{2} \mathrm{~N}\right) ; 24.9$ (d, J $\left.J_{C, P}=7.3 \mathrm{~Hz},\left(\mathrm{CH}_{3}\right)_{2} \mathrm{CH}\right) ; 21.0$ (d, $\left.J_{C, P}=7.2 \mathrm{~Hz}, \mathrm{OCH}_{2} \mathrm{CH}_{2} \mathrm{CN}\right) ; 20.4,20.8\left(\left(\mathrm{CH}_{3} \mathrm{CH}_{2} \mathrm{CH}_{2} \mathrm{CH}_{2}\right)_{2} \mathrm{~N}\right) ; 13.96,14.03\left(\left(\mathrm{CH}_{3} \mathrm{CH}_{2} \mathrm{CH}_{2} \mathrm{CH}_{2}\right)_{2} \mathrm{~N}\right)$. ${ }^{31} \mathrm{P}\left\{{ }^{1} \mathrm{H}\right\} \mathrm{NMR}\left(\mathrm{CD}_{3} \mathrm{CN}, 202.4 \mathrm{MHz}\right): \delta 147.95$.

HR MS (ESI+) m/z : [M+H] $]^{+}$Calcd for $\mathrm{C}_{56} \mathrm{H}_{73} \mathrm{O}_{10} \mathrm{~N}_{7} \mathrm{P}$ 1034.5151; found 1034.5148, [M+Na] ${ }^{+}$Calcd for $\mathrm{C}_{56} \mathrm{H}_{72} \mathrm{O}_{10} \mathrm{~N}_{7} \mathrm{PNa} 1056.4970$; found 1056.4969. 


\section{5'-0-[Bis(4-methoxyphenyl)phenylmethyl]-5-(2"'-nitrobenzyloxymethyl)-2'-deoxyuridine-3'-}

[2-cyanoethyl bis(1-methylethyl) phosphoramidite] (5b).

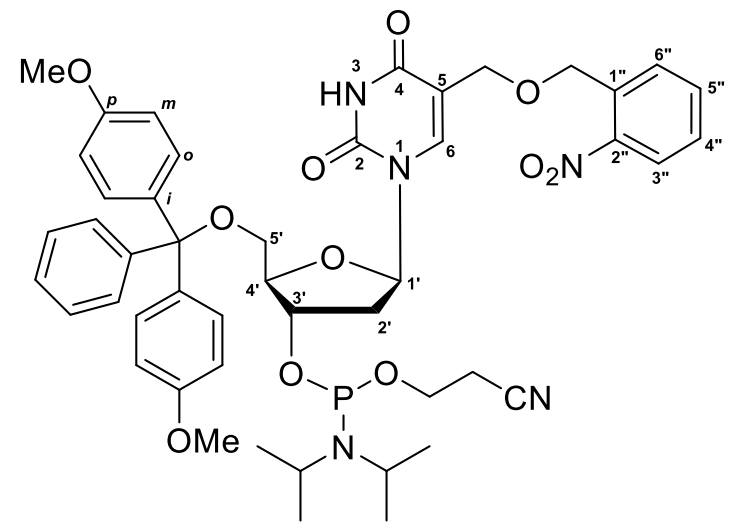

The title product $\mathbf{5 b}$ was obtained from the precursor $\mathbf{3 b}(500 \mathrm{mg}, 0.72 \mathrm{mmol}), N, N-$ diisopropylethylamine (313 $\mu \mathrm{L}, 1.8 \mathrm{mmol}, 2.5$ equiv) and 2-cyanoethyl-N,Ndiisopropylchlorophosphoramidite (192 $\mu \mathrm{L}, 0.86 \mathrm{mmol}, 1.2$ equiv.) following the general procedure B. The product was purified by flash chromatography (Cyclohexane: EtOAc 50: 50, Et ${ }_{3} \mathrm{~N}$ $0.5 \%)$ and obtained as a yellowish foam (476 $\mathrm{mg}, 74 \%)$.

${ }^{1} \mathrm{H}$ NMR (CD $3 \mathrm{CN}, 500.2 \mathrm{MHz}$ ): $\delta 9.27$ (bs, $1 \mathrm{H}, \mathrm{NH}-3$ ); 7.98 (dd, $1 \mathrm{H}, J_{3^{\prime \prime}, 4^{\prime \prime}}=8.2 \mathrm{~Hz}, J_{3^{\prime \prime}, 5^{\prime \prime}}=1.4 \mathrm{~Hz}, \mathrm{H}-$ $\left.3^{\prime \prime}\right) ; 7.79(\mathrm{~s}, 1 \mathrm{H}, \mathrm{H}-6) ; 7.62\left(\mathrm{ddt}, 1 \mathrm{H}, J_{6^{\prime \prime}, 5^{\prime \prime}}=7.8 \mathrm{~Hz}, J_{6^{\prime \prime}, 4^{\prime \prime}}=1.5 \mathrm{~Hz}, J_{5^{\prime \prime}, \mathrm{CH} 2}=1.0 \mathrm{~Hz}, \mathrm{H}-6^{\prime \prime}\right) ; 7.58$ (ddd, $\left.1 \mathrm{H}, J_{5^{\prime \prime}, 6^{\prime \prime}}=7.8 \mathrm{~Hz}, J_{5^{\prime \prime}, 4^{\prime \prime}}=7.2 \mathrm{~Hz}, J_{5^{\prime \prime}, 3^{\prime \prime}}=1.4 \mathrm{~Hz}, \mathrm{H}-5^{\prime \prime}\right)$; $7.42-7.49$ (m, 3H, H-4", H-o- $\mathrm{C}_{6} \mathrm{H}_{5}-\mathrm{DMTr}$ ); 7.25 - $7.34\left(\mathrm{~m}, 6 \mathrm{H}, \mathrm{H}-o-\mathrm{C}_{6} \mathrm{H}_{4}-\mathrm{DMTr}, \mathrm{H}-m-\mathrm{C}_{6} \mathrm{H}_{5}-\mathrm{DMTr}\right) ; 7.19\left(\mathrm{~m}, 1 \mathrm{H}, \mathrm{H}-p-\mathrm{C}_{6} \mathrm{H}_{5}-\mathrm{DMTr}\right) ; 6.79-6.84$ $\left(\mathrm{m}, 4 \mathrm{H}, \mathrm{H}-m-\mathrm{C}_{6} \mathrm{H}_{4}-\mathrm{DMTr}\right) ; 6.23\left(\mathrm{t}, 1 \mathrm{H}, J_{1^{\prime}, 2^{\prime}}=6.6 \mathrm{~Hz}, \mathrm{H}-1^{\prime}\right) ; 4.66$ (dddd, $1 \mathrm{H}, J_{\mathrm{H}, \mathrm{P}}=10.5 \mathrm{~Hz}, J_{3^{\prime}, 2^{\prime}}=6.4$ $\left.\mathrm{Hz}, 4.5 \mathrm{~Hz}, J_{3^{\prime}, 4^{\prime}}=3.5 \mathrm{~Hz}, \mathrm{H}-3^{\prime}\right) ; 4.59,4.62\left(2 \times \mathrm{d}, 2 \times 1 \mathrm{H}, J_{\text {gem }}=15.1 \mathrm{~Hz}, \mathrm{CH}_{2} \mathrm{O}-1^{\prime \prime}\right) ; 4.11$ (qd, $1 \mathrm{H}, J_{4^{\prime}, 3^{\prime}}$ $\left.=J_{4^{\prime}, 5^{\prime}}=3.5 \mathrm{~Hz}, J_{\mathrm{H}, \mathrm{P}}=1.0 \mathrm{~Hz}, \mathrm{H}-4^{\prime}\right) ; 4.01\left(\mathrm{~d}, J_{\text {gem }}=11.4 \mathrm{~Hz}, \mathrm{CH}_{\mathrm{a}} \mathrm{H}_{\mathrm{b}} \mathrm{O}-5\right)$; $3.55-3.78\left(\mathrm{~m}, 11 \mathrm{H}, \mathrm{CH}_{3} \mathrm{O}-\right.$ DMTr, $\left.\left(\mathrm{CH}_{3}\right)_{2} \mathrm{CH}, \mathrm{OCH}_{2} \mathrm{CH}_{2} \mathrm{CN}, \mathrm{CH}_{\mathrm{a}} \mathrm{H}_{\mathrm{b}} \mathrm{O}-5\right) ; 3.31-3.38\left(\mathrm{~m}, 2 \mathrm{H}, \mathrm{H}-5{ }^{\prime}\right) ; 2.52\left(\mathrm{t}, 2 \mathrm{H}, J_{\text {vic }}=6.0 \mathrm{~Hz}\right.$, $\left.\mathrm{OCH}_{2} \mathrm{CH}_{2} \mathrm{CN}\right) ; 2.34-2.46\left(\mathrm{~m}, 2 \mathrm{H}, \mathrm{H}-2^{\prime}\right) ; 1.15,1.17\left(2 \times \mathrm{d}, 2 \times 6 \mathrm{H}, J_{\text {vic }}=6.8 \mathrm{~Hz},\left(\mathrm{CH}_{3}\right)_{2} \mathrm{CH}\right)$. ${ }^{13} \mathrm{C}\{1 \mathrm{H}\} \operatorname{NMR}\left(\mathrm{CD}_{3} \mathrm{CN}, 125.8 \mathrm{MHz}\right): \delta 163.7$ (C-4); 159.8 (C-p- $\left.\mathrm{C}_{6} \mathrm{H}_{4}-\mathrm{DMTr}\right) ; 151.22$ (C-2); 148.5 (C2"); 145.9 (C-i-C $6 \mathrm{H}_{5}-\mathrm{DMTr}$ ); 140.4 (CH-6); 136.5, 136.8 (C-i-C $\mathrm{H}_{4}-\mathrm{DMTr}$ ); 135.6 (C-1");134.6 (CH5"); 131.11, 131.14 (CH-o-C6 $\mathrm{H}_{4}-\mathrm{DMTr}$ ); 129.8 (CH-6"); 129.2 (CH-4"); 129.1 (CH-o-C $\left.6 \mathrm{H}_{5}-\mathrm{DMTr}\right)$; 129.0 (CH-m- $\mathrm{C}_{6} \mathrm{H}_{5}-\mathrm{DMTr}$ ); 128.0 (CH-p- $\mathrm{C}_{6} \mathrm{H}_{5}-\mathrm{DMTr}$ ); 125.5 (CH-3"); 119.4 (CN); 114.1 (CH-m- $\mathrm{C}_{6} \mathrm{H}_{4}-$ DMTr); 87.5 (C-DMTr); 111.9 (C-5); 86.2 (d, JC,P $\left.=4.4 \mathrm{~Hz}, \mathrm{CH}-4^{\prime}\right) ; 85.8\left(\mathrm{CH}-1^{\prime}\right) ; 73.8$ (d, JC,P $=16.7$ 
$\left.\mathrm{Hz}, \mathrm{CH}-3^{\prime}\right) ; 69.6\left(\mathrm{CH}_{2} \mathrm{O}-1^{\prime \prime}\right) ; 65.9\left(\mathrm{CH}_{2} \mathrm{O}-5\right) ; 64.0\left(\mathrm{CH}_{2}-5^{\prime}\right) ; 59.5$ (d, J $\left.\mathrm{J}_{, \mathrm{P}}=19.1 \mathrm{~Hz}, \mathrm{OCH}_{2} \mathrm{CH}_{2} \mathrm{CN}\right) ; 55.9$ $\left(\mathrm{CH}_{3} \mathrm{O}-\mathrm{DMTr}\right) ; 44.0\left(\mathrm{~d}, \mathrm{~J}_{\mathrm{C}, \mathrm{P}}=12.4 \mathrm{~Hz},\left(\mathrm{CH}_{3}\right)_{2} \mathrm{CH}\right) ; 40.2\left(\mathrm{~d}, \mathrm{~J}_{\mathrm{C}, \mathrm{P}}=4.4 \mathrm{~Hz}, \mathrm{CH}_{2}-2^{\prime}\right) ; 24.88,24.91(2 \times \mathrm{d}$, $\left.J_{C, P}=7.3 \mathrm{~Hz},\left(\mathrm{CH}_{3}\right)_{2} \mathrm{CH}\right) ; 21.0\left(\mathrm{~d}, \mathrm{~J}_{\mathrm{C}, \mathrm{P}}=7.1 \mathrm{~Hz}, \mathrm{OCH}_{2} \mathrm{CH}_{2} \mathrm{CN}\right.$ ).

${ }^{31} \mathrm{P}\left\{{ }^{1} \mathrm{H}\right\} \mathrm{NMR}\left(\mathrm{CD}_{3} \mathrm{CN}, 202.5 \mathrm{MHz}\right): \delta 148.71$.

HR MS (ESI+) m/z: [M+H] $]^{+}$Calcd for $\mathrm{C}_{47} \mathrm{H}_{55} \mathrm{O}_{11} \mathrm{~N}_{5} \mathrm{P}$ 896.3630; found 896.3632.

\section{Solid-phase synthesis of oligonucleotides ON 2-8}

\subsection{Materials and methods}

Solvents and reagents for the solid-phase synthesis of oligonucleotides were purchased from Link Technologies, Sigma-Aldrich and Thermo Fisher-Scientifics. Natural phosphoramidites were purchased from Sigma-Aldrich. Modified oligonucleotides were synthesized through standard phosphoramidite chemistry with an automated DNA synthesizer (Mermade 8, Bioautomation). Purification of the prepared oligonucleotides was performed using semi-preparative HPLC (Waters modular HPLC system) on a column packed with $10 \mu \mathrm{m} \mathrm{C18}$ reversed phase (Phenomenex, Luna C18 (2) $100 \AA$ Å). The products were analyzed by MALDI-TOF MS and ESI-MS. Concentrations of DNA solutions were calculated using extinction coefficients obtained from the on-line tool at https://www.atdbio.com/tools/oligo-calculator and A260 values measured on a Cary100 Bio UV-Vis spectrophotometer (Varian).

\subsection{Oligonucleotide synthesis and purification}

Synthesis of oligonucleotides ON 2-8 were performed on a 1 umolar scale with the end Trityl off mode. The amidites were diluted to a $0.1 \mathrm{M}$ solution. Standard cycle procedures provided by Bioautomation were applied for the unmodified and modified phosphoramidites. The coupling volume and duration for the natural phosphoramidites were $220 \mu \mathrm{l}$ and 1 minute 30 seconds whereas that for the modified phosphoramidite was increased to $300 \mu \mathrm{l}$ and 6 minutes. Deprotections were carried out by incubating the reaction products in $30 \%$ aqueous $\mathrm{NH}_{3}$ at $55^{\circ} \mathrm{C}$ for 6 hours. HPLC purification of the oligonucleotides was performed using a linear gradiant of 
acetonitrile ( 0 to $30 \%)$ in $0.1 \mathrm{M} \mathrm{TEAB}$ buffer $(\mathrm{pH} 7.6)$ in 30 minutes. The sequences of the oligonucleotides are shown in Table S1.

Table S1: Sequences of the oligonucleotides ON 1-8. ${ }^{*} \mathrm{CH}_{2} \mathrm{ONB}$

\begin{tabular}{|c|c|}
\hline $\mathbf{O N}$ & Sequence \\
\hline $\mathbf{1}$ & TCTATTTGACAAAAATGGGC \\
\hline $\mathbf{2}$ & TCTATU*TGACAAAAATGGGC \\
\hline $\mathbf{3}$ & TCTATTU*GACAAAAATGGGC \\
\hline $\mathbf{4}$ & TCTATTTGAC*AAAAATGGGC \\
\hline $\mathbf{5}$ & TCTATU*U*GAC*AAAAATGGGC \\
\hline $\mathbf{6}$ & TCTATTTGACAAAAAU*GGGC \\
\hline $\mathbf{7}$ & TCTATTTGACAAAAATGGGC*T \\
\hline $\mathbf{8}$ & TCTATTTGACAAAAAU*GGGC*T \\
\hline
\end{tabular}

\section{Enzymatic synthesis of modified DNA}

\subsection{Materials and methods}

Synthetic oligonucleotides were purchased from Generi Biotech. Natural nucleoside triphosphates (dATP, dCTP, dGTP, dTTP) were purchased from New England Biolabs. Taq DNA polymerase for ThermoPol buffer was purchased from New England Biolabs. Sodium azide and DTT used in the irradiation experiments were purchased from Sigma Aldrich. All PCR products were purified with Agencourt AMPure XP magnetic particles (Beckman Coulter Life Science - GE Healthcare). Concentration of DNA solutions was calculated using A260 values measured on a Nanodrop 1000 Spectrophotometer (Thermo Scientific). All gels were analysed with fluorescence scanner Typhoon FLA 9500 (GE Healthcare, USA). Image J Quantificator was used for the quantification analysis of the gel. All solutions for biochemistry experiments were prepared in Milli-Q water. The PCR products were fully characterized by Sanger sequencing. 


\subsection{PCR Experiments}

Table S2: List of Oligonucleotides used for the PCR experiments and sequencing

\begin{tabular}{|c|c|c|}
\hline Oligonucleotide & Sequence $\left(5^{\prime}-3^{\prime}\right)$ & Length \\
\hline \multicolumn{3}{|l|}{ PRIMERS } \\
\hline Pveg_F_222 (ON 1) & TCTATTTGACAAAAATGGGC & 20-mer \\
\hline REV-PgII-R1/R3 & GGAGAGCGTTCACCGACA & 18-mer \\
\hline FAM-REV-PgII-R1/R3 ${ }^{c}$ & GGAGAGCGTTCACCGACA & 18-mer \\
\hline \multicolumn{3}{|l|}{ TEMPLATE } \\
\hline Temp Pveg $222^{a, b}$ & $\begin{array}{l}\text { TCTATTTGACAAAAATGGGCTCGTGTTGTACAATAAATGT } \\
\text { GTCTAAGCTTGGGTCCCACCTGACCCCATGCCGAACTCAG } \\
\text { AAGTGAAACGCCGTAGCGCCGATGGTAGTGTGGGGTCTC } \\
\text { CCCATGCGAGAGTAGGGAACTGCCAGGCATCAAATAAAA } \\
\text { CGAAAGGCTCAGTCGAAAGACTGGGCCTTTCGTTTTATCT } \\
\text { GTTGTTIGTCGGTGAACGCTCTCC }\end{array}$ & 222-mer \\
\hline
\end{tabular}

${ }^{a}$ primer sequences in template are underlined

${ }^{b}$ core promoter sequence of the template is in bold italics

${ }^{c} 5^{\prime}$-end of oligonucleotide is labelled by 6-carboxyfluorescein (6-FAM)

\subsubsection{Synthesis of the unmodified 222DNA1 and modified DNA NB-222DNA2-8 templates.}

To prepare the natural and modified templates for transcription, PCR reactions were performed in a total final volume of $30 \mu \mathrm{L}$. Natural DNAs (positive controls on agarose gels), which were used as controls for the DNA transcription experiments, were synthesized according to the procedure for modified DNA without any additives and in the presence of natural forward primer (Pveg_F_222). All modified DNA templates were prepared by PCR in the presence of modified forward primers (ON 2-8) and either non-labelled or FAM labelled natural reverse primers (REVPgIl-R1/R3) from the Pveg plasmid directly. One PCR reaction mixture (30 $\mu \mathrm{L})$ contained Taq DNA polymerase for ThermoPol buffer (New England Biolabs; $5000 \mathrm{U} / \mathrm{mL} ; 1.8 \mu \mathrm{L}$ ) with ThermoPol buffer (3 $\mu \mathrm{L})$, natural dNTPs (4 mM; $1.125 \mu \mathrm{L})$, primers (20 $\mu \mathrm{M} ; 4.5 \mu \mathrm{L}$; ON 2-8 and $20 \mu \mathrm{M}$; $4.5 \mu \mathrm{L}$; REV-PgII-R1/R3) and appropriate plasmid template (70 ng). The reaction was performed in a total 
volume $30 \mu \mathrm{L}(3 \times 10 \mu \mathrm{L})$. Forty PCR cycles were run in the thermal cycler under the following conditions: preheating for 3 minutes at $95^{\circ} \mathrm{C}$, denaturation for 1 minute at $94^{\circ} \mathrm{C}$, annealing for 1 minute at $52^{\circ} \mathrm{C}$, extension for 1.5 minutes at $75^{\circ} \mathrm{C}$, followed by final extension step of 5 minutes at $75^{\circ} \mathrm{C} .30 \mu \mathrm{L}$ of PCR reaction mixture was combined into one Eppendorf vial and PCR product was purified using Agencourt AMPure XP magnetic particles. In the last step of purification, the product was eluted with $20 \mu \mathrm{L}$ of MilliQ water and the concentration was measured by Nanodrop. For non labeled PCR products, approximately $100 \mathrm{ng}$ of DNA was loaded on a control $1.3 \%$ agarose gel stained with GelRed (Biotium) and analyzed in 0.5xTBE buffer. The sequence of the templates were confirmed by Sanger DNA sequencing.

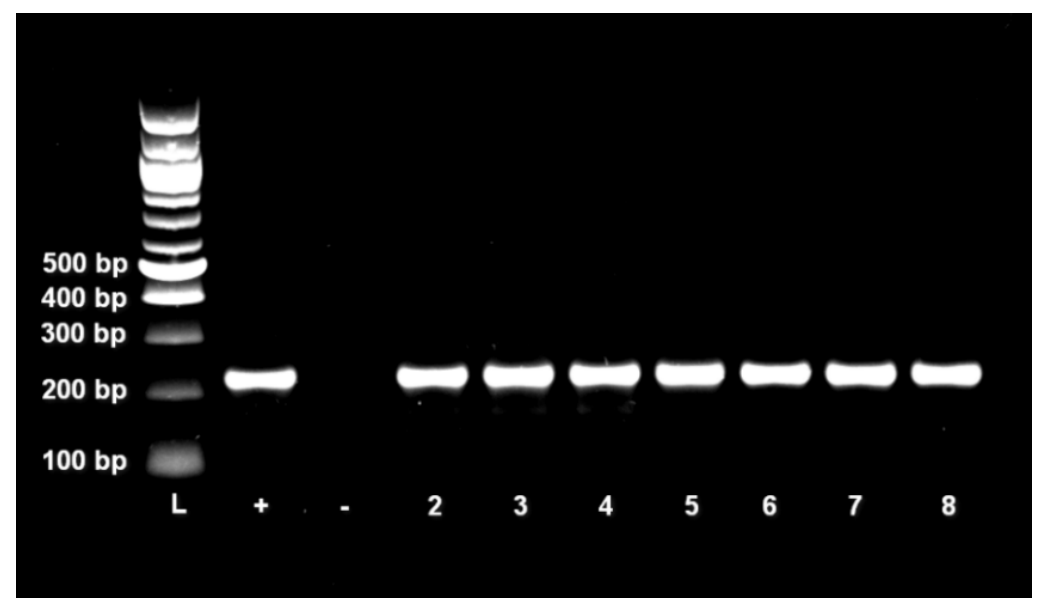

Figure S2: Agarose gel analysis of natural and modified PCR template products amplified from the plasmid by Taq DNA polymerase. Lane 1: $100 \mathrm{bp}$ ladder (commercial mix of dsDNA with the specific length); Lane 2 (+): PCR product with natural forward primer (ON 1); Lane 3: (-): PCR product in the absence of both primers; Lane 4 (2): PCR product with ON 2 as forward primer; Lane 5 (3): PCR product with ON 3 as forward primer; Lane 6 (4): PCR product with ON 4 as forward primer; Lane 7 (5): PCR product with ON 5 as forward primer; Lane 8 (6): PCR product with ON 6 as forward primer; Lane 9 (7): PCR product with ON 7 as forward primer; Lane 10 (8): PCR product with ON 8 as forward primer. 


\subsection{Quantification of DNA templates}

Quantification using radioactive labelling ${ }^{9,10}$ could not be used here due to the practical difficulties involved in distinguishing the template and the transcript which are of similar length. Since the modifications were only one or a few in the $5^{\prime}$ end of the DNA template, we assumed that it cannot quench the FAM at the $3^{\prime}$ end. Therefore, FAM labelling at the $3^{\prime}$ end was chosen as the method to quantify the PCR products for transcription. To verify the concentrations of modified DNAs for the in vitro transcription assay, FAM labelled DNA templates were prepared (using FAM labelled reverse primer (FAM-REV-PgII-R1/R3) in $30 \mu$ l reactions. The templates were then purified and finally diluted in $20 \mu \mathrm{l} \mathrm{H} \mathrm{H}_{2} \mathrm{O} .1 \mu \mathrm{l}$ of the DNA (along with $4 \mu \mathrm{l} \mathrm{H}_{2} \mathrm{O}$ and $1 \mu \mathrm{l}$ XX DNA loading dye) was loaded on a 1.3\% agarose gel without Gelred. The relative intensities of the DNA bands in the gels were analyzed using the ImageJ software. These values were then used to determine relative concentrations of the modified DNA templates in all the transcription studies.

\subsection{Deprotection of DNA by irradiation with UV lamp $400 \mathrm{~nm}$ (3W).}

The FAM labelled DNA after purification and quantification was used for the deprotection experiments. Two batches of each sample were prepared to serve as the non-irradiated and irradiated samples. Approximately $240 \mathrm{ng}$ (according to Nanodrop) of the natural DNA was taken and diluted to the final concentration of approximately $20 \mathrm{ng} / \mu \mathrm{l}$ either with $\mathrm{H}_{2} \mathrm{O}$ (for nonirradiated samples) or with $\mathrm{H}_{2} \mathrm{O}$ and additives- $1 \mu \mathrm{L}$ of $1 \mathrm{mM} \mathrm{NaN}_{3}$ and $1 \mu \mathrm{L}$ of $50 \mathrm{mM}$ DTT (for irradiated samples). Then the modified DNA was diluted in the same manner, based on quantification correction (see 3.3). Irradiation was performed on samples diluted in the presence of additives, at room temperature. The natural and modified samples containing either $U^{\mathrm{NB}}$ or both $U^{N B}$ and $C^{N B}$ (unmodified 222DNA1 and NB-222DNA2-8) were irradiated for 30 minutes and the samples containing only $C^{\text {NB }}$ (NB-222DNA-4 and 7) for 10 minutes, following the optimized protocols ${ }^{10}$. We then used both the non-irradiated and irradiated DNA samples directly as templates for the in vitro transcription assay. 


\section{Transcription studies}

\subsection{General remarks for the experiments of transcription}

\subsubsection{Multiple round transcriptions of modified DNA}

Multiple round in vitro transcription assays were performed in a volume of $10 \mu$ containing $5 \mathrm{ng}$ of DNA template, $40 \mathrm{mM}$ Tris- $\mathrm{Cl} \mathrm{pH}$ 8, $10 \mathrm{mM} \mathrm{MgCl}$, $1 \mathrm{mM}$ DTT, $90 \mathrm{mM} \mathrm{KCl}, 10 \mu \mathrm{g} / \mathrm{ml} \mathrm{BSA}, 30$ nM RNA polymerase holoenzyme from Escherichia coli (New England Biolabs) and NTPs (200 $\mu$ M ATP, $1000 \mu \mathrm{M}$ GTP, $200 \mu \mathrm{M}$ CTP, $10 \mu \mathrm{M}$ UTP plus $3.7 \mathrm{kBq}$ [ $\alpha-32 \mathrm{P}] \mathrm{UTP})$. After preheating the samples for 10 minutes at $37^{\circ} \mathrm{C}$, the transcription reaction was initiated by adding the NTP mix and run for 10 minutes at $37^{\circ} \mathrm{C}$. The reaction was terminated by adding $10 \mu$ of stop solution (95\% formamide, $20 \mathrm{mM}$ EDTA, $\mathrm{pH}$ 8.0). The samples were then incubated at $95^{\circ} \mathrm{C}$ for 5 minutes and chilled on ice. $10 \mu \mathrm{l}$ of the reaction were analyzed on a 7\% polyacrylamide gel. Dried gels were exposed to Fuji MS phosphor storage screens and scanned with Molecular Imager FX (Biorad). At least five independent experiments were performed using three different PCR batches.

\subsubsection{Quantification of relative transcriptions}

The signals from the gel were analyzed using Quantity One software (Biorad). To quantify the transcription intensity, background was subtracted and the bands were normalized to the value of non-modified DNA template which was set to $100 \%$.

\subsection{Transcription data of the shorter forms of natural Pveg template}

Two shorter forms (from the 5' end) of the original 339 mer Pveg template were synthesized and their transcription was compared to the original template used in the previous studies ${ }^{9,10}$. Only a 
single experiment with a single batch was carried out. The shorter 222 mer, which shows almost the same activity as that of the original template was chosen as the template for further studies.

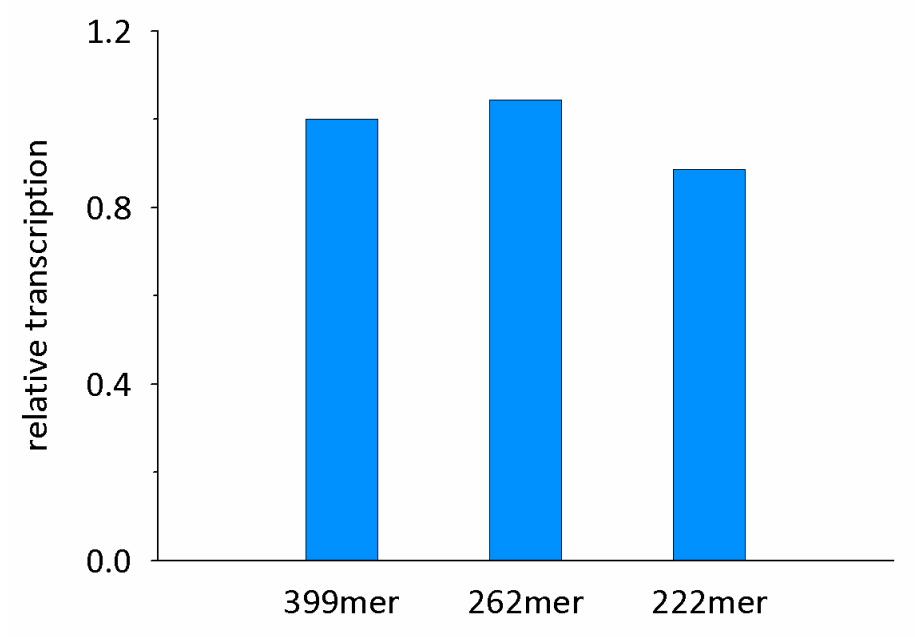

Figure S3: Transcription of different lengths of natural Pveg template.

\subsection{Transcription data for the DNA Templates 222DNA1, NB-222DNA2-8 and hm-222DNA2-8.}

All DNA samples (FAM labelled) used for the transcription studies were synthesized according to the mentioned protocols (See 3.2.1., 3.3. and 3.4). The non-irradiated and irradiated samples were directly used as templates for in vitro transcription assays. The transcription experiments were performed according to the mentioned protocols (4.1). 


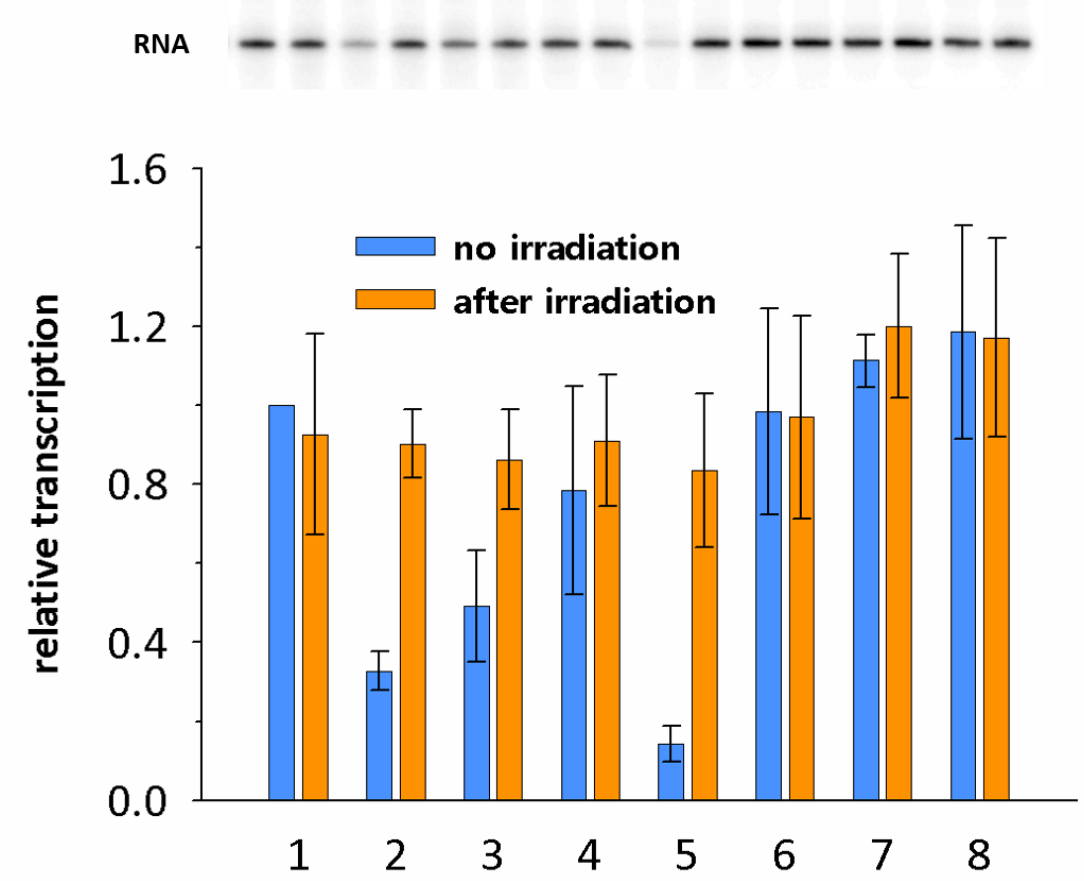

Figure S4: Transcription of DNA Templates unmodified 222DNA1 (nonirradiated and irradiated), NB-222DNA2-8 and hm-222DNA2-8. Representative primary data (radiolabeled RNA transcripts) are shown above the graph. The bars show the average from at least five independent experiments, the error bars show \pm SD.

Table S3: Average relative transcription (+ SD; average from 5 experiments) of the DNA templates unmodified 222DNA1 (nonirradiated and irradiated), NB-222DNA2-8 and hm-222DNA2-8.

\begin{tabular}{|c|c|c|}
\hline \multirow[b]{2}{*}{ DNA Template } & \multicolumn{2}{|c|}{ Average relative transcription $\pm S D$} \\
\hline & $\begin{array}{c}\text { No irradiation } \\
\text { (unmodified 222DNA1 } \\
\text { or } \\
\text { NB-222DNA2-8) }\end{array}$ & $\begin{array}{c}\text { After irradiation } \\
\text { (unmodified 222DNA1 or } \\
\text { hm-222DNA2-8) }\end{array}$ \\
\hline 1 & 1 & $0.93 \pm 0.26$ \\
\hline 2 & $0.33 \pm 0.05$ & $0.90 \pm 0.09$ \\
\hline 3 & $0.49 \pm 0.14$ & $0.86 \pm 0.13$ \\
\hline 4 & $0.78 \pm 0.26$ & $0.91 \pm 0.17$ \\
\hline 5 & $0.14 \pm 0.05$ & $0.83 \pm 0.19$ \\
\hline 6 & $0.98 \pm 0.26$ & $0.97 \pm 0.26$ \\
\hline 7 & $1.11 \pm 0.07$ & $1.20 \pm 0.18$ \\
\hline 8 & $1.19 \pm 0.27$ & $1.17 \pm 0.25$ \\
\hline
\end{tabular}




\subsection{Transcription data for the kinetic study of deprotection of DNA Template NB-222DNA-5.}

The kinetic study of deprotection was done on the NB-222DNA-5 template. This template contains both uridine and cytidine modified bases. The FAM labelled DNA sample NB-222DNA-5 used for the transcription studies was synthesized according to the mentioned protocols (See 3.2.1, 3.3). Approx. $480 \mathrm{ng}$ of this stock DNA was irradiated by the UV lamp (400nm) as per (3.4) and aliquots were taken at the following time intervals $10 \mathrm{~min} / 20 \mathrm{~min} / 30 \mathrm{~min} / 40 \mathrm{~min} /$ and $60 \mathrm{~min}$. These progressively irradiated DNA templates were then directly used as templates in the in vitro multiple transcription assay, which was performed essentially as described (4.1.).

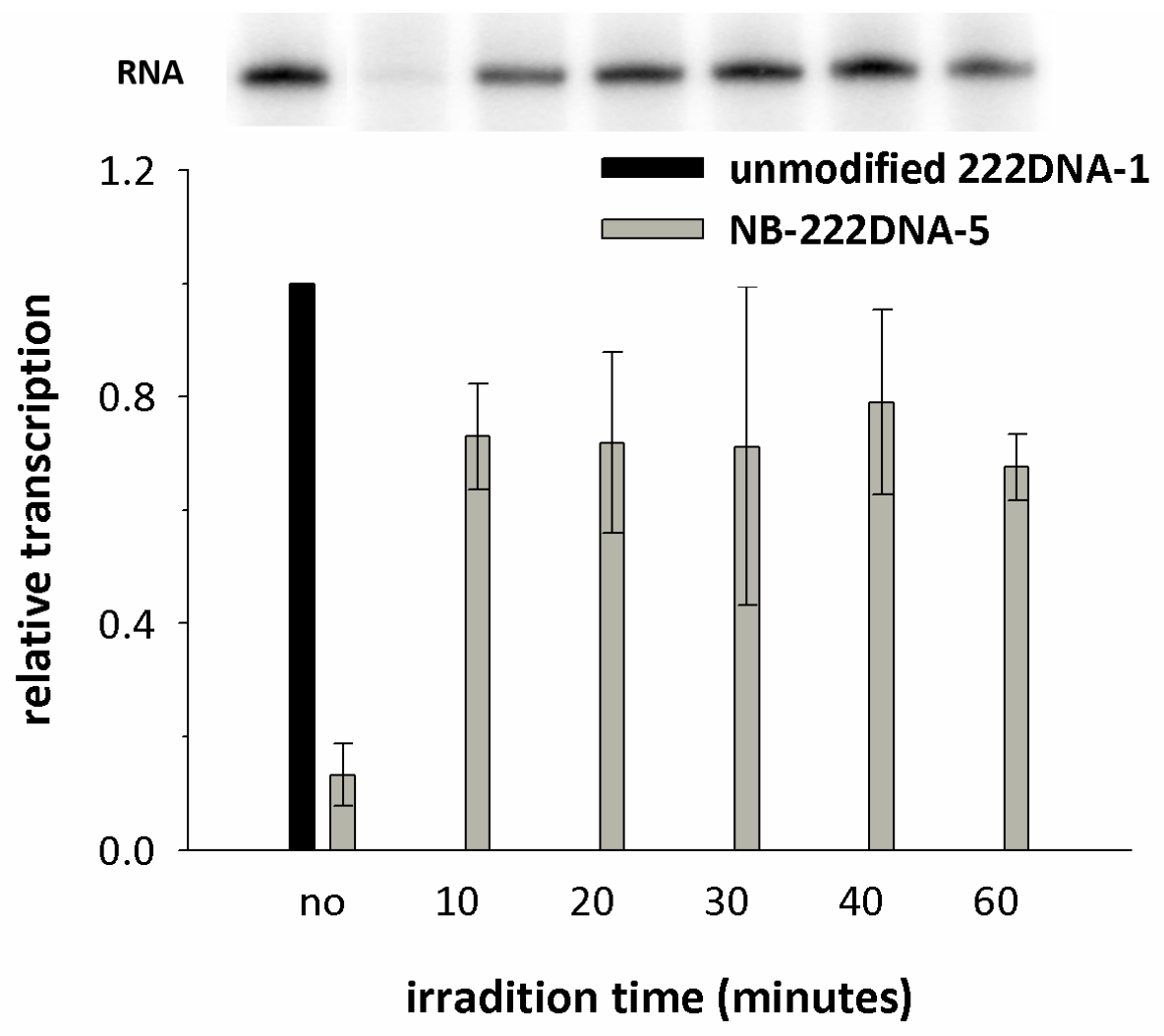

Figure S5: Transcription of DNA template NB-222DNA-5 irradiated at different time intervals. Representative primary data (radiolabeled RNA transcripts) are shown above the graph. The bars show averages of two experiments. The error bars show the range. 


\section{MALDI TOF AND ESI SPECTRA}

MALDI TOF SPECTRA

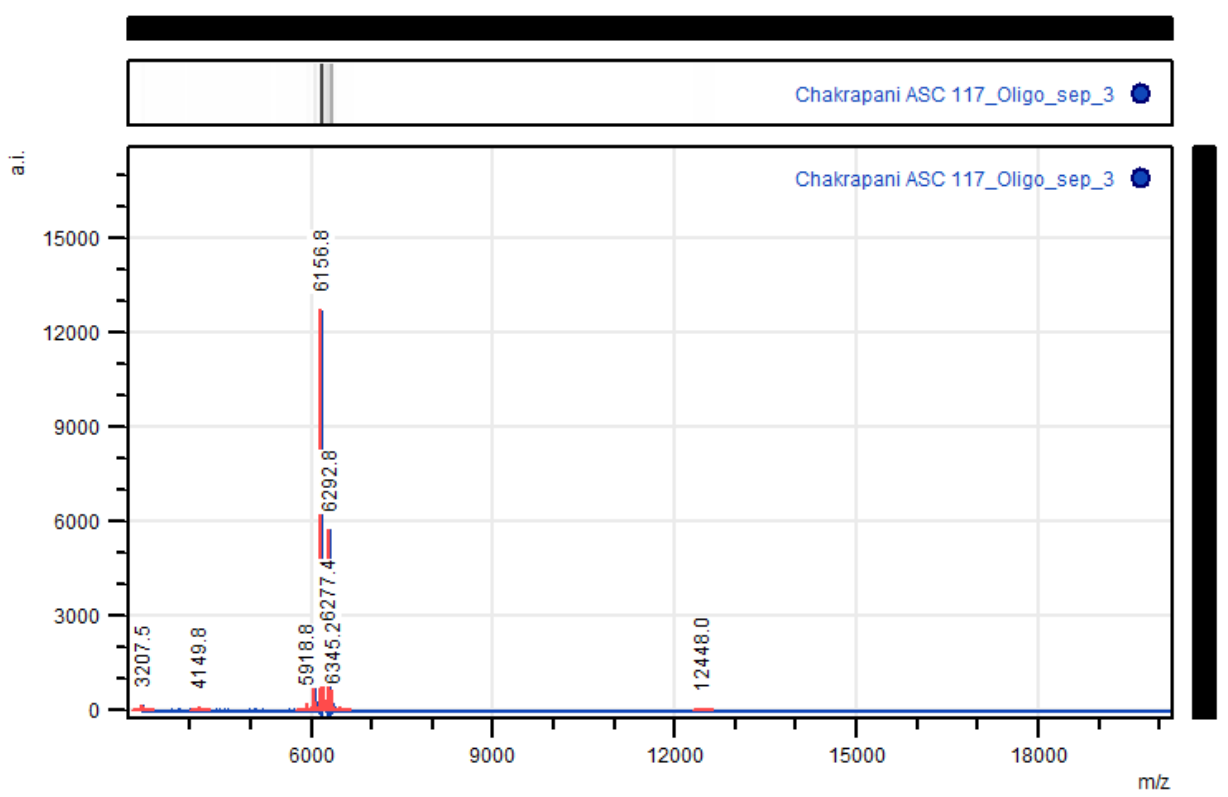

Figure S6: MALDI-TOF MS spectrum of ON 2. Calculated for $[\mathrm{M}]^{+}=6291.13 \mathrm{Da},[\mathrm{M}-\mathrm{NB}]^{+}=$ 6156.13 Da; found: $[\mathrm{M}+\mathrm{H}]^{+}=6292.8 \mathrm{Da},[\mathrm{M}-\mathrm{NB}]^{+}=6156.8 \mathrm{Da}$.

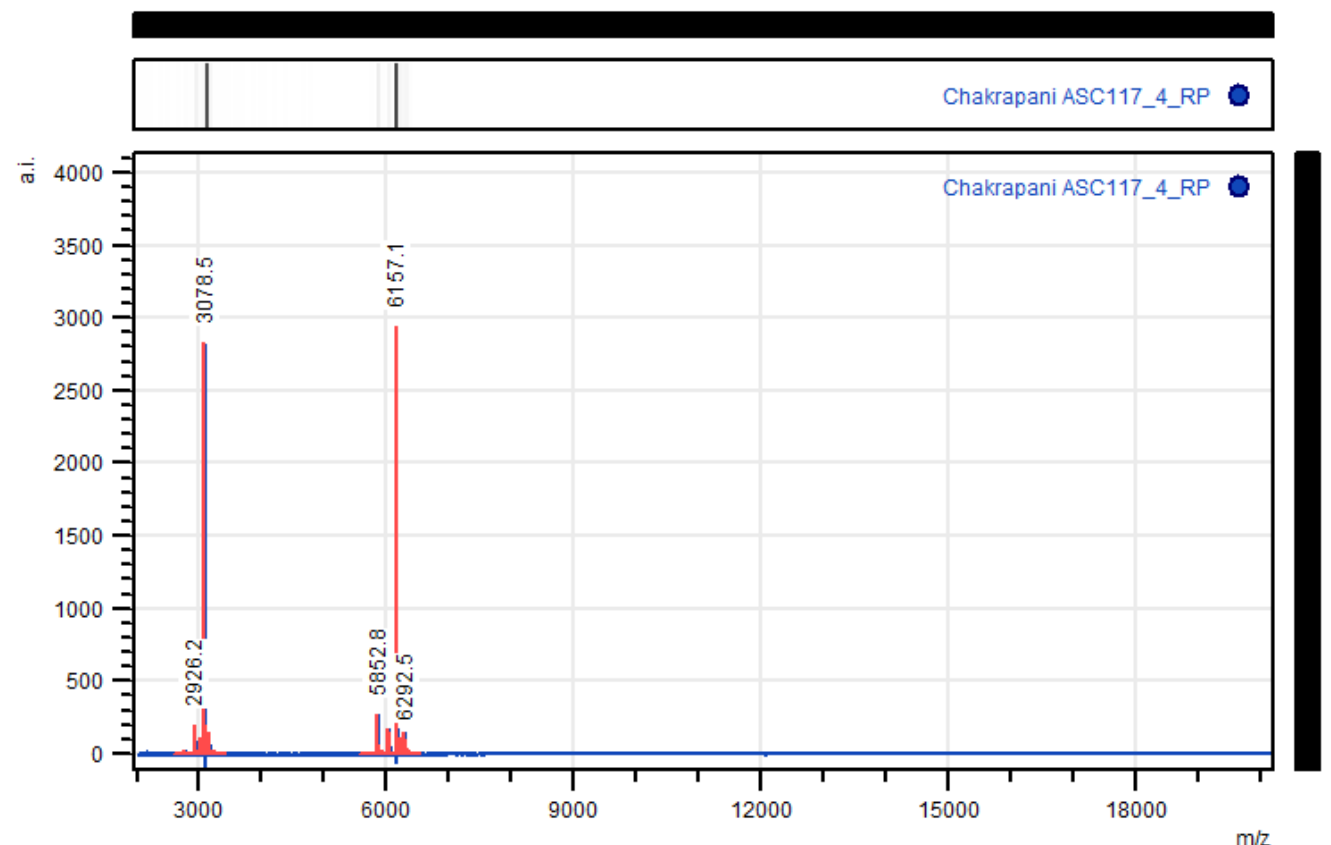

Figure S7: MALDI-TOF MS spectrum of ON 3. Calculated for $[\mathrm{M}]^{+}=6291.13 \mathrm{Da},[\mathrm{M}-\mathrm{NB}]^{+}=$ 6156.13 Da; found: $[\mathrm{M}+\mathrm{H}]^{+}=6292.5 \mathrm{Da},[\mathrm{M}-\mathrm{NB}+\mathrm{H}]^{+}=6157.1 \mathrm{Da}$. 


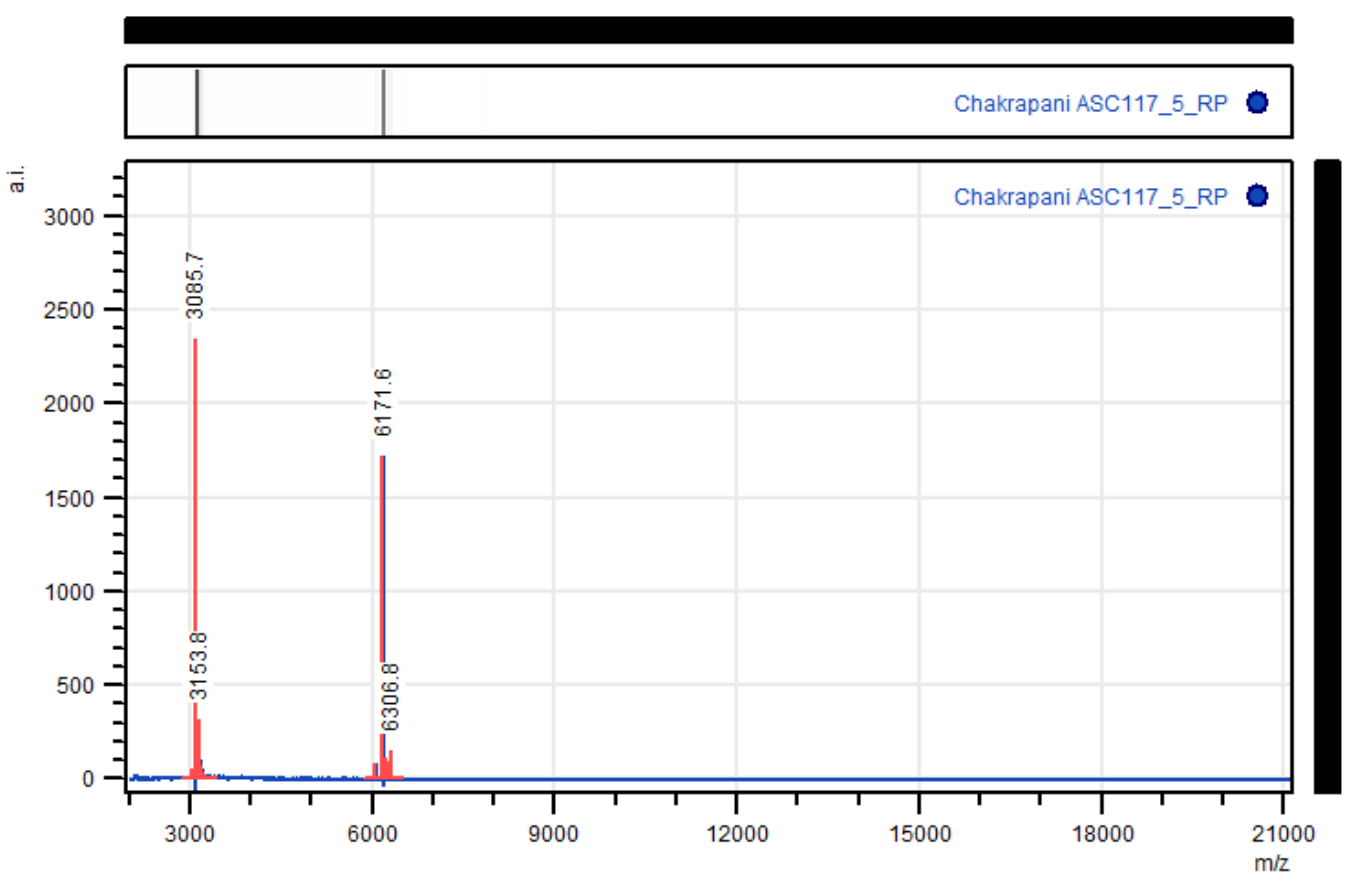

Figure S8: MALDI-TOF MS spectrum of ON 4. Calculated for $[\mathrm{M}]^{+}=6305.15 \mathrm{Da},[\mathrm{M}-\mathrm{NB}]^{+}=$ 6170.15 Da; found: $[\mathrm{M}+\mathrm{H}]^{+}=6306.8 \mathrm{Da},[\mathrm{M}-\mathrm{NB}+\mathrm{H}]^{+}=6171.6 \mathrm{Da}$.

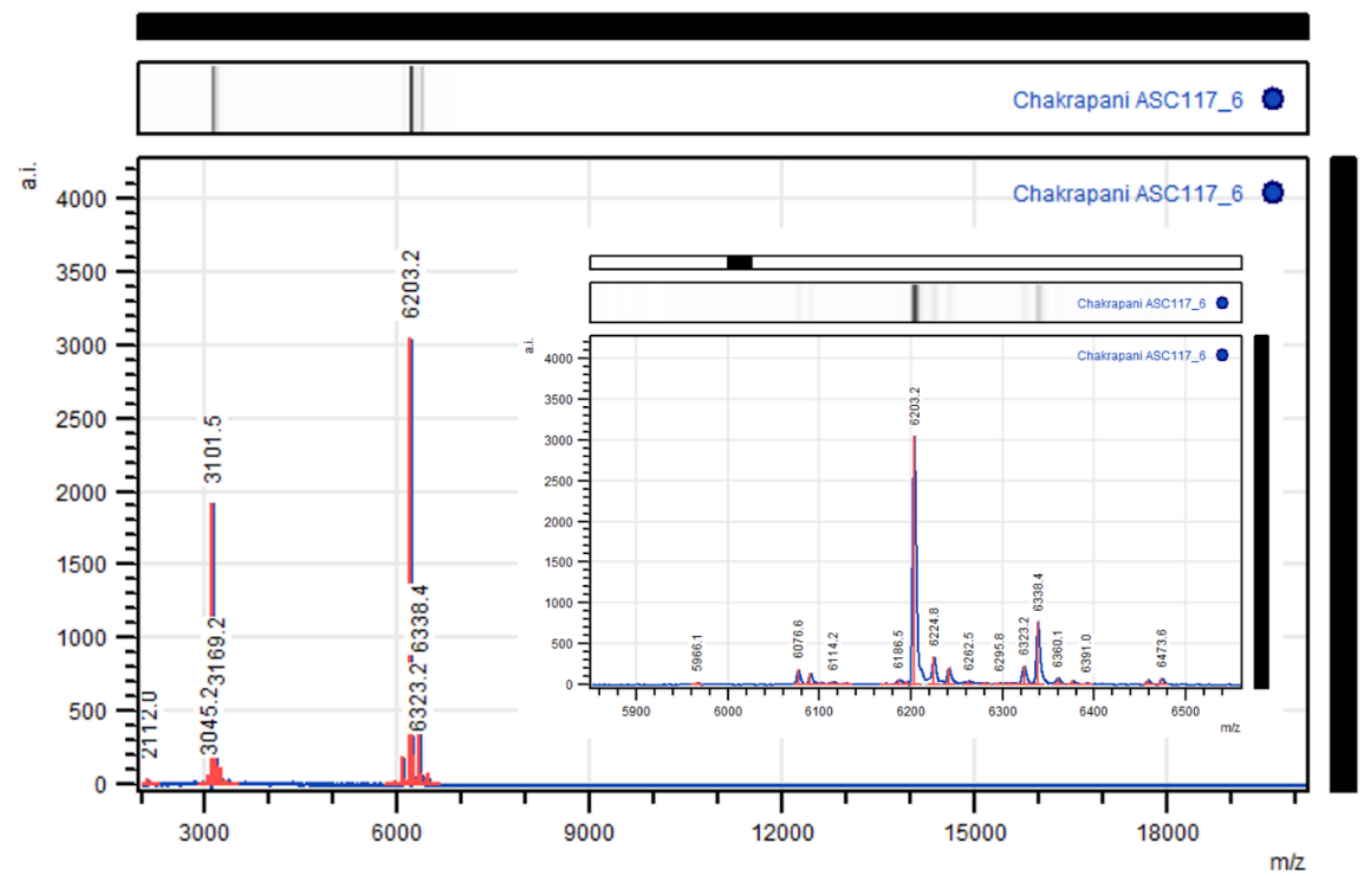

Figure S9: MALDI-TOF MS spectrum of ON 5. Calculated for $[\mathrm{M}]^{+}=6607.21 \mathrm{Da},[\mathrm{M}-\mathrm{NB}]^{+}=$ 6472.21 Da, $[\mathrm{M}-2 \mathrm{NB}]^{+}=6337.21 \mathrm{Da},[\mathrm{M}-3 N B]^{+}=6202.21 \mathrm{Da}$; found: $[\mathrm{M}-\mathrm{NB}+\mathrm{H}]^{+}=6473.6 \mathrm{Da}$, $[\mathrm{M}-2 \mathrm{NB}+\mathrm{H}]^{+}=6338.4 \mathrm{Da} ;[\mathrm{M}-3 \mathrm{NB}+\mathrm{H}]^{+}=6203.2 \mathrm{Da}$. 


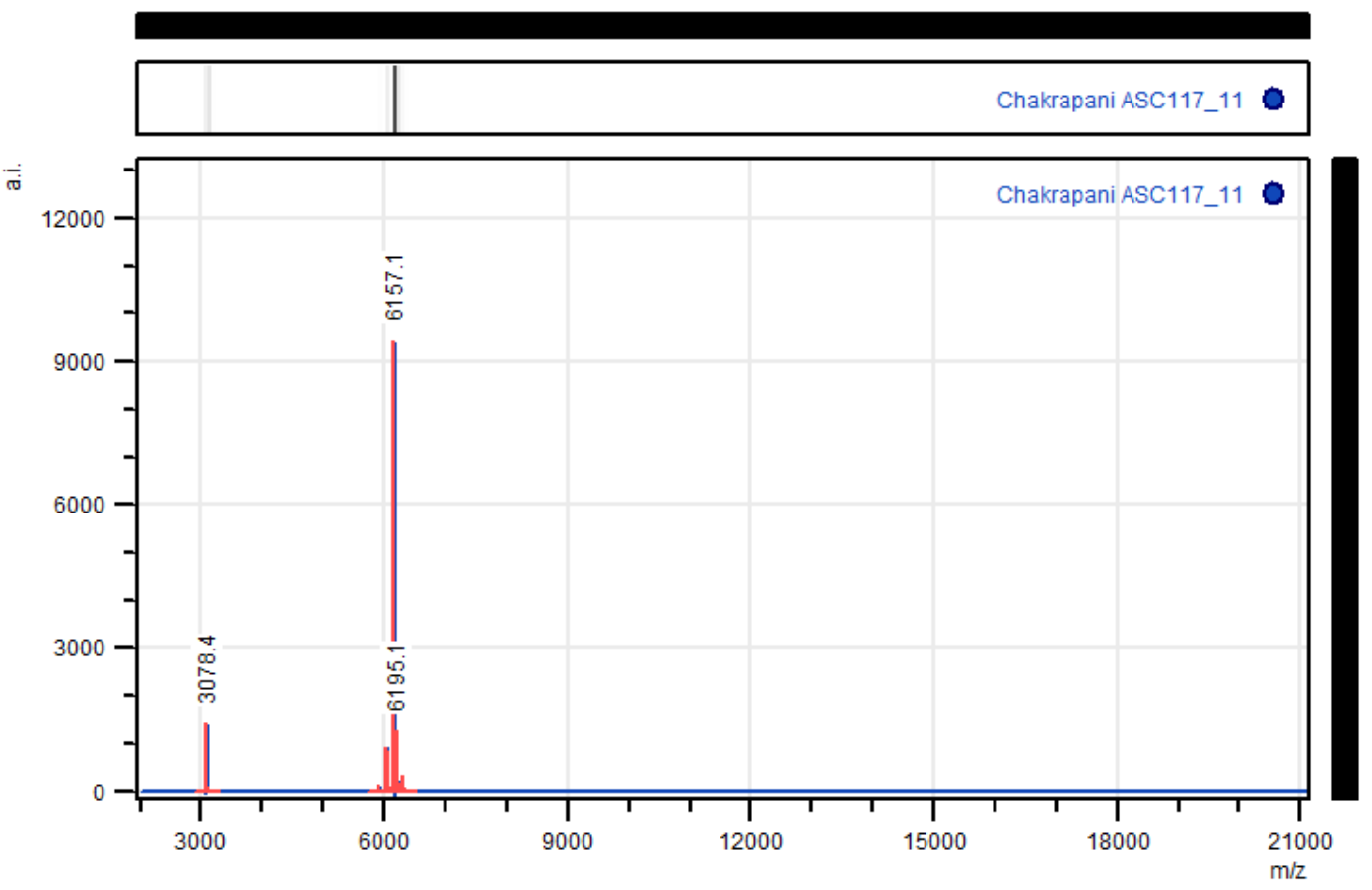

Figure S10: MALDI-TOF MS spectrum of ON 6. Calculated for $[\mathrm{M}]^{+}=6291.13 \mathrm{Da},[\mathrm{M}-\mathrm{NB}]^{+}=$ 6156.13; found: $[\mathrm{M}-\mathrm{NB}+\mathrm{H}]^{+}=6157.1 \mathrm{Da}$.

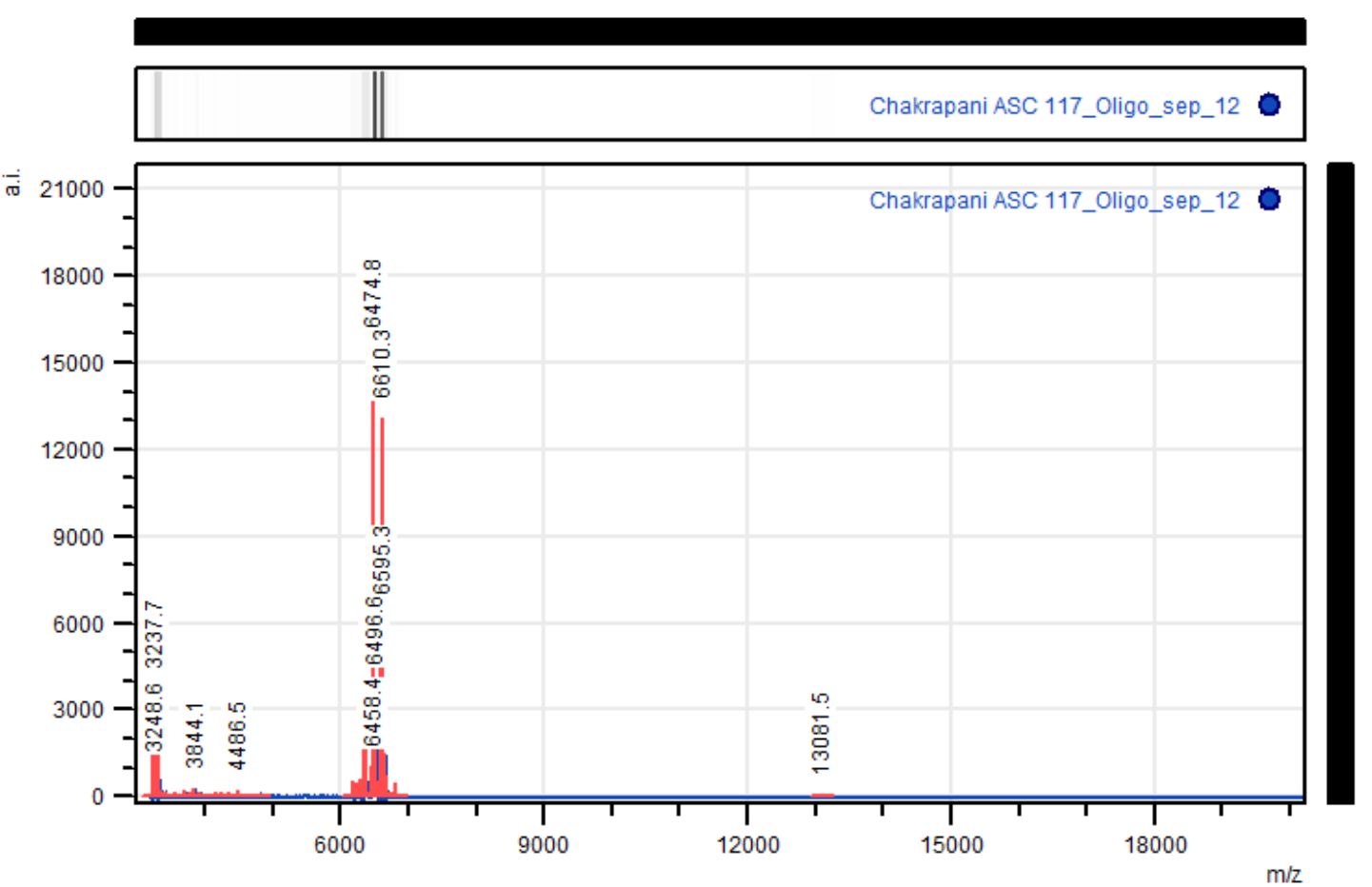

Figure S11: MALDI-TOF MS spectrum of ON 7. Calculated for $[\mathrm{M}]^{+}=6609.35 \mathrm{Da},[\mathrm{M}-\mathrm{NB}]^{+}=$ 6474.35 Da; found: $[\mathrm{M}+\mathrm{H}]^{+}=6610.3 \mathrm{Da},[\mathrm{M}-\mathrm{NB}]^{+}=6474.8 \mathrm{Da}$. 


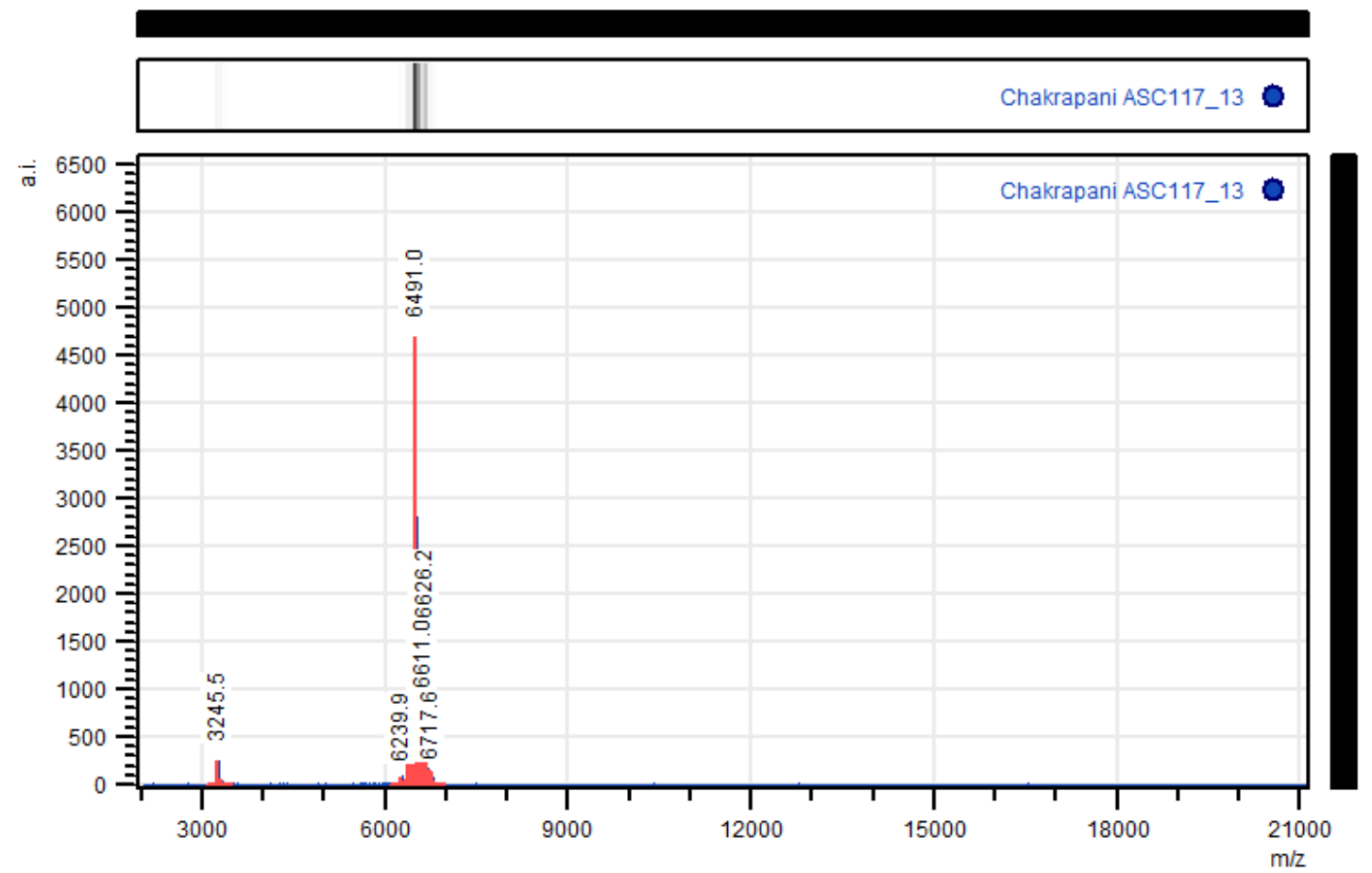

Figure S12: MALDI-TOF MS spectrum of ON 8. Calculated for $[\mathrm{M}]^{+}=6760.38 \mathrm{Da},[\mathrm{M}-\mathrm{NB}]^{+}=$ $6625.38 \mathrm{Da} ;[\mathrm{M}-2 \mathrm{NB}]^{+}=6490.38 \mathrm{Da}$; found: $[\mathrm{M}-\mathrm{NB}+\mathrm{H}]^{+}=6626.2 \mathrm{Da},[\mathrm{M}-2 \mathrm{NB}+\mathrm{H}]^{+}=6491.0 \mathrm{Da}$.

\section{ESI SPECTRA}

ESI-MS spectra of ON 2-8 was recorded to confirm the incorporation of intact 5-(2"Nitrobenzyloxy)methyl nucleosides.

Table S4: Mass obtained from ESI-MS for ON 2-8.

\begin{tabular}{|c|c|c|}
\hline ON & Mass calculated for $[\mathrm{M}]^{+}$ & Mass found \\
\hline 2 & 6291.13 & $6290.08[\mathrm{M}-\mathrm{H}]^{+}$ \\
\hline 3 & 6291.13 & $6290.08[\mathrm{M}-\mathrm{H}]^{+}$ \\
\hline 4 & 6305.15 & $6304.09[\mathrm{M}-\mathrm{H}]^{+}$ \\
\hline 5 & 6607.21 & $6606.14[\mathrm{M}-\mathrm{H}]^{+}$ \\
\hline 6 & 6291.13 & $6290.08[\mathrm{M}-\mathrm{H}]^{+}$ \\
\hline 7 & 6609.35 & $6608.14[\mathrm{M}-\mathrm{H}]^{+}$ \\
\hline 8 & 6760.38 & $6760.16[\mathrm{M}]^{+}$ \\
\hline
\end{tabular}




\section{Sequencing analysis of PCR products}

The correct sequence of all PCR products (non labelled) was confirmed with LIGHTRUN tube sequencing service (GATC Biotech AG, Germany) using standard Sanger sequencing. Sequencing was done with two primers, Pveg_F_222 (for primary strand) and REV-PgII-R1/R3 (for complementary strand). The red underlined part shows exact match of the sequenced DNA with the expected sequence in the presence of reverse primer. Blue underlined part shows exact match of the sequenced DNA with the expected sequence in the presence of forward primer. The part correctly sequenced in the presence of both forward and reverse primer is shown in double violet underlining.

\section{DNA1}

5'TCTATTTGACAAAAATGGGCTCGTGTTGTACAATAAATGTGTCTAAGCTTGGGTCCCACCTGACCCCAT GCCGAACTCAGAAGTGAAACGCCGTAGCGCCGATGGTAGTGTGGGGTCTCCCCATGCGAGAGTAGGGA ACTGCCAGGCATCAAATAAAACGAAAGGCTCAGTCGAAAGACTGGGCCTTTCGTTTTATCTGTTGTTTGT CGGTGAACGCTCTCC-3'

Primary strand (exact match for $124 \mathrm{bp})$ :
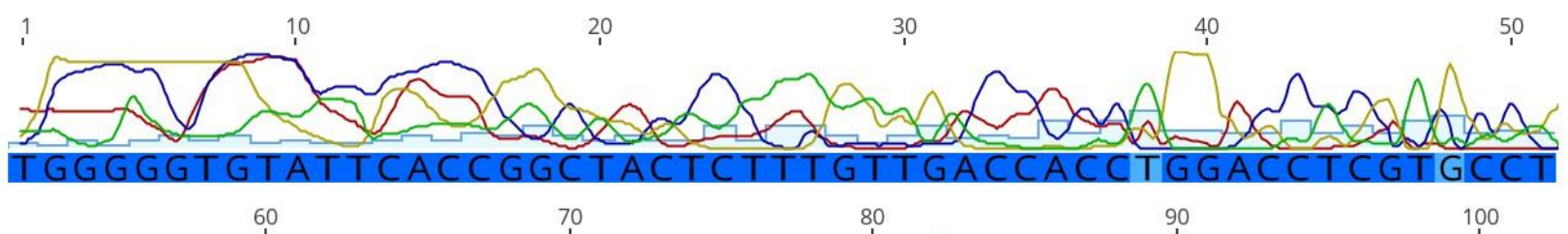

70

100

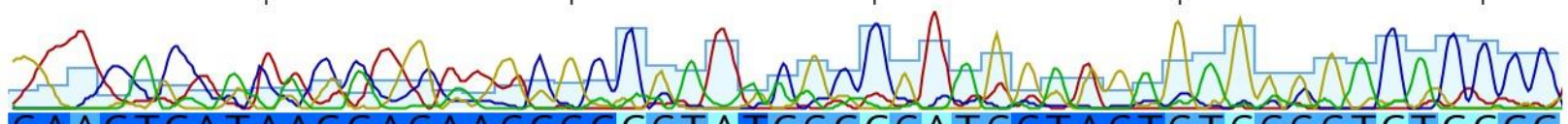
GAACTCATAACCAGAAGCGCCGTATCGCCGATGGTAGTGTGGGGTCTCCCC

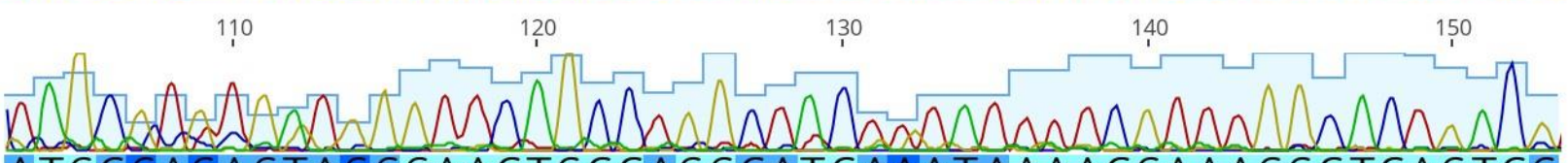
ATGCGAGAGTAGGGAACTGCCAGGCATCAAATAAAACGAAAGGCTCAGTCG

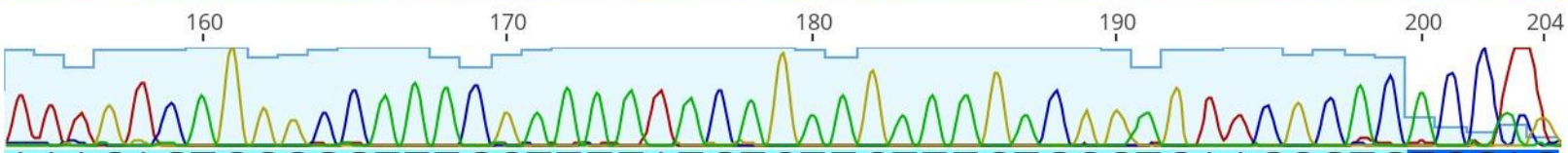
AAAGACTGGGCCTTTCGTTTTATCTGTTGTTTGTCGGTGAACGCTCTCCAG 
Complementary strand (exact match for $142 \mathrm{bp}$ ):
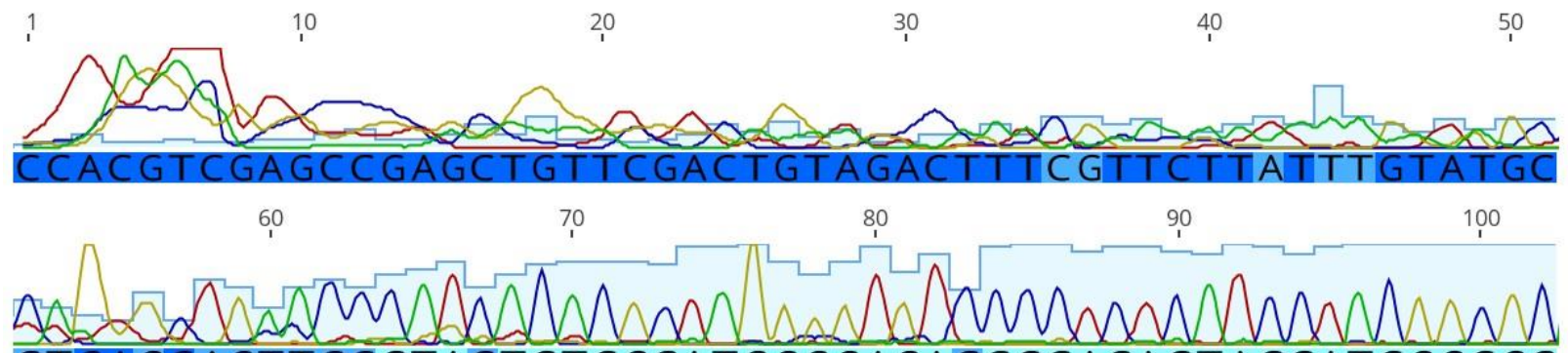

CTGAGCAGTTCCCTACTCTCGCATGGGGAGACCCCACACTACCATCGGCGC

110

120

140

150

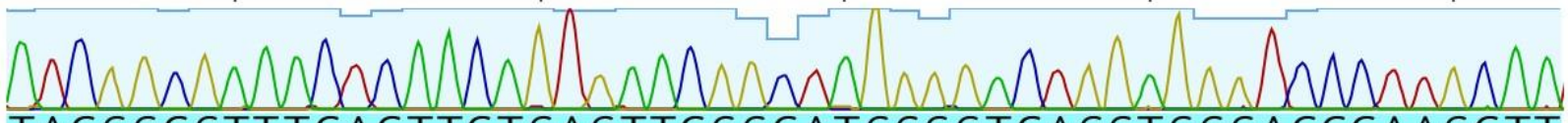
TACGGCGTTTCACTTCTGAGTTCGGCATGGGGTCAGGTGGGACCCAAGCTT AGACACATTTATTGTACAACACGAGCCCATTTTTGTCAAATAGAACCGGTT

NB-222DNA2

5’1CTATTTGACAAAAATGGGCTCGTGTTGTACAATAAATGTGTCTAAGCTTGGGTCCCACCTGACCCCAT GCCGAACTCAGAAGTGAAACGCCGTAGCGCCGATGGTAGTGTGGGGTCTCCCCATGCGAGAGTAGGGA ACTGCCAGGCATCAAATAAAACGAAAGGCTCAGTCGAAAGACTGGGCCTTTCGTTTTATCTGTTGTTTGT CGGTGAACGCTCTCC-3'

Primary strand (exact match for $126 \mathrm{bp})$ :

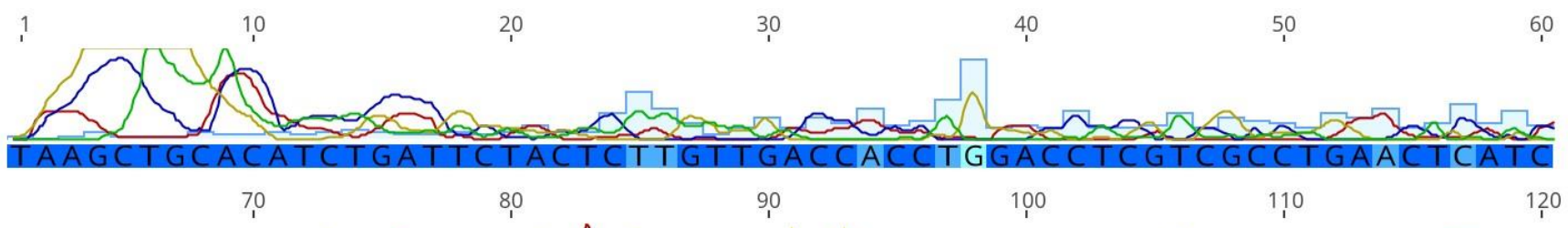

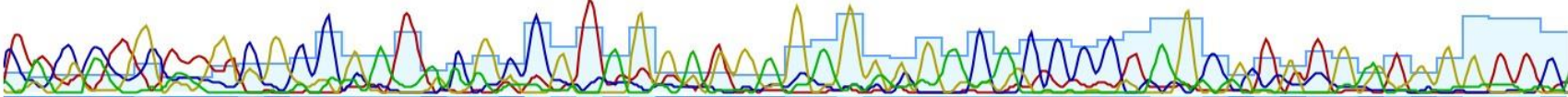
AACCAGAAGCGCCGTATCGCCGATGGTAGTGTGGGGTCTCCCCATGCGAGAGTAGGGAAC

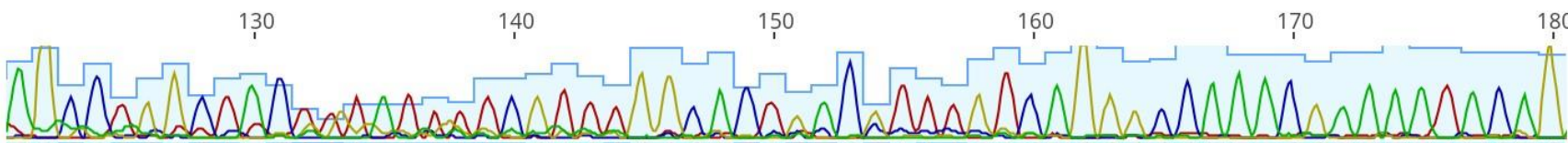
TGCCAGGCATCAAATAAAACGAAAGGCTCAGTCGAAAGACTGGGCCTTTCGTTTTATCTG

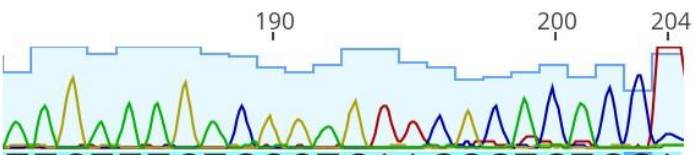

TTGTTTGTCGGTGAACGCTCTCCA 
Complementary strand (exact match for $160 \mathrm{bp}$ ):
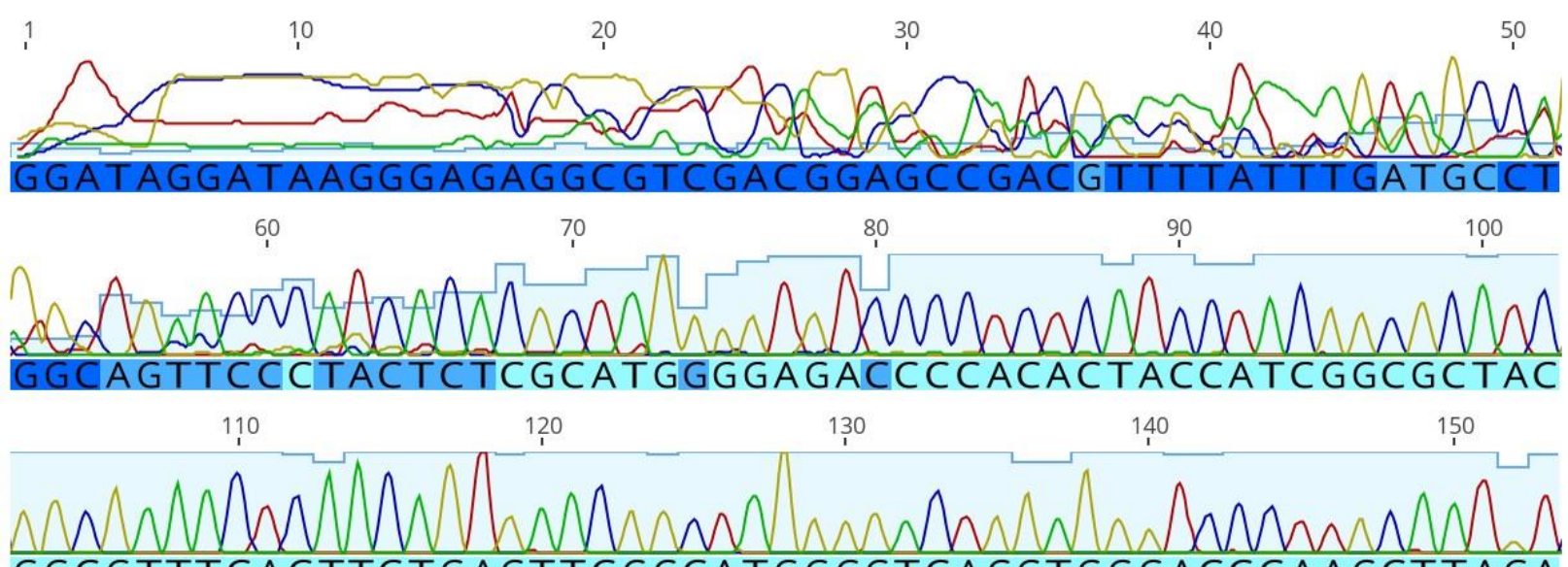

GGCGTTTCACTTCTGAGTTCGGCATGGGGTCAGGTGGGACCCAAGCTTAGA

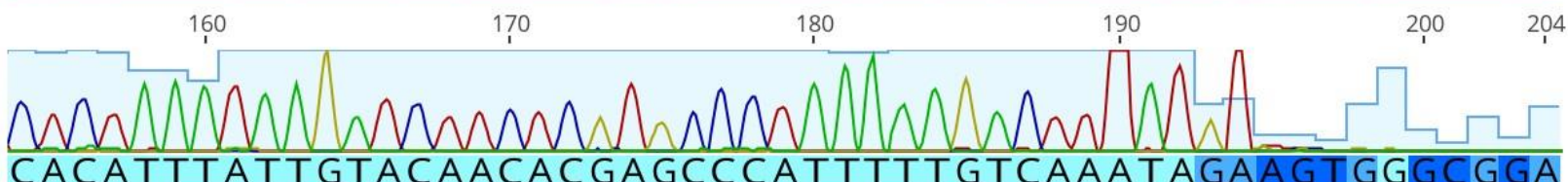

CACATTTATTGTACAACACGAGCCCATTTTTGTCAAATAGAAGTGGGCGGA

\section{NB-222DNA3}

5'TCTATTTGACAAAAATGGGCTCGTGTTGTACAATAAATGTGTCTAAGCTTGGGTCCCACCTGACCCCAT GCCGAACTCAGAAGTGAAACGCCGTAGCGCCGATGGTAGTGTGGGGTCTCCCCATGCGAGAGTAGGGA ACTGCCAGGCATCAAATAAAACGAAAGGCTCAGTCGAAAGACTGGGCCTTTCGTTTTATCTGTTGTTTGT CGGTGAACGCTCTCC-3'

Primary strand (exact match for $124 \mathrm{bp}$ ):

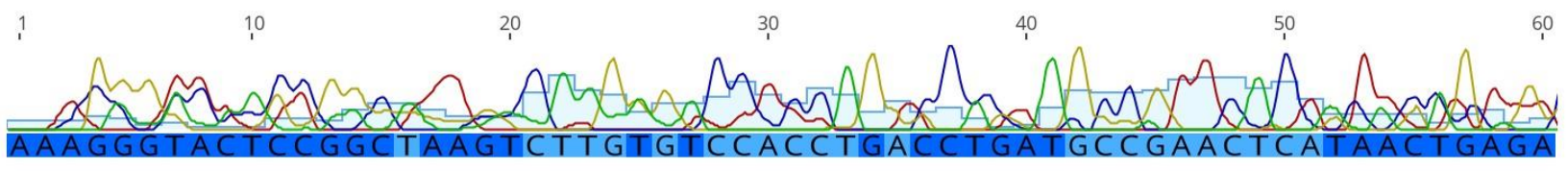

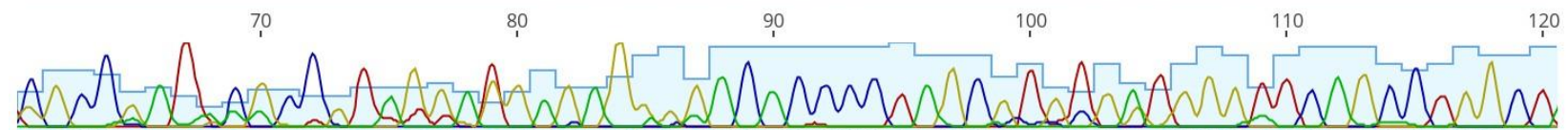
CGCCGTATCGCCGATGGTAGTGTGGGGTCTCCCCATGCGAGAGTAGGGAACTGCCAGGCA

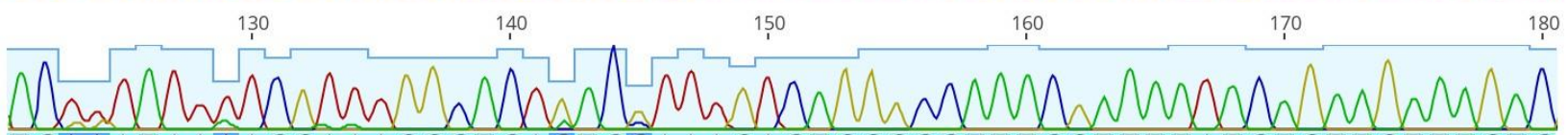
TCAAATAAAACGAAAGGCTCAGTCGAAAGACTGGGCCTTTCGTTTTATCTGTTGTTTGTC

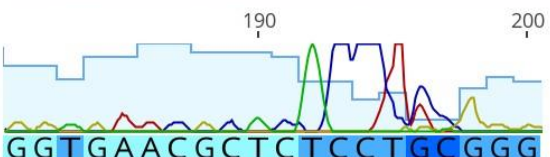


Complementary strand (exact match for $156 \mathrm{bp}$ ):

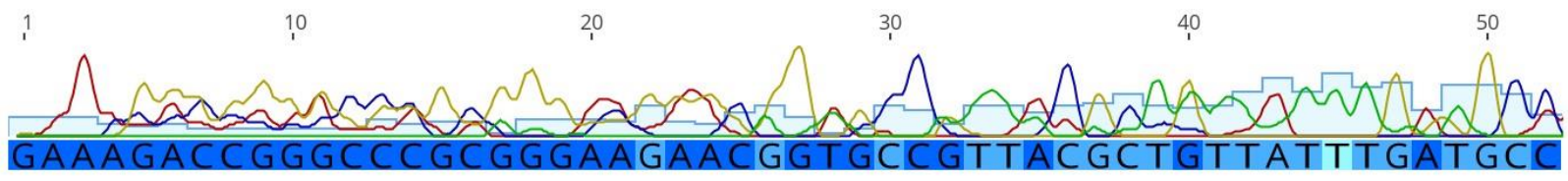

60

80

900100

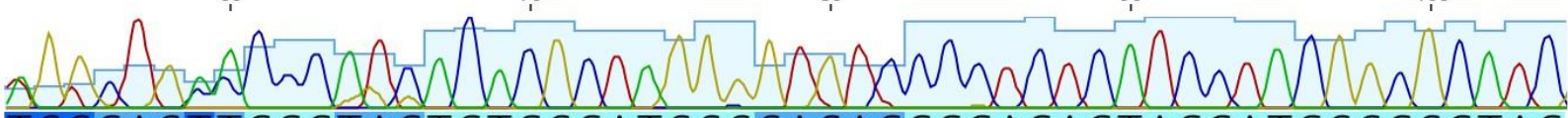

TGGCAGTTCCCTACTCTCGCATGGGGAGACCCCACACTACCATCGGCGCTAC

110

120

130

150

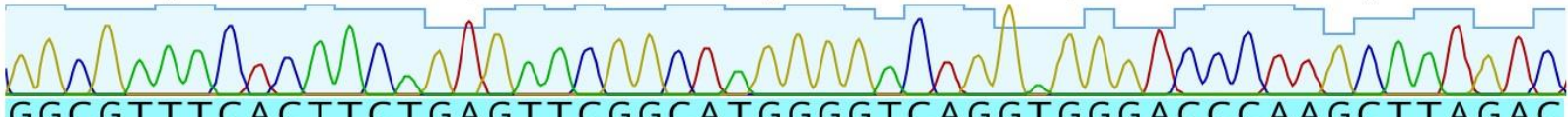

GGCGTTTCACTTCTGAGTTCGGCATGGGGTCAGGTGGGACCCAAGCTTAGAC

160

170

180

190

$200 \quad 204$

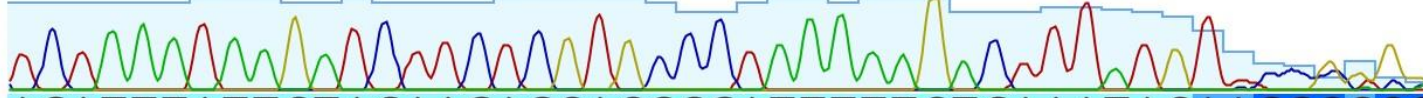

ACATTTATTGTACAACACGAGCCCATTTTTGTCAAATAGAACCGGGGG

\section{NB-222DNA4}

5'TCTATTTGACAAAAATGGGCTCGTGTTGTACAATAAATGTGTCTAAGCTTGGGTCCCACCTGACCCCAT

GCCGAACTCAGAAGTGAAACGCCGTAGCGCCGATGGTAGTGTGGGGTCTCCCCATGCGAGAGTAGGGA

ACTGCCAGGCATCAAATAAAACGAAAGGCTCAGTCGAAAGACTGGGCCTTTCGTTTTATCTGTTGTTTGT

CGGTGAACGCTCTCC-3'

Primary strand (exact match for $135 \mathrm{bp})$ :

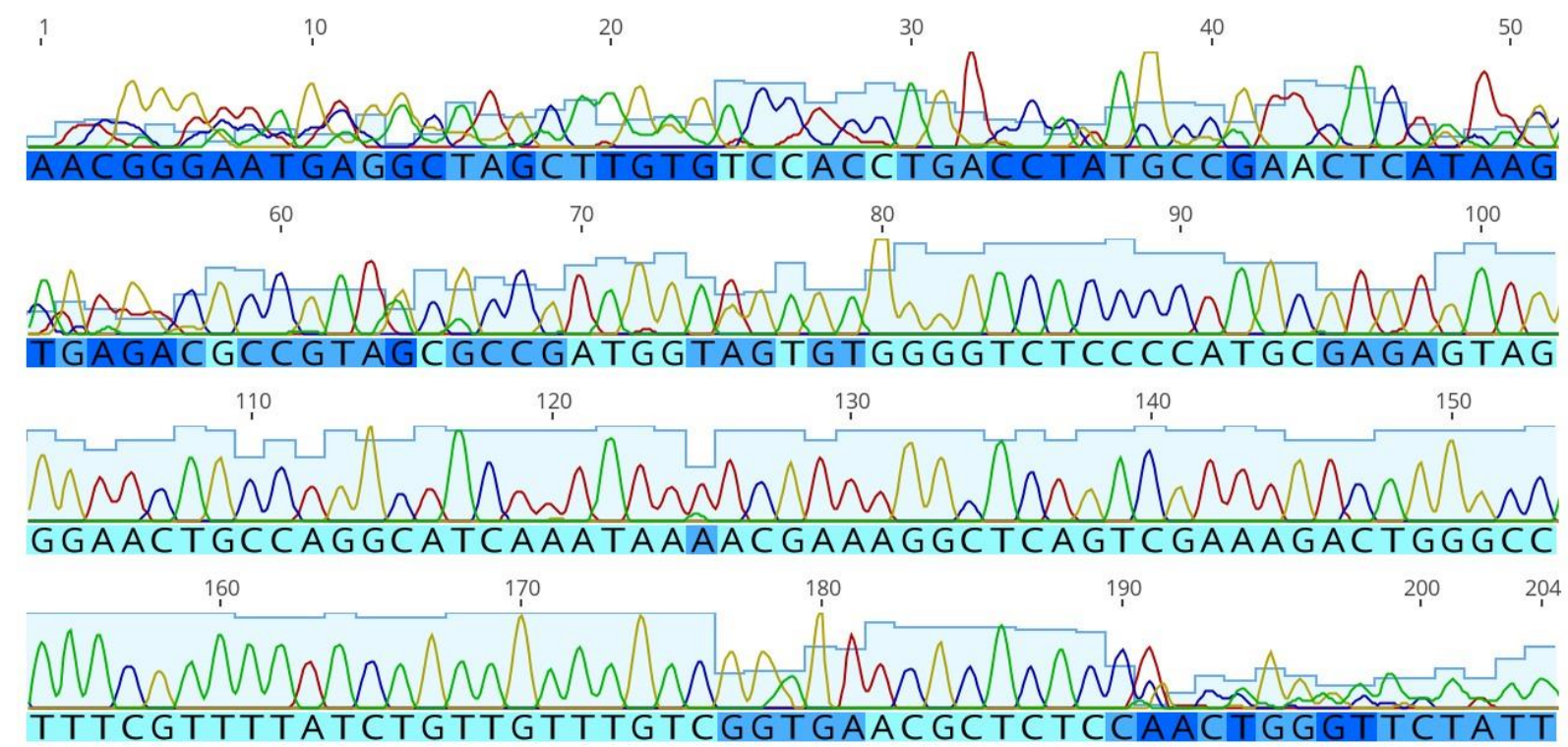


Complementary strand (exact match for $160 \mathrm{bp}$ ):
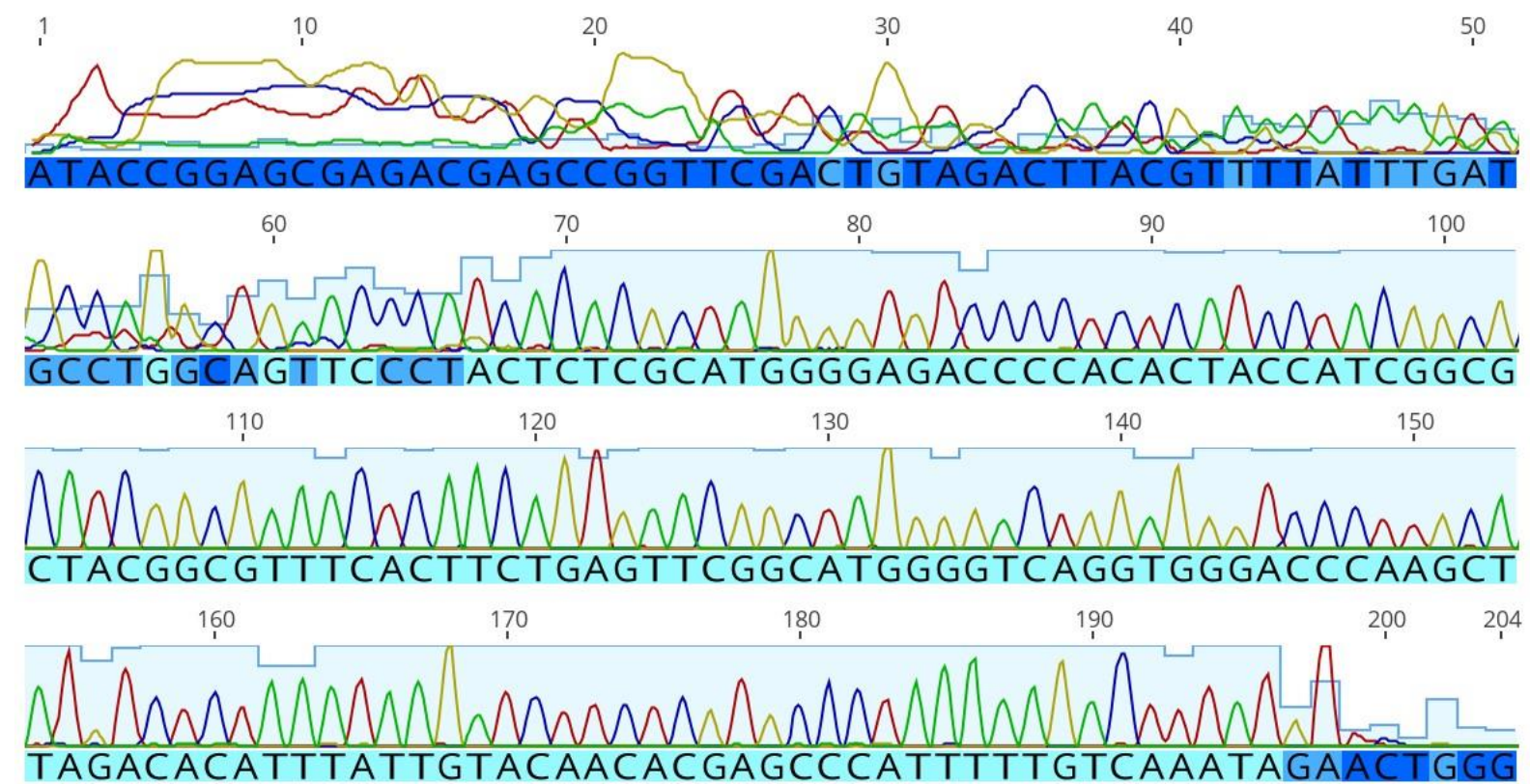

\section{NB-222DNA5}

5'ICTATTTGACAAAAATGGGCTCGTGTTGTACAATAAATGTGTCTAAGCTTGGGTCCCACCTGACCCCAT GCCGAACTCAGAAGTGAAACGCCGTAGCGCCGATGGTAGTGTGGGGTCTCCCCATGCGAGAGTAGGGA ACTGCCAGGCATCAAATAAAACGAAAGGCTCAGTCGAAAGACTGGGCCTTTCGTTTTATCTGTTGTTTGT CGGTGAACGCTCTCC-3'

Primary strand (exact match for $138 \mathrm{bp}$ ):

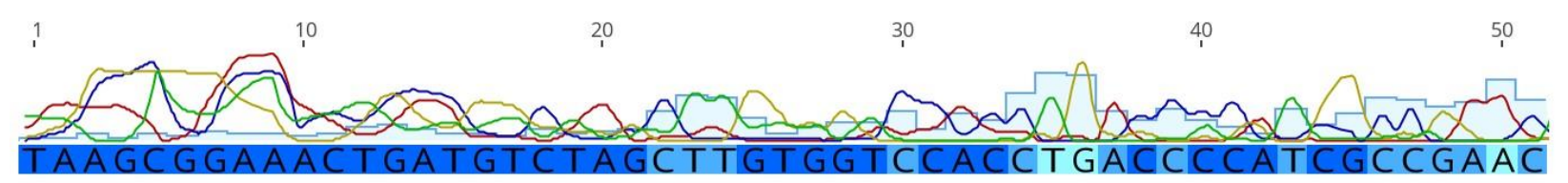

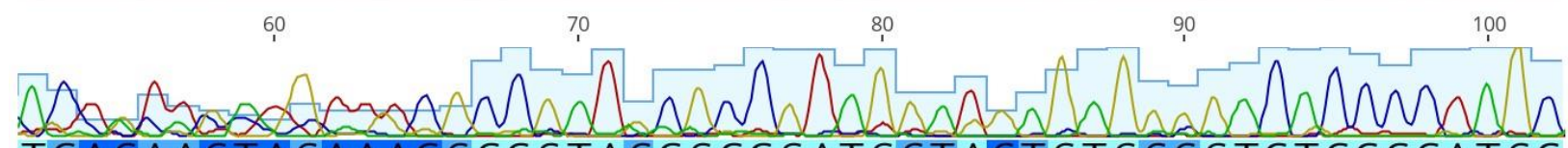
TCAGAAGTAGAAACGCCGTAGCGCCGATGGTAGTGTGGGGTCTCCCCATGC

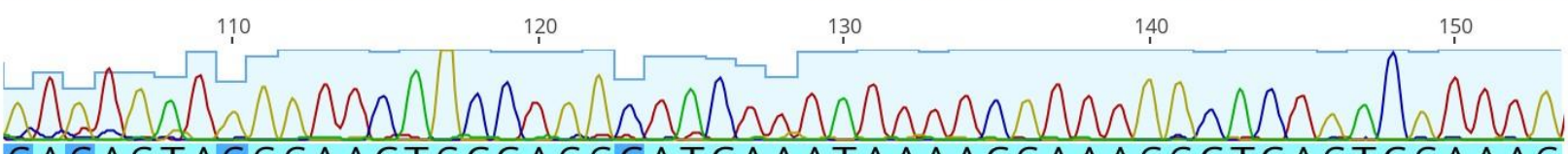
GAGAGTAGGGAACT GCCAGGCATCAAATAAAACGAAAGGCTCAGTCGAAAG 160 170 180 $200 \quad 204$

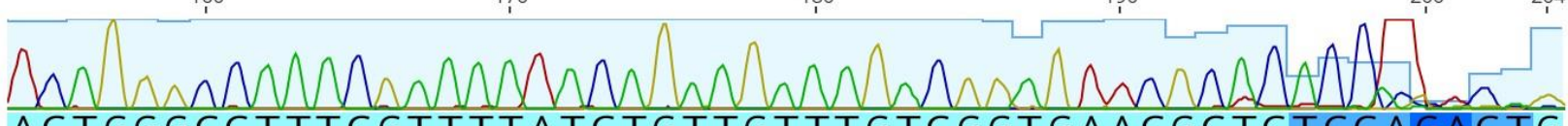
ACTGGGCCTTTCGTTTTATCTGTTGTTTGTCGGTGAACGCTCTCCAGACTG 
Complementary strand (exact match for $142 \mathrm{bp}$ ):
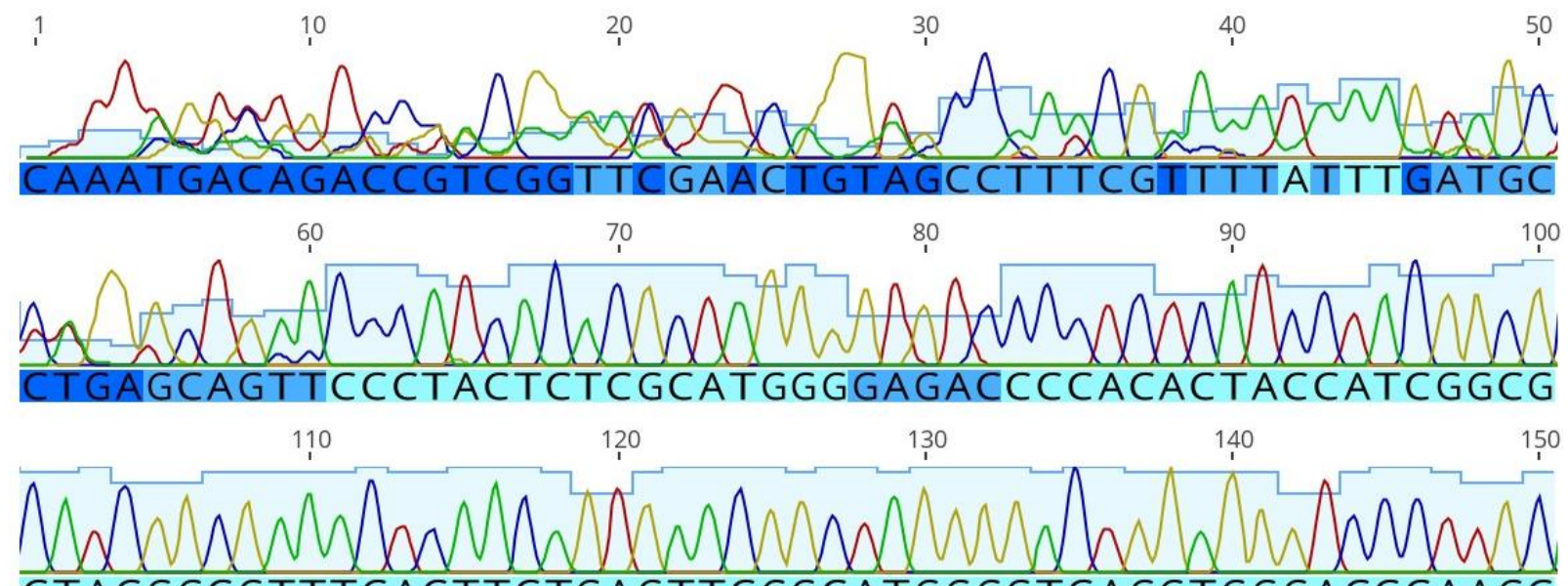

CTACGGCGTTTCACTTCTGAGTTCGGCATGGGGTCAGGTGGGACCCAAGC

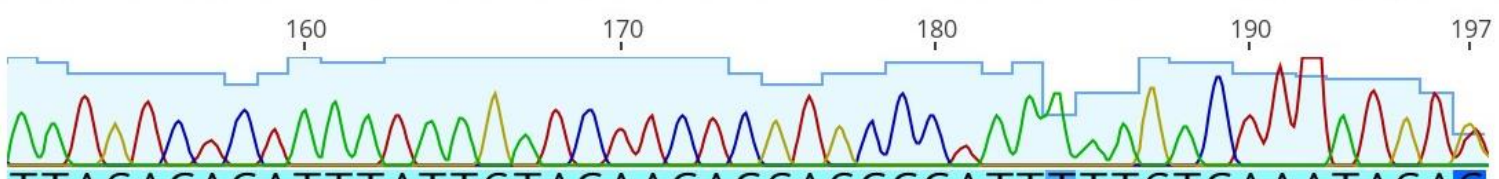

TTAGACACATTTATTGTACAACACGAGCCCATTTTTGTCAAATAGAG

NB-222DNA6

5’TCTATTTGACAAAAATGGGCTCGTGTTGTACAATAAATGTGTCTAAGCTTGGGTCCCACCTGACCCCAT GCCGAACTCAGAAGTGAAACGCCGTAGCGCCGATGGTAGTGTGGGGTCTCCCCATGCGAGAGTAGGGA ACTGCCAGGCATCAAATAAAACGAAAGGCTCAGTCGAAAGACTGGGCCTTTCGTTTTATCTGTTGTTTGT CGGTGAACGCTCTCC-3'

Primary strand (exact match for $126 \mathrm{bp})$

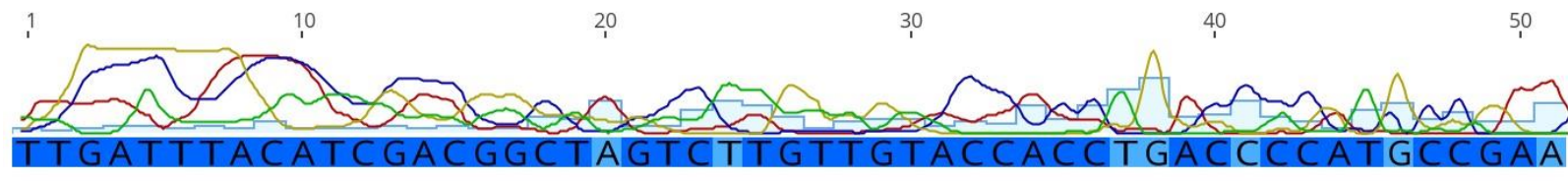

60

70

90

100

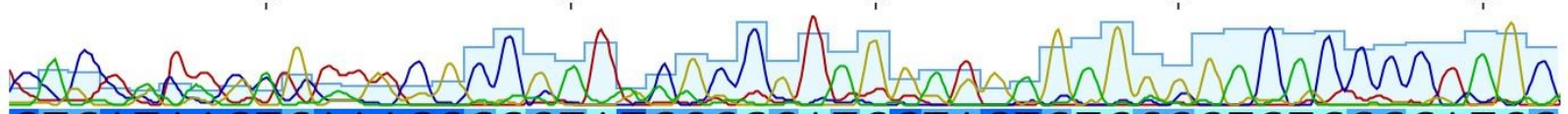
CTCATAACT GAAACGCCGTATC GCCGAT GGTAGTGT GGGGTCTCCCCAT GC 110

120

130

140

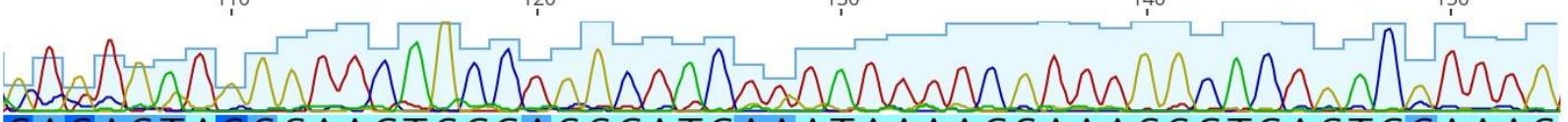

GAGAGTAGGGAACTGCCAGGCATCAAATAAAACGAAAGGCTCAGTCGAAAG

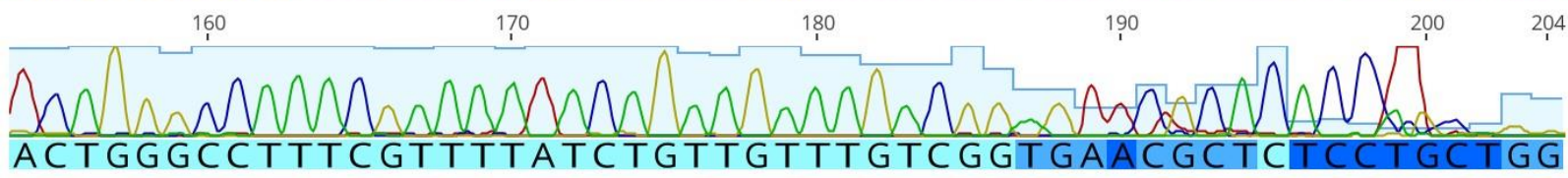


Complementary strand (exact match for $154 \mathrm{bp})$

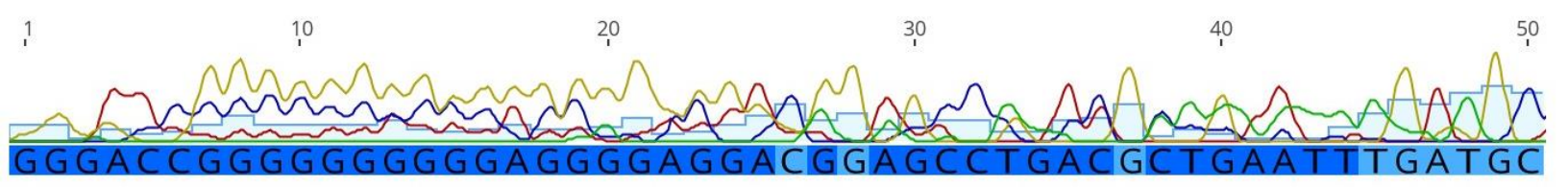

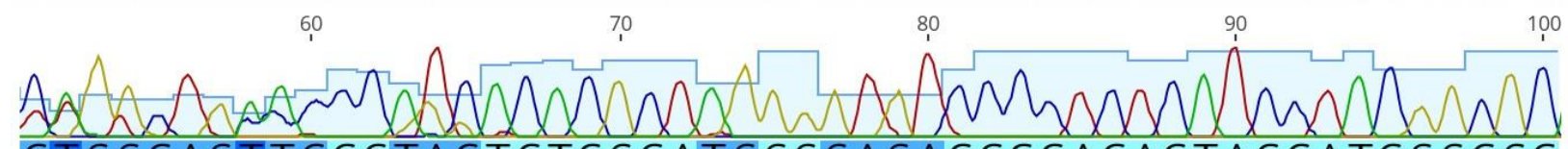
CTGGCAGTTCCCTACTCTCGCATGGGGAGACCCCACACTACCATCGGCGC

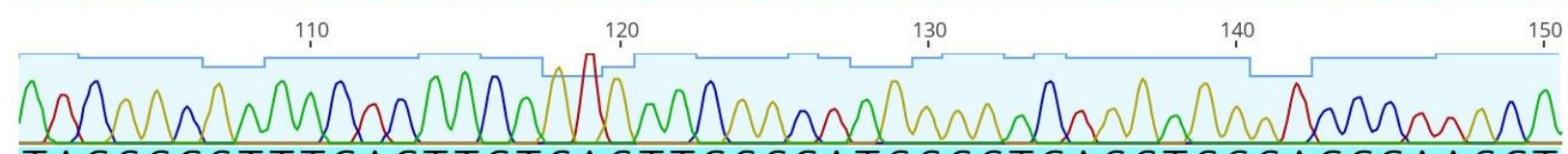
TACGGCGTTTCACTTCTGAGTTCGGCATGGGGTCAGGTGGGACCCAAGCT

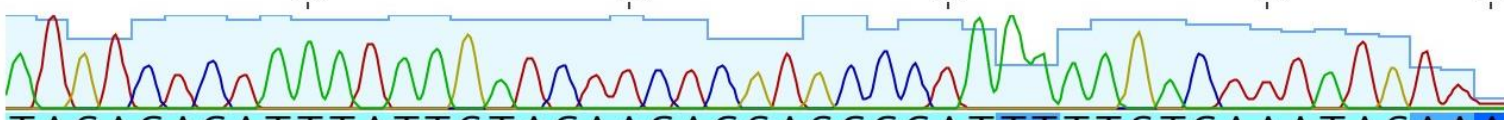

TAGACACATTTATTGTACAACACGAGCCCATTTTTGTCAAATAGAAA

\section{NB-222DNA7}

5'TCTATTTGACAAAAATGGGCTCGTGTTGTACAATAAATGTGTCTAAGCTTGGGTCCCACCTGACCCCAT GCCGAACTCAGAAGTGAAACGCCGTAGCGCCGATGGTAGTGTGGGGTCTCCCCATGCGAGAGTAGGGA ACTGCCAGGCATCAAATAAAACGAAAGGCTCAGTCGAAAGACTGGGCCTTTCGTTTTATCTGTTGTTTGT CGGTGAACGCTCTCC-3'

Primary strand (exact match for 126 bp)

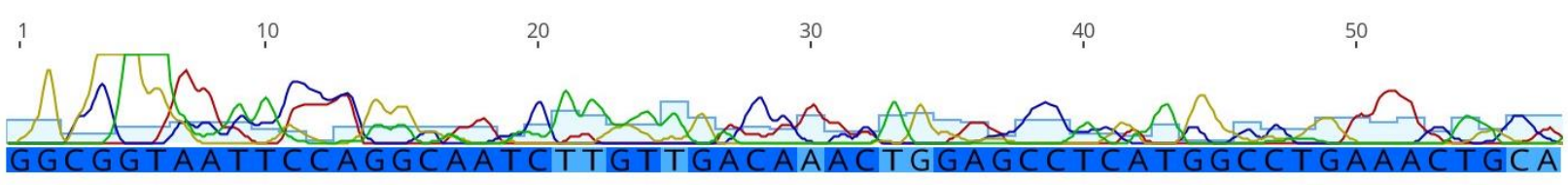

60

70

80

90

100

110 DCATCCTAGAAACGCCGTATCGCCGATGGTAGTGTGGGGTCTCCCCATGCGAGAGTA

(120) GGGAACTGCCAGGCATCAAATAAAACGAAAGGCTCAGTCGAAAGACTGGGCCTTTCG

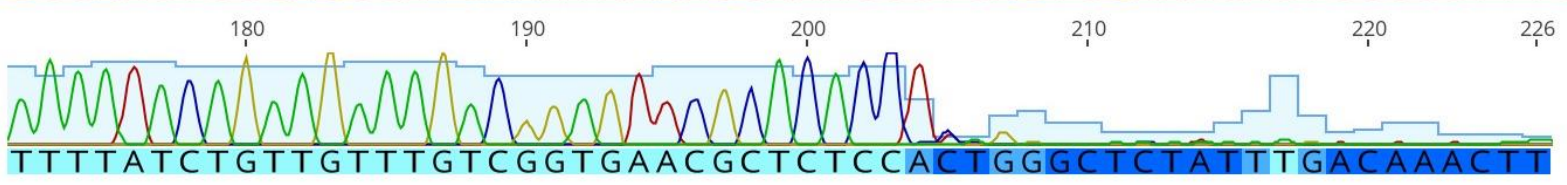


Complementary strand (exact match for $143 \mathrm{bp}$ )

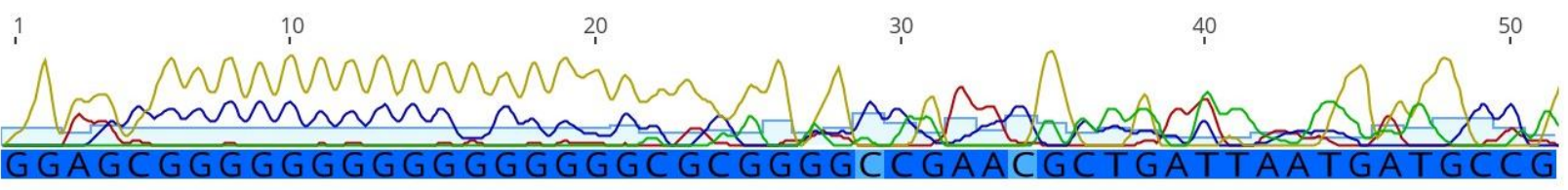

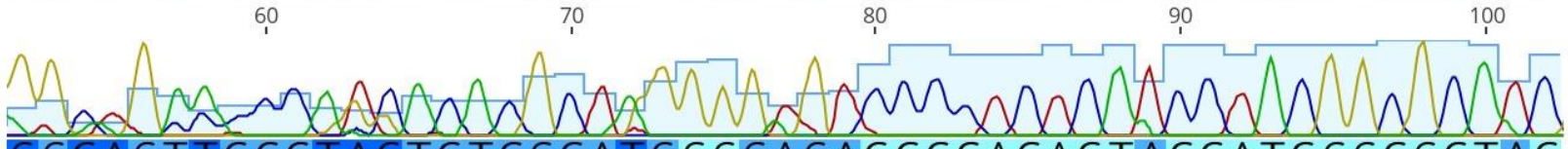
GGCAGTTCCCTACTCTCGCATGGGGAGACCCCACACTACCATCGGCGCTAC

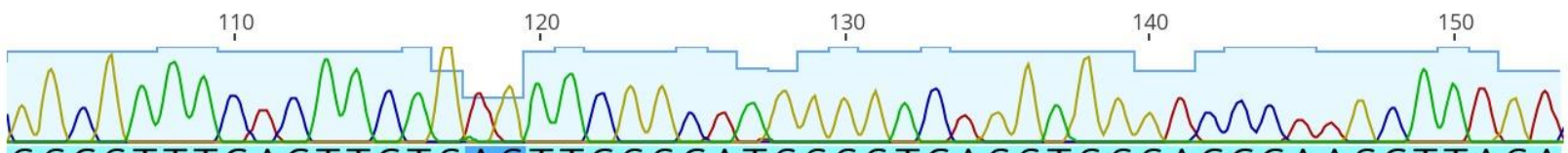
GGCGTTTCACTTCTGAGTTCGGCATGGGGTCAGGTGGGACCCAAGCTTAGA CW WACATTTATTGTACAACACGAGCCCATTTTTGTCAAATAGAAAACTGGGTG

NB-222DNA8

5'ICTATTTGACAAAAATGGGCTCGTGTTGTACAATAAATGTGTCTAAGCTTGGGTCCCACCTGACCCCAT GCCGAACTCAGAAGTGAAACGCCGTAGCGCCGATGGTAGTGTGGGGTCTCCCCATGCGAGAGTAGGGA ACTGCCAGGCATCAAATAAAACGAAAGGCTCAGTCGAAAGACTGGGCCTTTCGTTTTATCTGTTGTTTGT CGGTGAACGCTCTCC-3'

(Primary strand (exact match for $138 \mathrm{bp}$ )

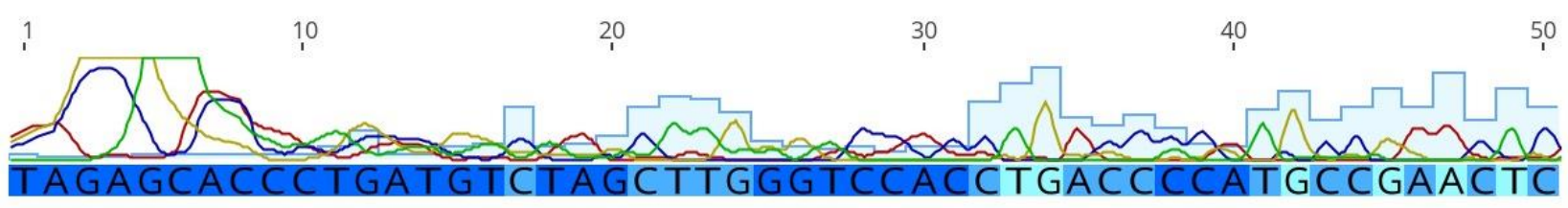

(100)

(100)

(100) AGAAGTAGAAACGCCGTAGCGCCGATGGTAGTGTGGGGTCTCCCCATGCG

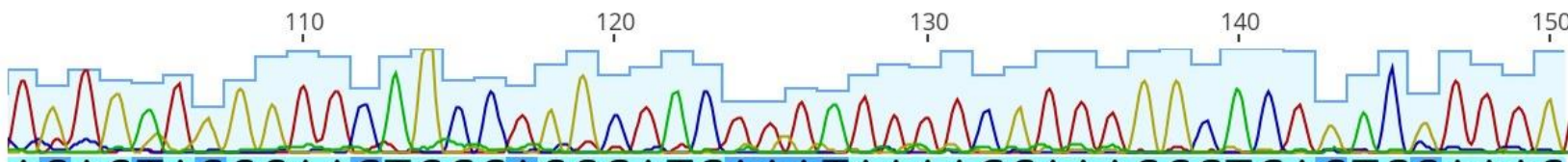
AGAGTAGGGAACTGCCAGGCATCAAATAAAACGAAAGGCTCAGTCGAAAG

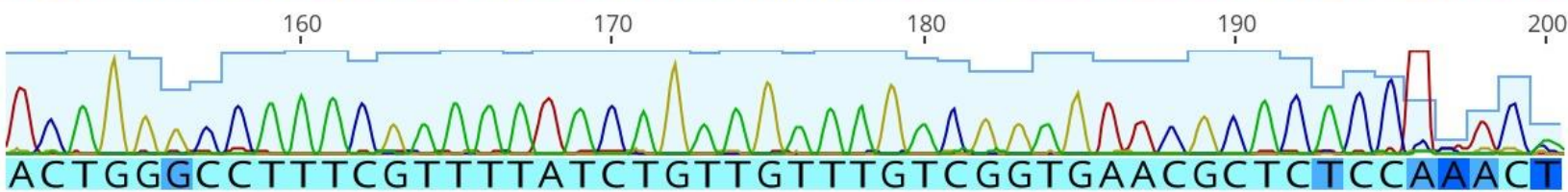


Complementary strand (exact match for $151 \mathrm{bp}$ )
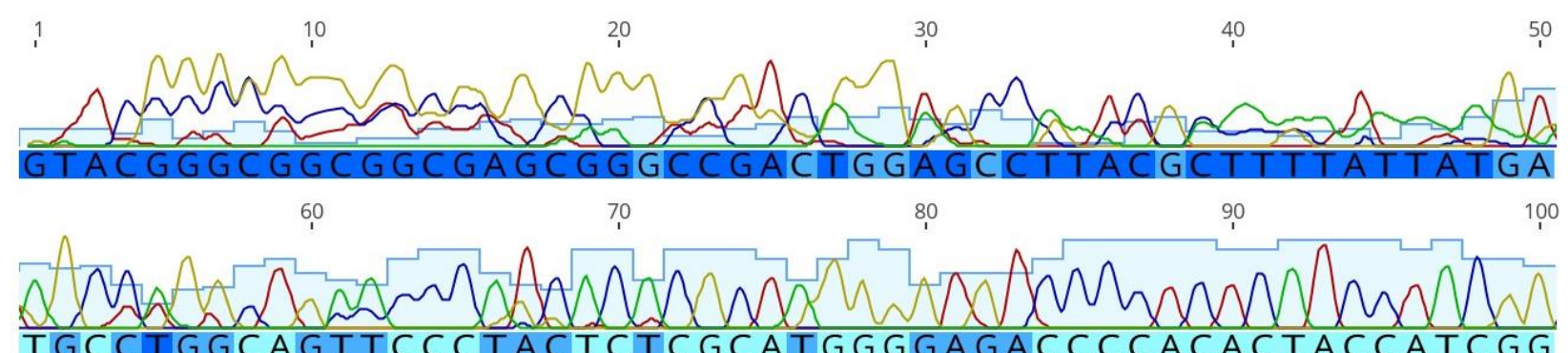

TGCCTGGCAGTTC C CTACT CTCGCATGGGGAGAC C C CACACTAC CATCGG

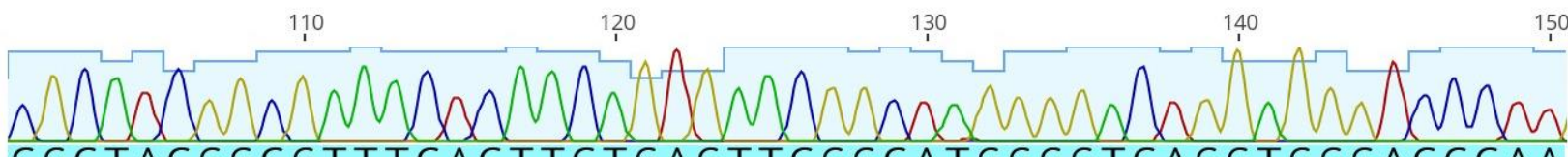
CGCTACGGCGTTTCACTTCTGAGTTCGGCATGGGGTCAGGTGGGACCCAA

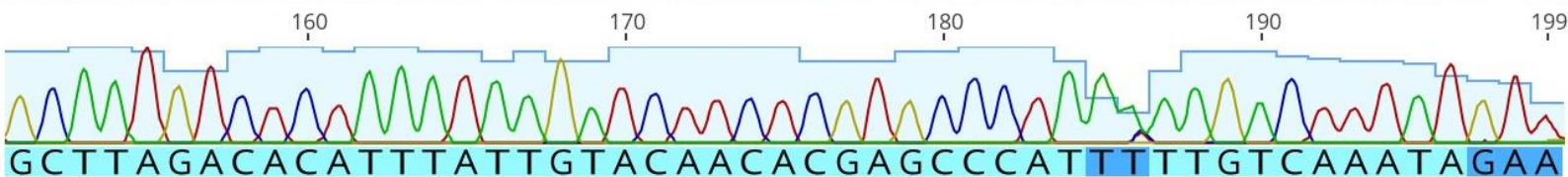




\section{Copies of NMR Spectra}

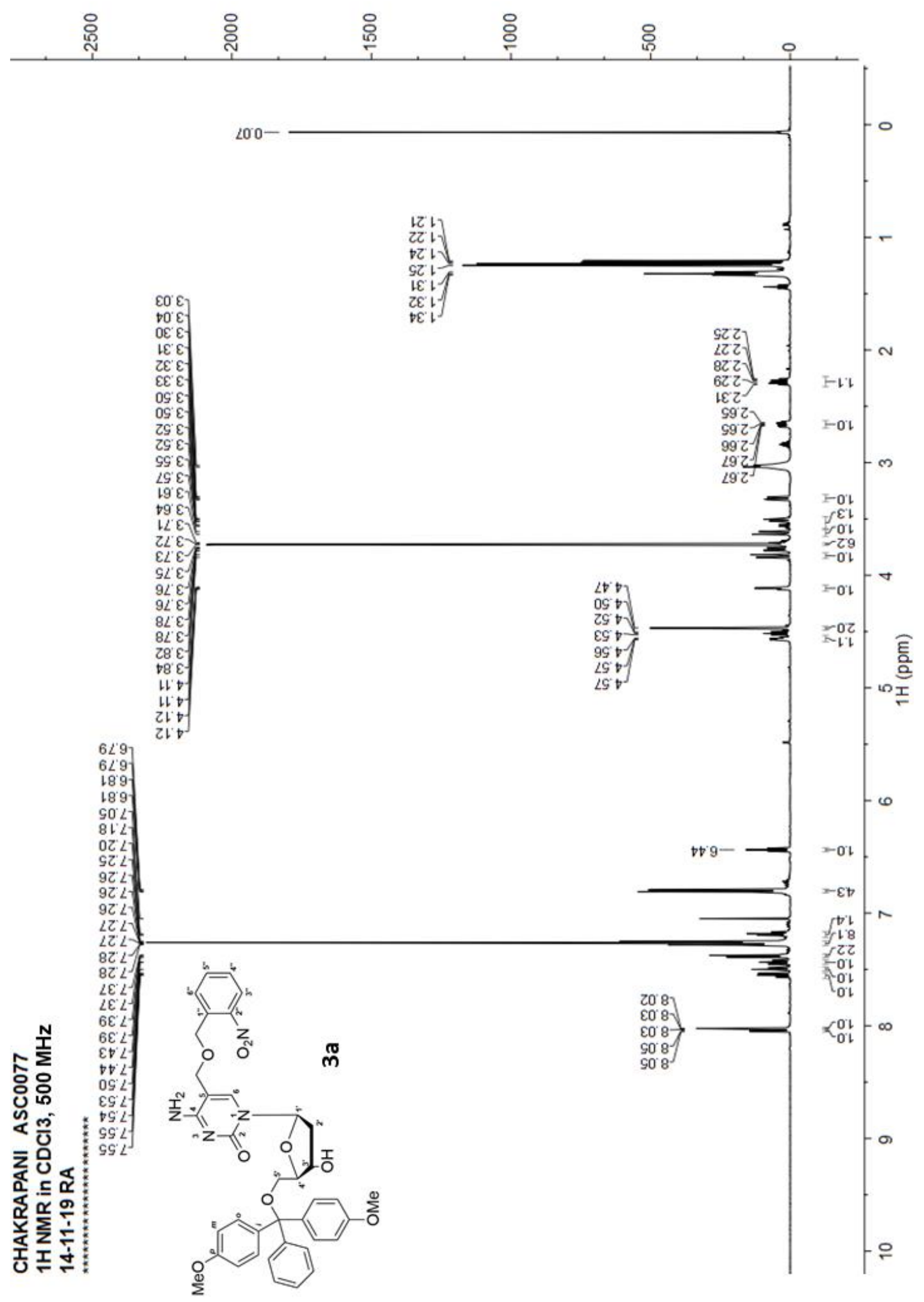




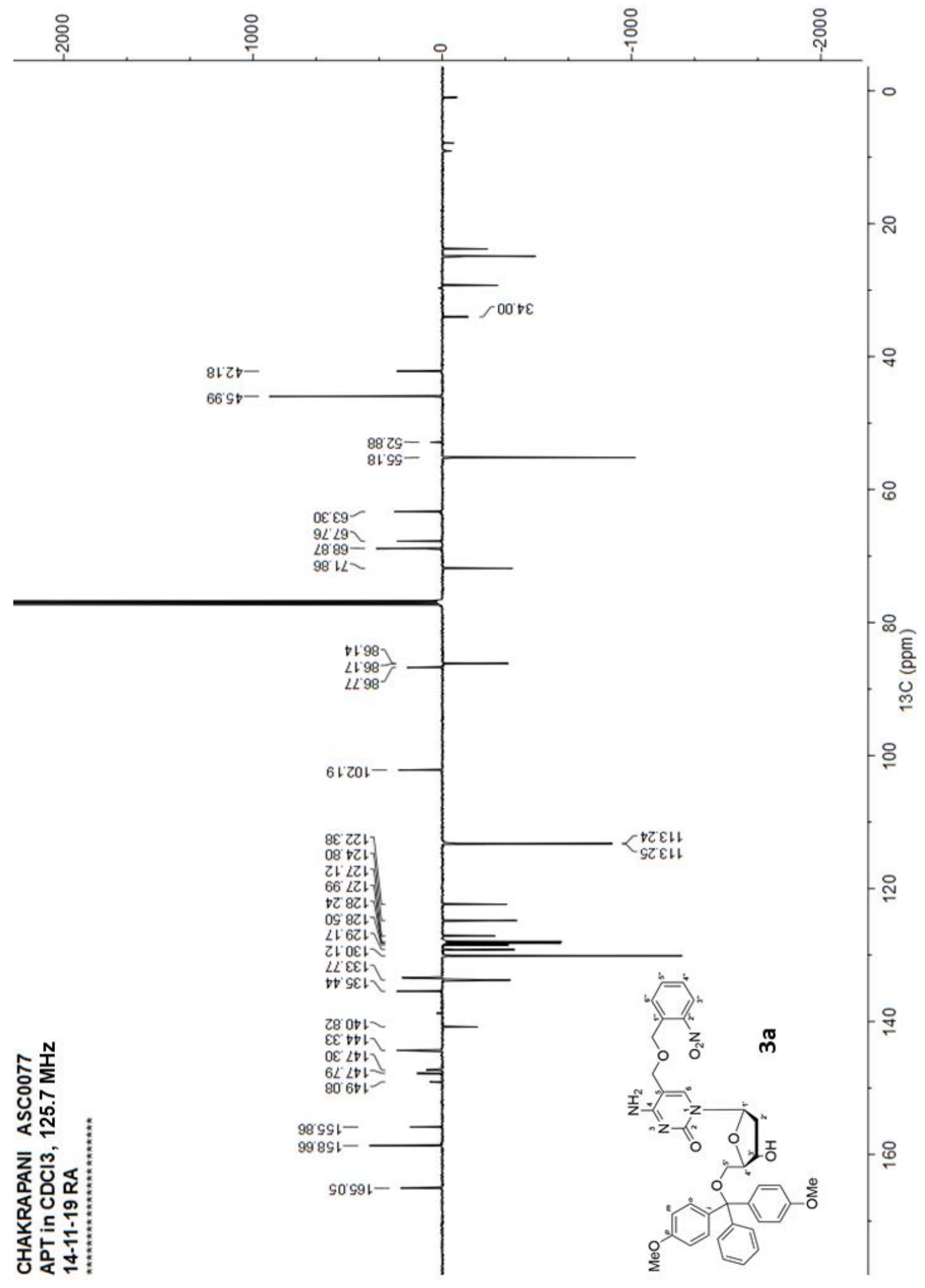




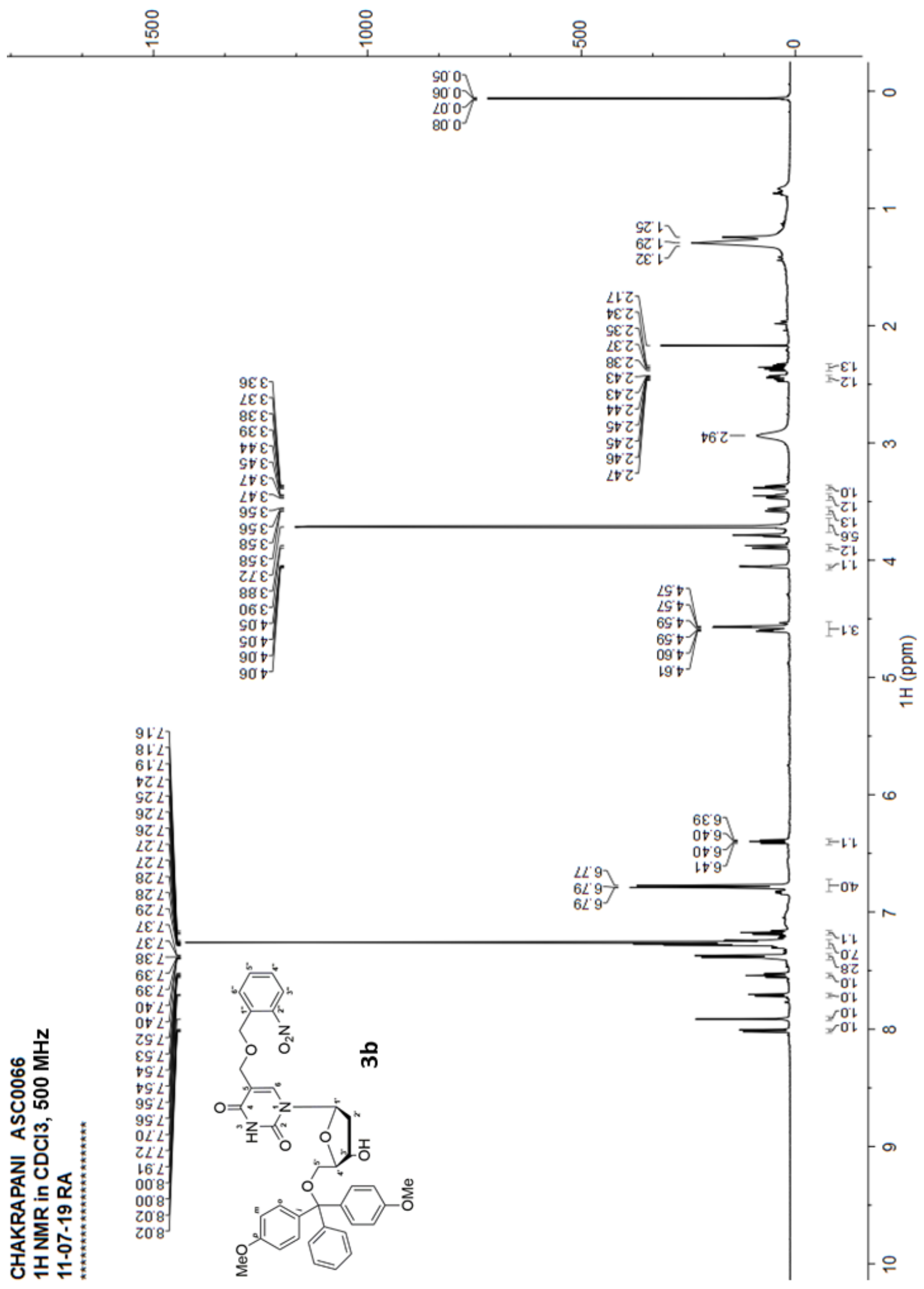




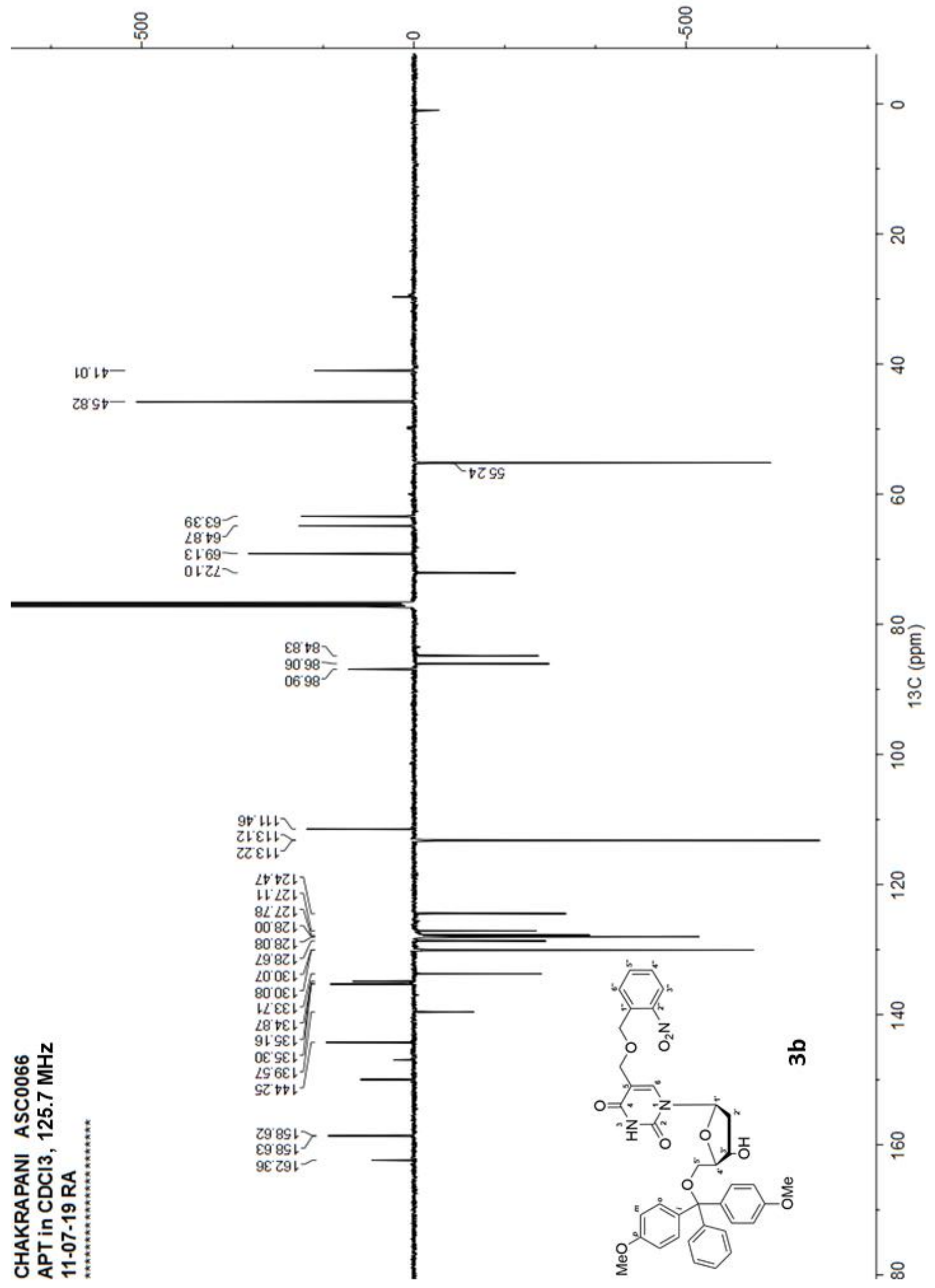




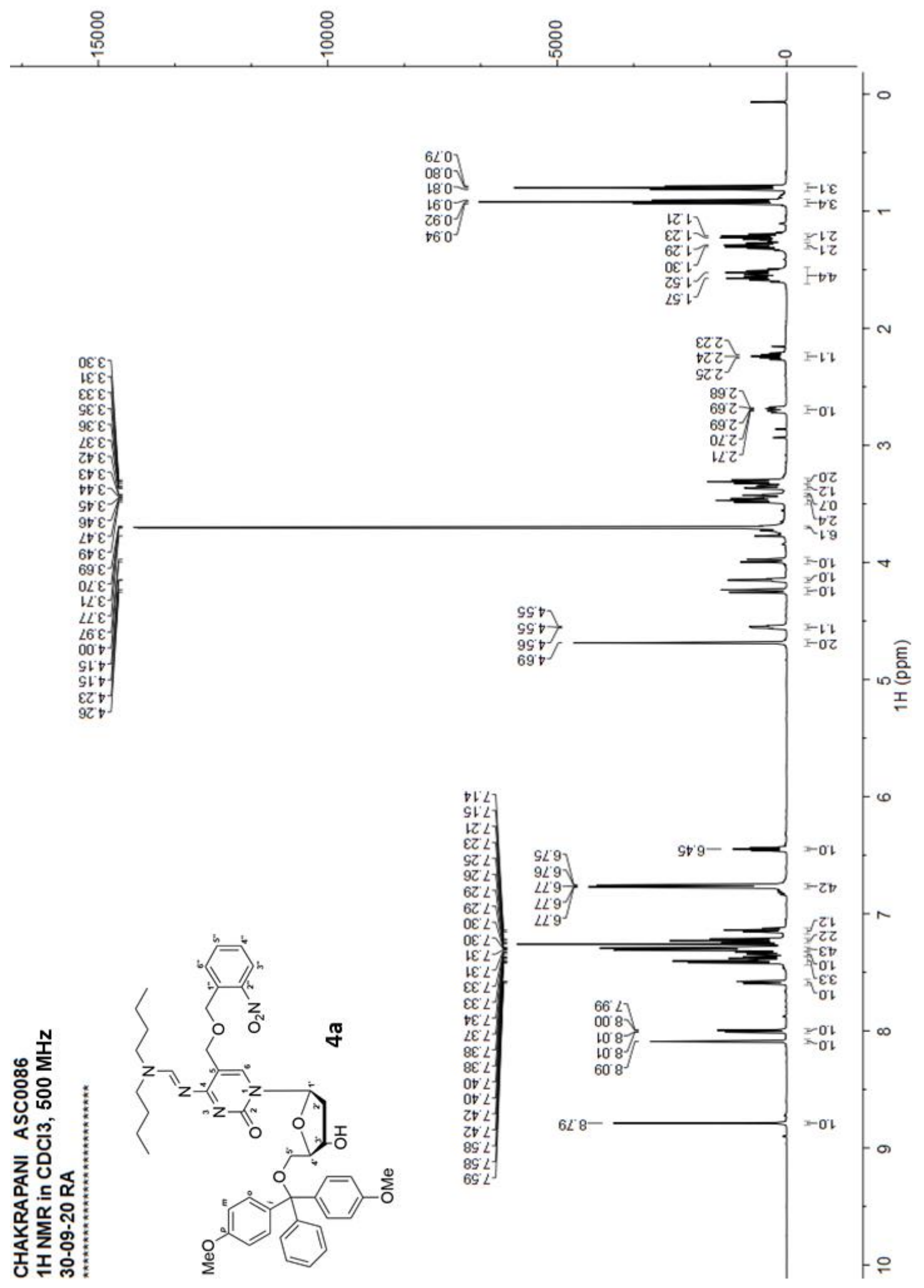




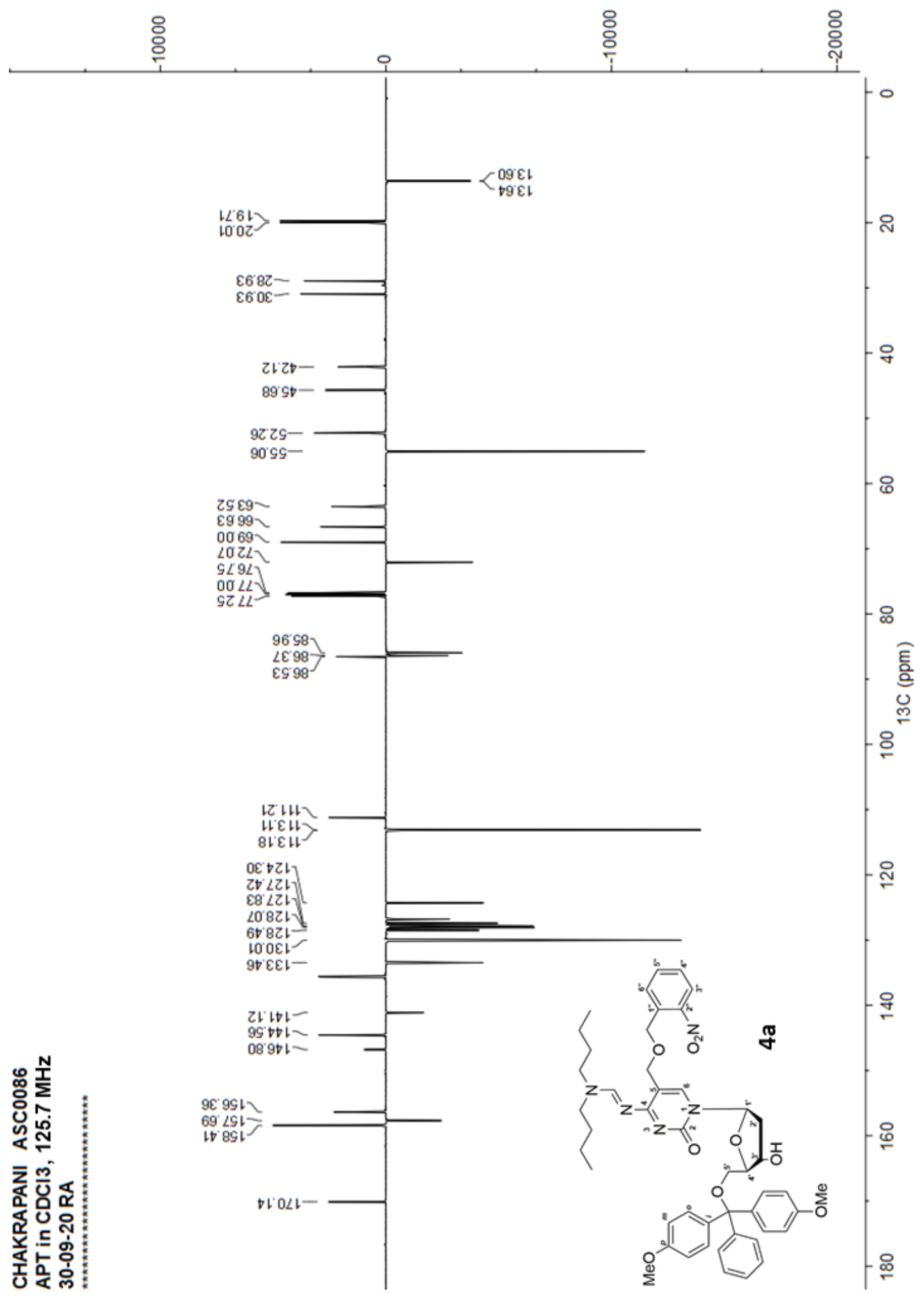




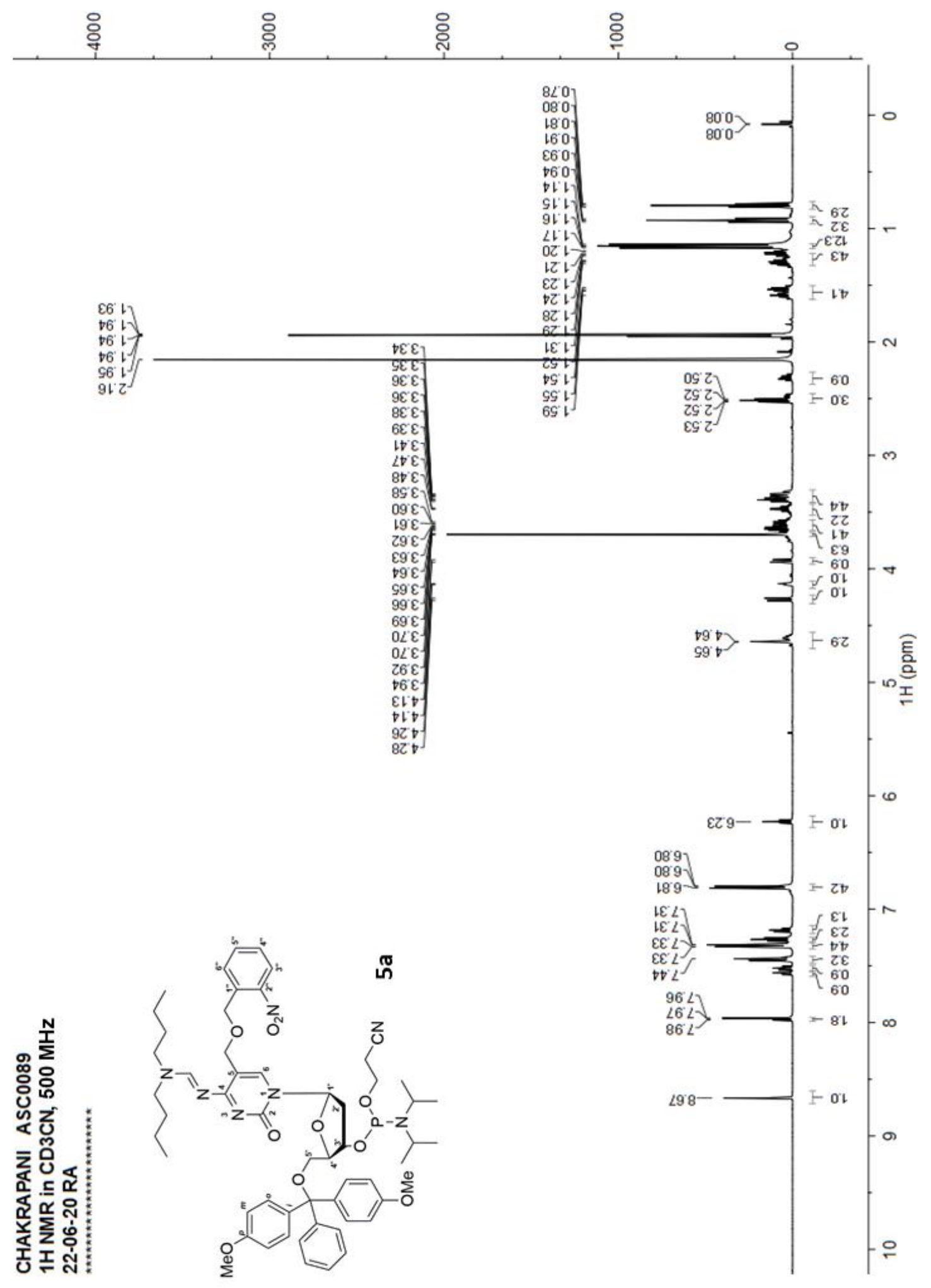




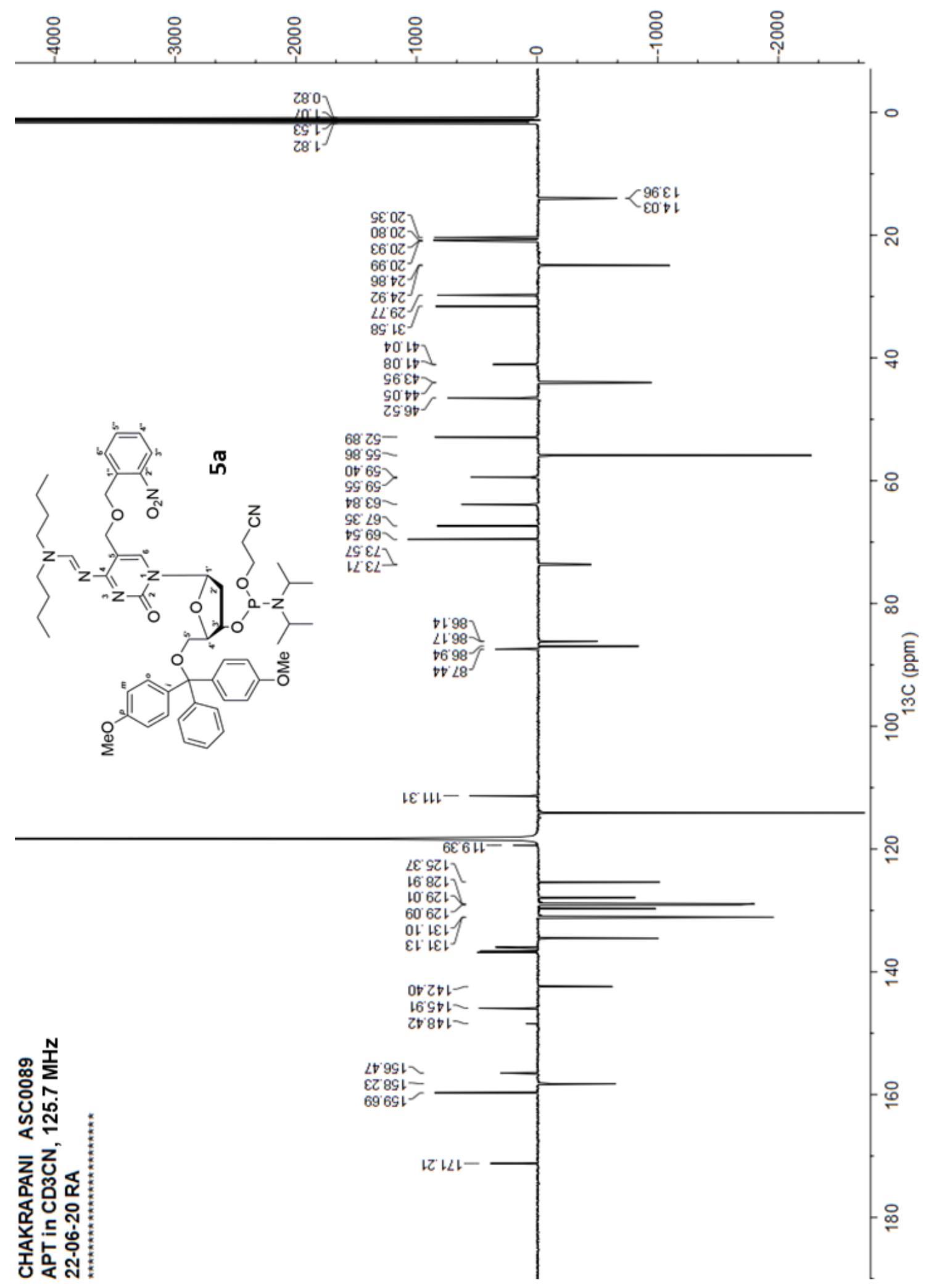




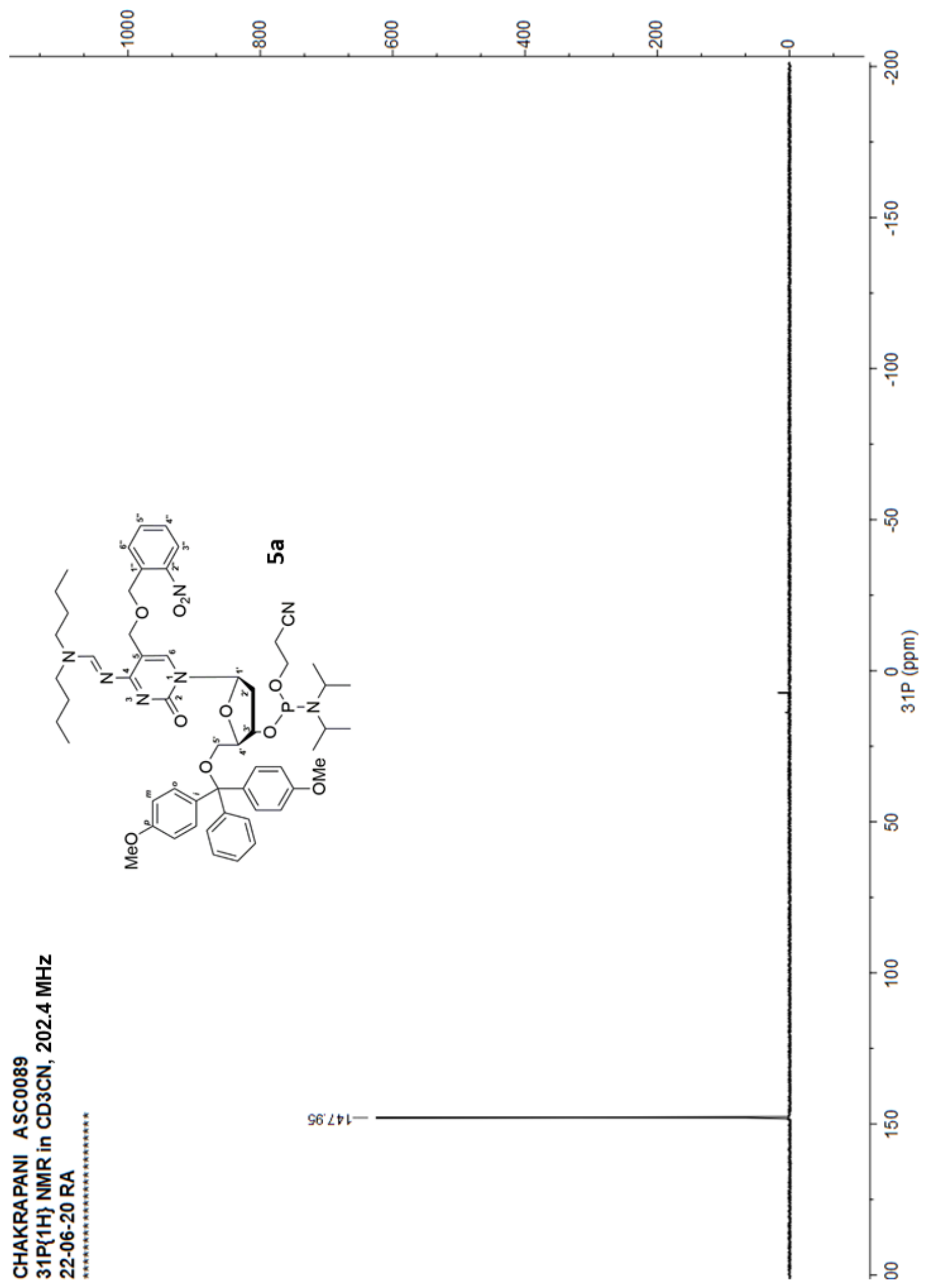




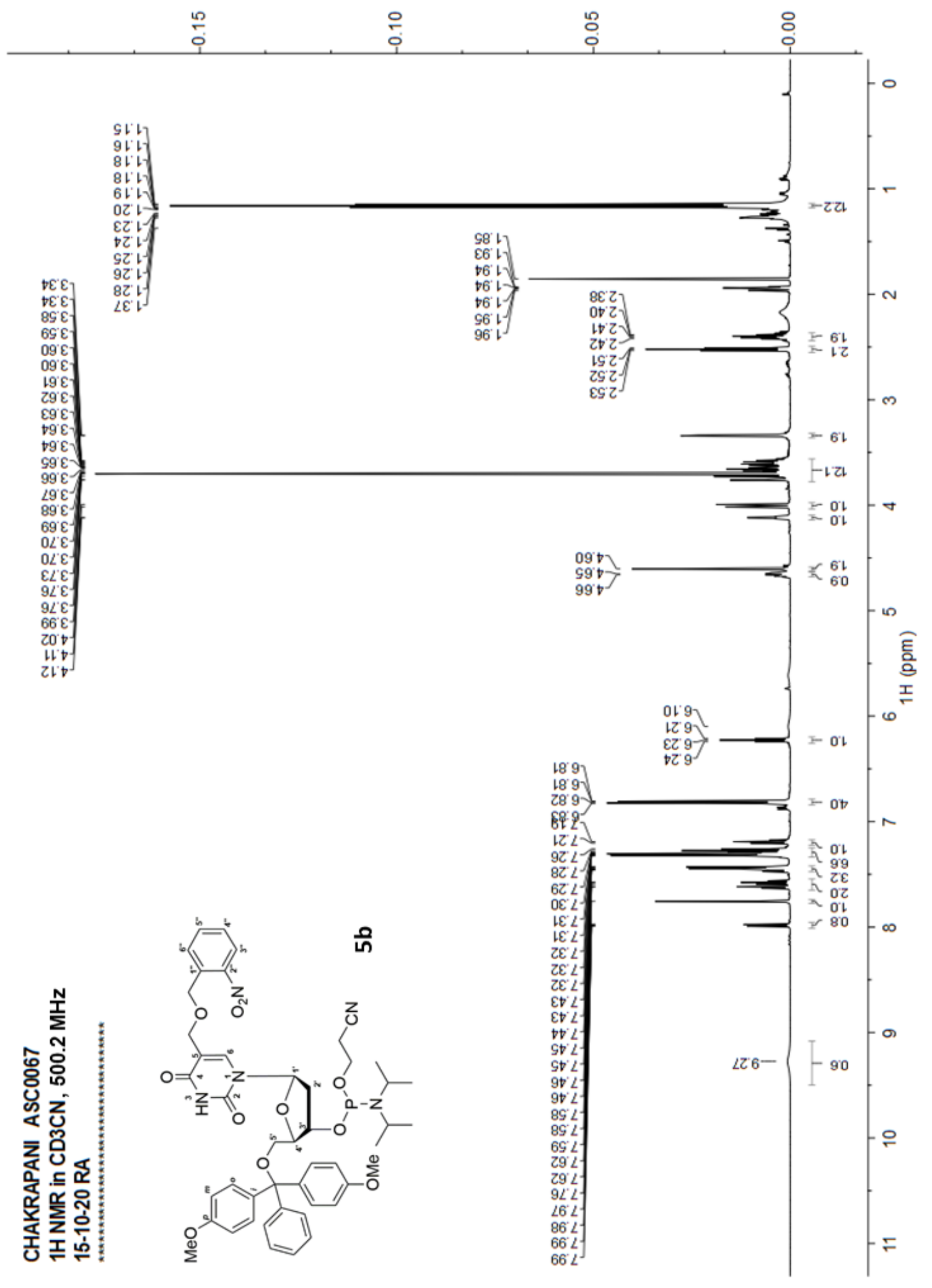




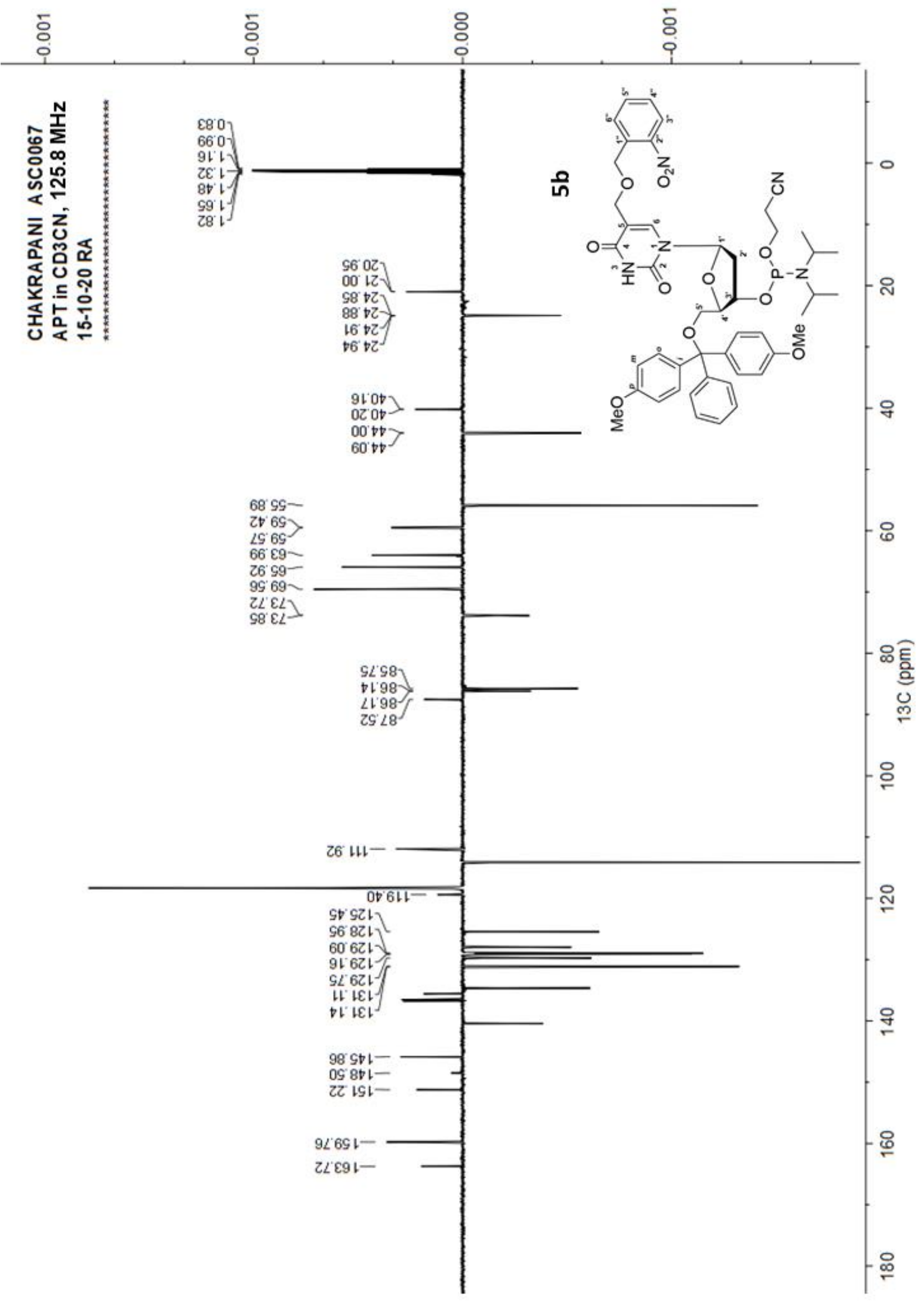




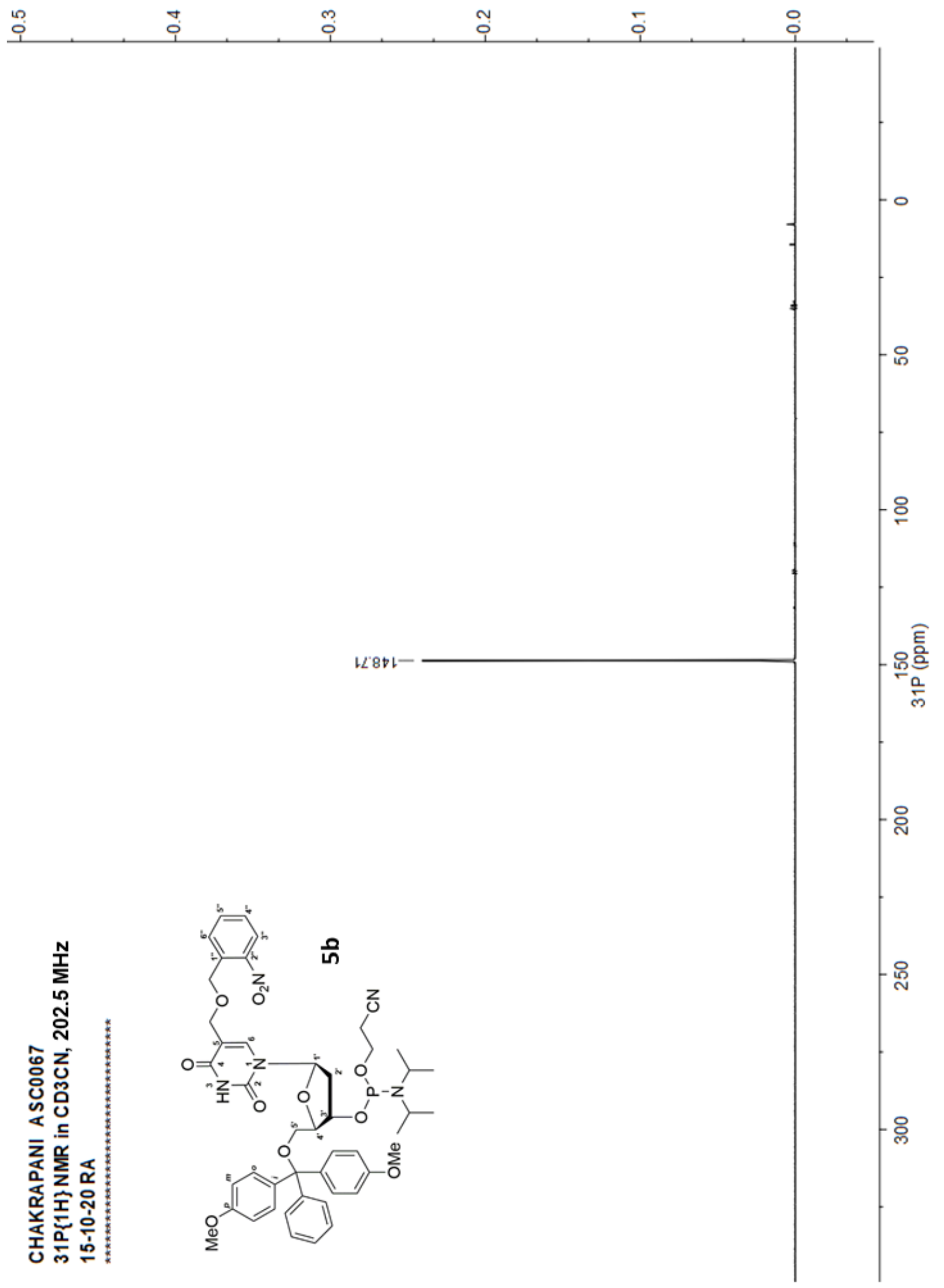




\section{References}

1. Gourlain. T.; Sidorov. A.; Mignet. N.; Thorpe. S. J.; Lee. S. E; Grasby. J. A.; Williams. D. M. Nucleic Acids Res, 2001, 29, 1898-1905.

2. Stupi, B. P.; Li, H.; Wang, J.; Wu, W.; Morris, S. E.; Litosh, V. A.; Muniz, J.; Hersh, M. N.; Metzker, M. L. Angew. Chem. 2012, 51, 1724-1727.

3. Sun. Q.; Sun. J.; Gong. S.S.; Wang. C.J.; Pu. S. Z.; Feng. F. D. Rsc Adv, 2014, 4, 3603636039.

4. Litosh, V. A.; Wu, W.; Stupi, B. P.; Wang, J.; Morris, S. E.; Hersh, M. N.; Metzker, M. L. Nucleic Acids Res. 2011, 39, e39-e39.

5. Vaníková. Z.; Hocek. M. Angew. Chem. Int. Ed. 2014, 53, 6734-6737.

6. (a) Boháčová. S.; Vaníková. Z.; Poštová Slavětínská. L.; Hocek. M. Org Biomol Chem, 2018, 16, 5427-5432. (b) Boháčová, S.; Ludvíková, L.; Poštová Slavětínská, L.; Vaníková, Z.; Klán, P.; Hocek, M. Org. Biomol. Chem. 2018, 16, 1527-1535.

7. Münzel, M.; Globisch, D.; Brückl, T.; Wagner, M.; Welzmiller, V.; Michalakis, S.; Müller, M.; Biel, M.; Carell, T. Angew. Chem. Int. Ed. 2010, 49, 5375-5377.

8. Kulikov, A.; Arumugam, S.; Popik, V. V. J. Org. Chem. 2008, 73, 7611-7615.

9. Janoušková, M.; Vaníková, Z.; Nici, F.; Boháčová, S.; Vítovská, D.; Šanderová, H.; Hocek, M.; Krásný, L. Chem. Commun. 2017, 53, 13253-13255.

10. Vaníková, Z.; Janoušková, M.; Kambová, M.; Krásný, L.; Hocek M. Chem. Sci. 2019, 10, 3937-3942. 